WCH-138

Rev. 2

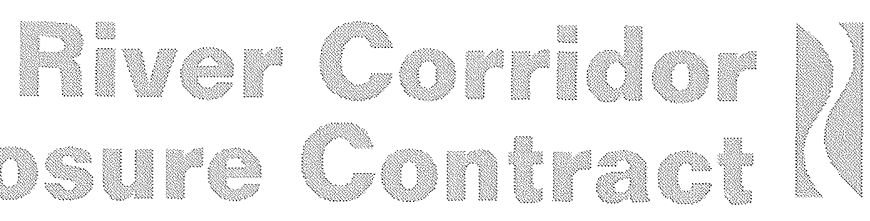

\title{
Waste Management Information System (WMIS) User Guide
}

December 2008

\section{Washington Closure Hanford}

Prepared for the U.S. Department of Energy, Richland Operations Office Office of Assistant Manager for River Corridor

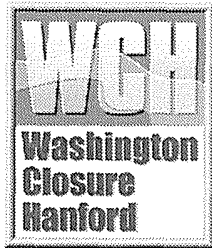


TRADEMARK DISCLAIMER

Reference herein to any specific commercial product, process, or service by trade name, trademark, manufacturer, or otherwise,

does not necessarily constitute or imply its endorsement,

recommendation, or favoring by the United States Government or any agency thereof or its contractors or subcontractors.

This report has been reproduced from the best available copy.

Printed in the United States of America 


\section{LIMITED DISCLOSURE APPROVAL PAGE}

Title: $\quad$ Waste Management Information System (WMIS) User Guide

Author Name: R. E. Broz

Approval: $\quad$ R. T. Hynes, Program Sponsor, Waste Services Manager

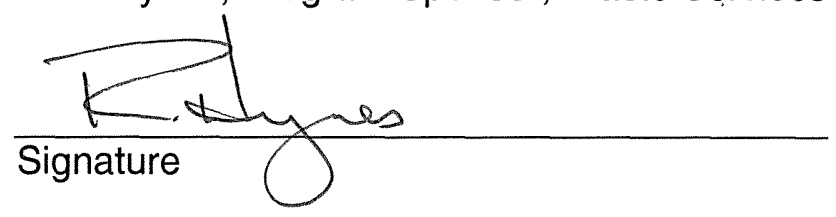

$\frac{12 / 29 \mid 08}{\text { Date }}$



WCH-138

Rev. 2

\section{River Corridor ? Closure Contract}

\section{Waste Management Information System (WMIS) User Guide}

December 2008

Author:

R. E. Broz 


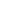




\section{TABLE OF CONTENTS}

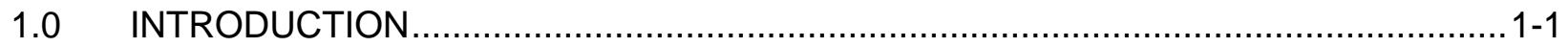

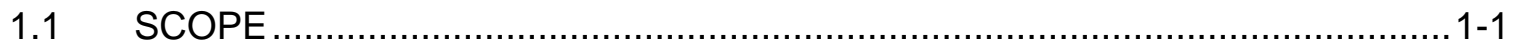

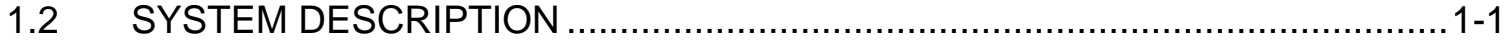

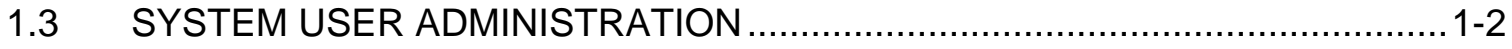

1.4 MODULE INTERRELATIONS AND PROCESS FLOW …............................1-3

1.4.1 Administration Module (WMIS100) ............................................. 1-4

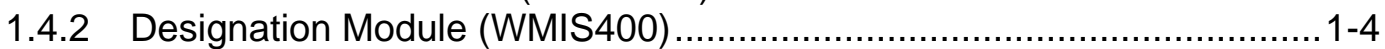

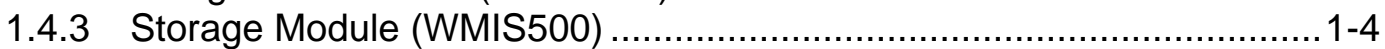

1.4.4 PDA Storage Module (WMIS600) .............................................. $1-5$

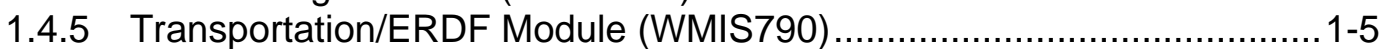

1.4.6 Container Management Module (WMIS800) .................................. 1-5

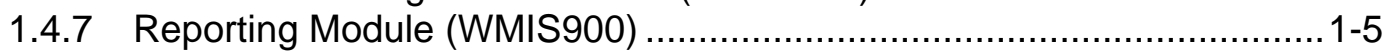

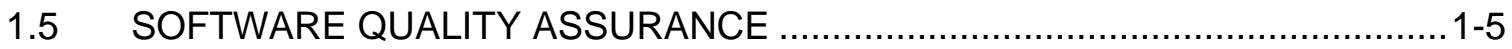

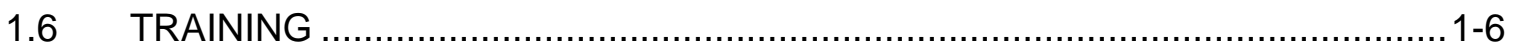

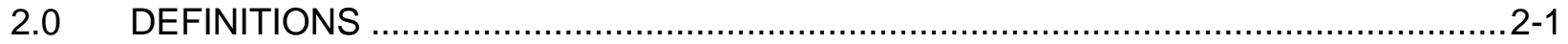

3.0 WMIS110 - ADMINISTRATION MODULE .......................................................

3.1 WMIS110 COMPANY DATA ADMINISTRATION ...................................

3.2 WMIS120 USER DATA ADMINISTRATION …..........................................

3.3 WMIS130 FACILITY DATA ADMINISTRATION .........................................

3.4 WMIS140 PIN SELECTION DATA ADMINISTRATION .............................

3.5 WMIS150 STATUS CODE DATA ADMINISTRATION ...............................

3.6 WMIS160 PROFILE DATA ADMINISTRATION .......................................

3.7 WMIS170 LIST STATIC LOOK-UP TABLES ............................................

3.8 WMIS180 ERDF TRUCK INVENTORY ................................................... $3-20$

3.9 WMIS190 LABEL FUNCTION ADMINISTRATION ................................ $3-23$

3.10 WMIS200 WASTE COMPONENTS ADMINISTRATION ............................ 3-26

3.11 WMIS210 WMIS ERDF CONTAINER MAINTENANCE

LOV ADMINISTRATION..................................................................

3.12 WMIS220 WMIS ERDF ORIGINS ................................................. $3-32$ 
4.0 WMIS400 - DESIGNATION MODULE …...............................................................

4.1 WMIS400 DESIGNATION SEARCH .................................................... $4-1$

4.2 WMIS410 DESIGNATION BASICS ...................................................... 4-5

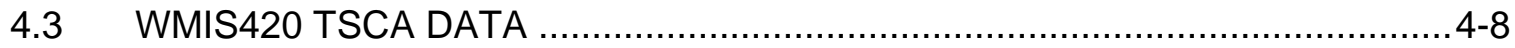

4.4 WMIS430 DESIGNATION CONSTITUENTS ………................................. 4-9

4.5 WMIS440 DESIGNATION ISOTOPES................................................... $4-11$

4.6 WMIS450 DANGEROUS WASTE AND LAND DISPOSAL RESTRICTION (LDR) DATA ............................................................ $4-14$

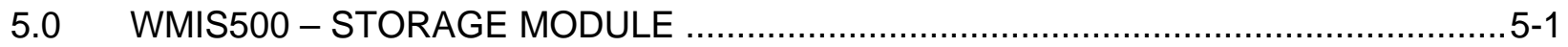

5.1 WMIS500 STORAGE CONTAINER SEARCH ……................................... 5-1

$5.2 \quad$ WMIS505 COPY/REPACK/COMBINE ……………................................ 5-4

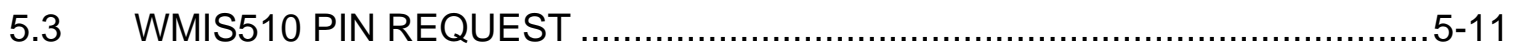

5.4 WMIS515 CONTAINER INVENTORY ..................................................... $5-15$

$5.5 \quad$ WMIS520 CONTAINER BASICS ………………................................. $5-16$

5.6 WMIS525 CONTAINER BASICS RAD DATA ………................................ 5-17

$5.7 \quad$ WMIS530 CONTAINER PACKAGE SUMMARY .......................................... 5-19

5.8 WMIS540 PHYSICAL COMPONENTS DETAIL........................................ 5-21

5.9 WMIS550 PACKAGING COMPONENTS............................................... 5-24

5.10 WMIS560 CONSTITUENTS ..................................................................

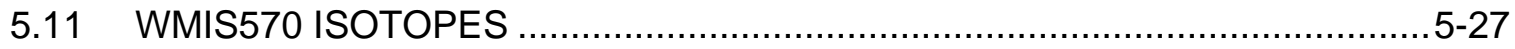

5.12 WMIS575 CONTAINER HISTORY...................................................... 5-29

6.0 WMIS 600 - PDA OPERATIONS MODULE ……...............................................

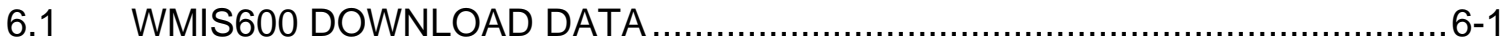

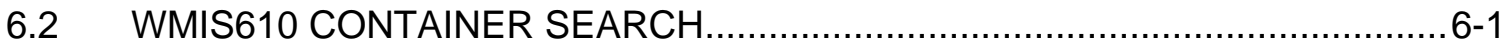

6.3 WMIS615 - COPY/REPACK/COMBINE ................................................ 6-1

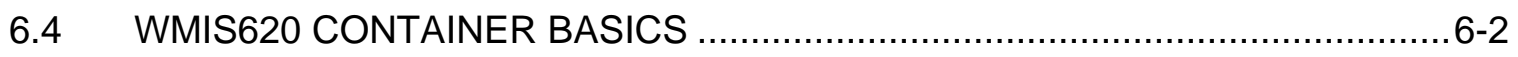

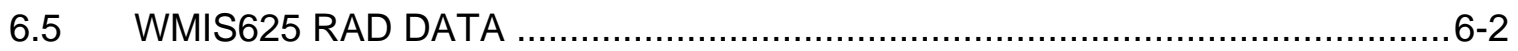

6.6 WMIS630 CONTAINER/PACKAGE SUMMARY ....................................... 6-2 


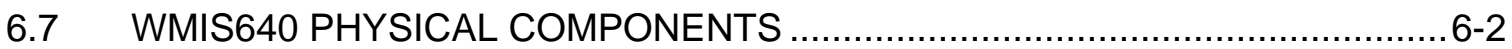

6.8 WMIS650 PACKAGING COMPONENTS.................................................... $6-3$

6.9 WMIS675 CONTAINER HISTORY ............................................................

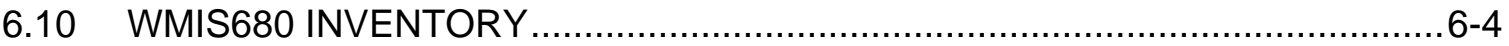

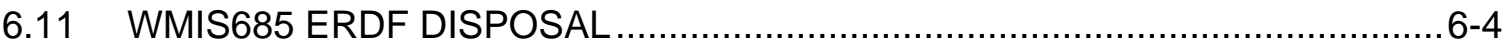

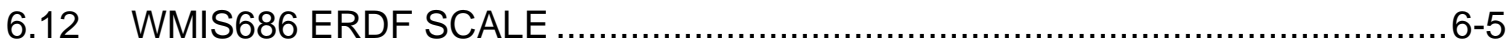

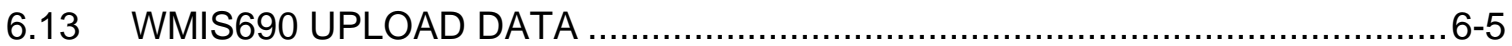

7.0 WMIS700 - TRANSPORTATION MODULE .............................................................

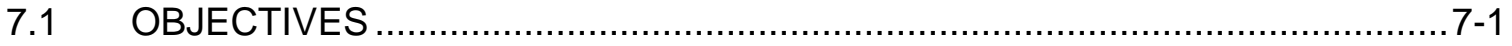

$7.2 \quad$ SCOPE

7.2.1 Shipment Management Form ………………...............................

7.3 PROVIDE TRANSPORTATION REPORTS ..............................................

7.3.1 Onsite Waste Tracking Form ............................................................ 7-2

7.3.2 Uniform Hazardous Waste Manifest .................................................... $7-2$

7.3.3 Uniform Hazardous Waste Manifest Summary Attachment

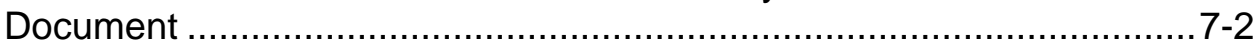

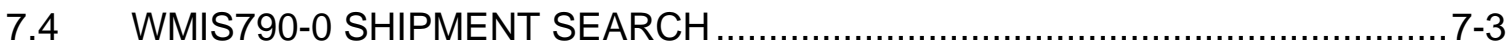

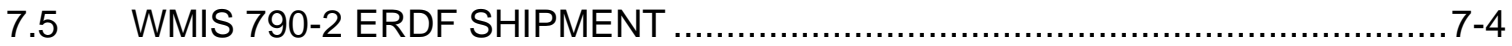

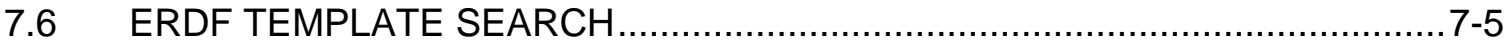

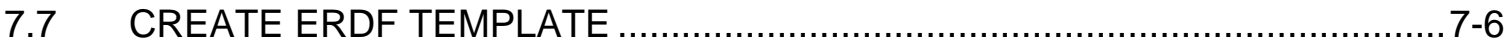

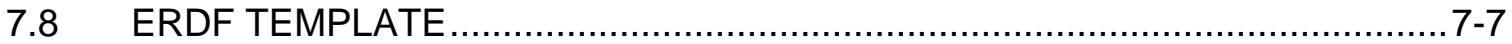

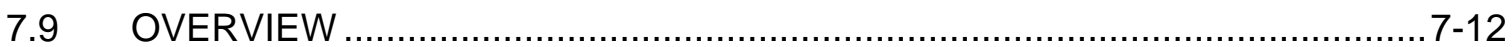

7.10 WMIS800 PURCHASE ORDER SEARCH............................................. 7-13

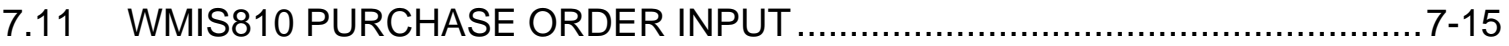

7.12 WMIS820 CONTAINER RECEIPT ..........................................................

7.13 WMIS820 CONTAINER RECEIPT DETAIL ……......................................

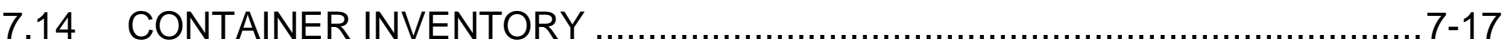




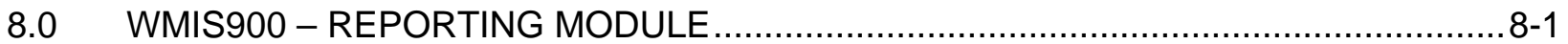

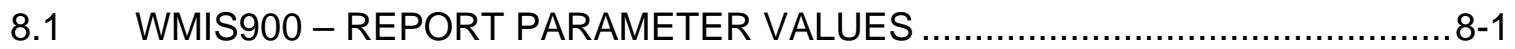

8.2 WMIS910 - CONTAINER LISTING ................................................... $8-2$

8.3 WMIS920 - STANDING WASTE INVENTORY ........................................ 8-2

8.4 WMIS930 -CONTAINER LISTING DETAILED ......................................... $8-2$

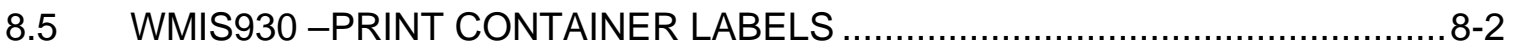

8.6 WMIS930 -WASTE CONTAINER CONTENTS REPORT ............................. 8 -3

8.7 WMIS930 -LAND DISPOSAL NOTIFICATION AND CERTIFICATION.............8-3

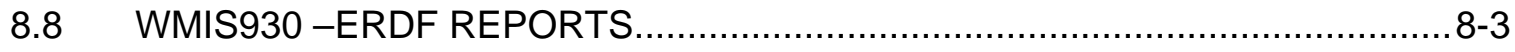

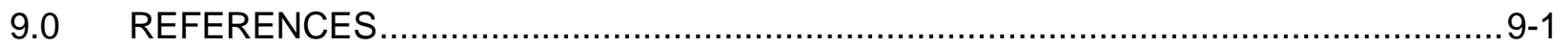

\section{APPENDIX}

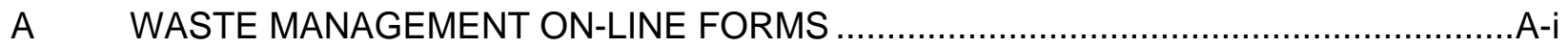

\section{FIGURES}

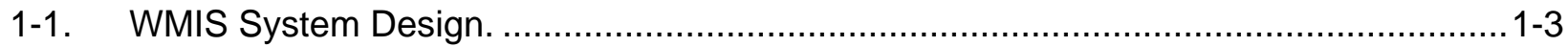

1-2. PDA Electronic Data Flow. ...........................................................................

\section{TABLES}

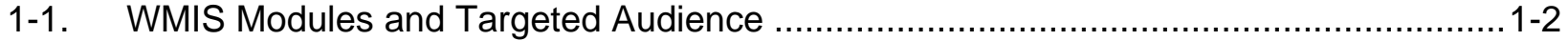

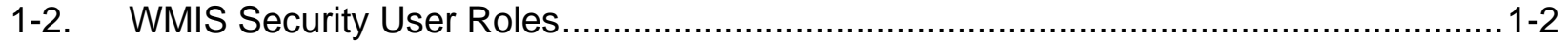

4-1. Basic Designation Screen Fields …................................................................

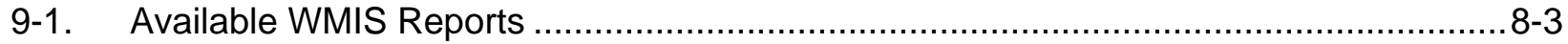




\section{WMIS SCREEN SHOTS}

3-1. Administration - Companies ……………..........................................................

3-2. Administration - Add Company .......................................................................

3-3. Administration - Edit Company ..................................................................... 3-3

3-4. Administration - Users ………………

3-5. Administration - Add User ………………

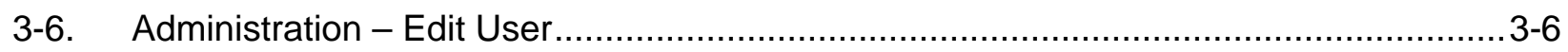

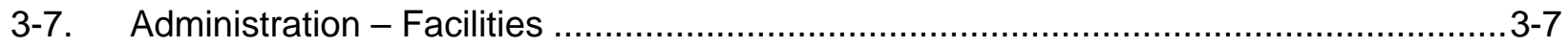

3-8. Administration - Add Facility ........................................................................

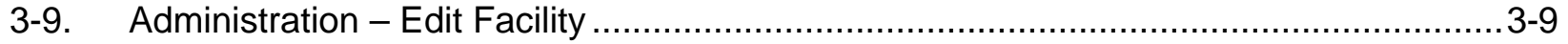

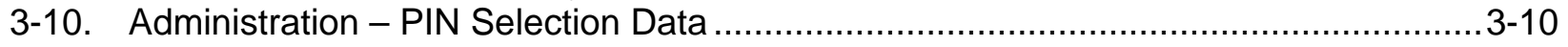

3-11. Administration - Add PIN Selection Data.......................................................... 3-11

3-12. Administration - Edit PIN Selection ……....................................................... 3-12

3-13. Administration - Status Code Data …………................................................ 3-13

3-14. Administration - Add Status Code Data......................................................... 3-14

3-15. Administration - Edit Status Code Data ........................................................... 3-15

3-16. Administration - Profile Data..........................................................................

3-17. Administration - Add Profile Data. ………..................................................... 3-17

3-18. Administration - Profile Data Administration Edit...................................................3-18

3-19. Administration - Static Lookup Lists ............................................................... 3-19

3-20. Administration - ERDF Truck Inventory ……..................................................... 3-20

3-21. Administration - Add ERDF Truck ………......................................................

3-22. Administration - Edit ERDF Truck …………...............................................

3-23. Administration - Label Printers ……………...................................................

3-24. Administration - Add Label Printer ...............................................................

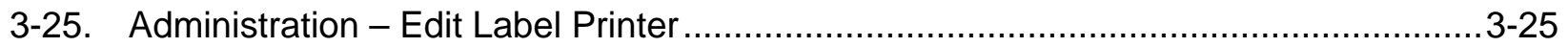

3-26. Administration - WMIS Waste Components ....................................................... 3-26

3-27. Administration - Add WMIS Component.............................................................

3-28. Administration - Edit Waste Component. ............................................................ 3-28

3-29. Administration - Container Maintenance LOV .................................................. $3-29$

3-30. Administration - Add Container Readiness Check List Item....................................3-30

3-31. Administration - Edit Container Maintenance Items ...............................................3-31

3-32. Administration - WMIS ERDF Origins. ……...................................................

3-33. Administration - Add WMIS ERDF Origin ……..................................................

3-34. Administration - Edit WMIS ERDF Origin ..................................................... $3-34$

4-1. Designation - Search ............................................................................

4-2. Sample Search Results..............................................................................

4-3. Designation - Create New ....................................................................

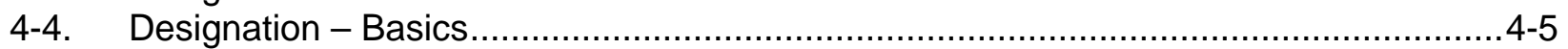

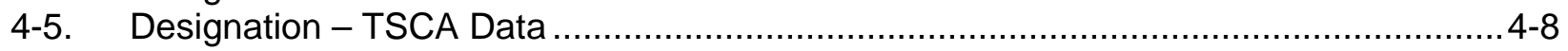

4-6. Designation - Constituents. ........................................................................... 4-9

4-7. Designation - Add Designation Constituents Search ........................................... 4-10

4-8. Designation - Isotopes........................................................................... 4-11

4-9. Designation - Add Designation Isotopes Search............................................... 4-12

4-10. Designation - Dangerous Waste \& LDR ..................................................... 4-14

5-1. Storage - Container Search......................................................................... 5-1

5-2. Example of Search Results ........................................................................... 5-3

5-3. Storage - Container Copy Repack Combine …….............................................. 5-4

5-4. Example of Search Results ................................................................................ 5-5 


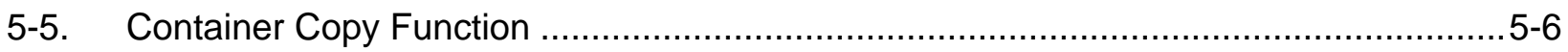

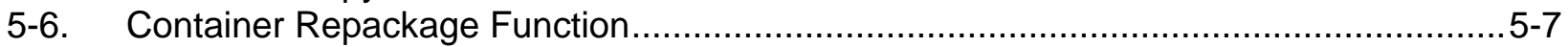

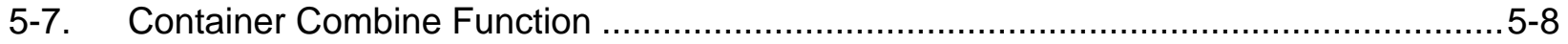

5-8. Cope Repack Combine Destination Screen ..................................................... 5-10

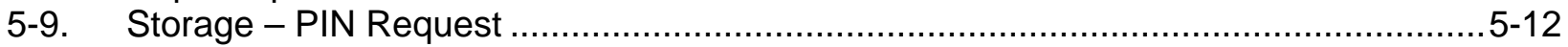

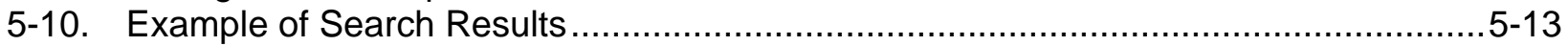

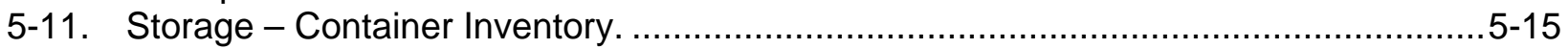

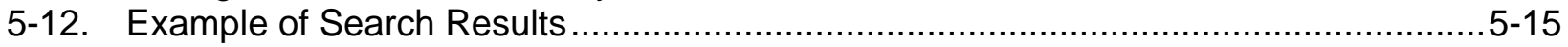

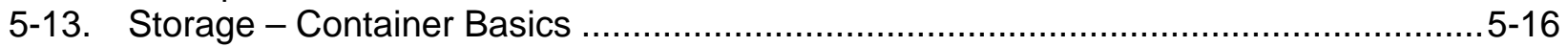

5-14. Storage - Container Basics Rad .................................................................. 5-17

5-15. Storage - Container Package/Summary ............................................................ 5-19

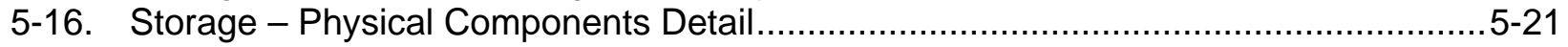

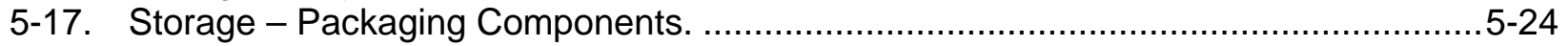

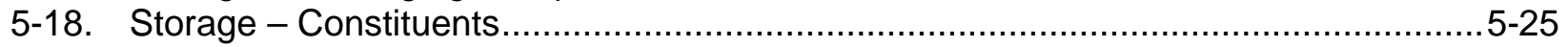

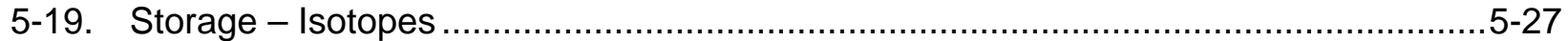

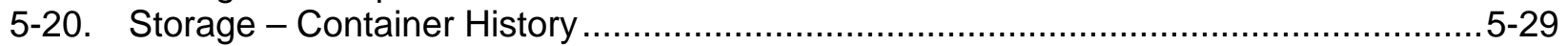

7-1. Transportation/ERDF - Shipment Search....................................................

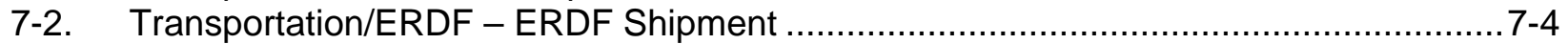

7-3. Transportation/ERDF - ERDF Template Search …………................................ $7-5$

7-4. Transportation/ERDF - Create ERDF Template................................................

7-5. Transportation/ERDF - Template Create Shipments ……...................................... $7-7$

7-6. Transportation/ERDF - Edit Template Constituents …...........................................

7-7. Transportation/ERDF - Edit Template Isotopes ……..........................................

7-8. Transportation/ERDF - Edit Template Items ………....................................... 7-10

7-9. Transportation/ERDF - Copy Template ………...............................................

8-1. Purchase Order - Search .......................................................................

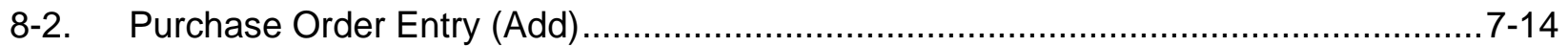

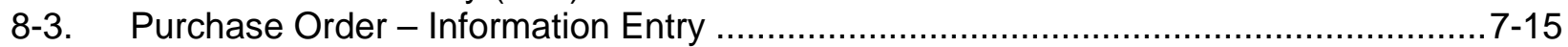

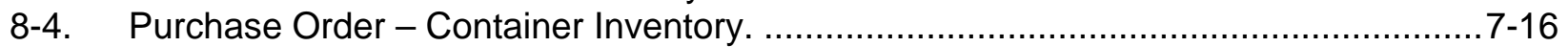

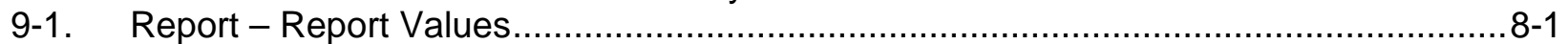

9-2. Reports - Print Container Labels $\quad$................................................................. 8-2

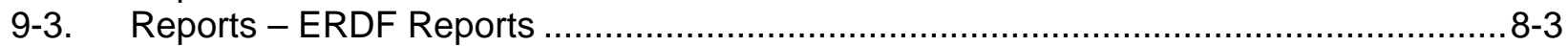




\section{REVISION HISTORY}

\begin{tabular}{|c|c|l|c|}
\hline Revision & Date & \multicolumn{1}{|c|}{ Reason for revision } & Revision initiator \\
\hline 1 & $02 / 5 / 08$ & $\begin{array}{l}\text { Incorporation of software quality assurance } \\
\text { requirements and incorporation of new WMIS } \\
\text { release 2.1.3 and 2.1.4. }\end{array}$ & 1 \\
\hline 2 & $12 / 23 / 08$ & $\begin{array}{l}\text { Incorporation of WMIS release 2.1.6 changes and } \\
\text { computer security requirements }\end{array}$ & R. Broz \\
\hline
\end{tabular}


WHC-138

Rev. 2 


\section{ACRONYMS}

\begin{tabular}{|c|c|}
\hline CAS & Chemical Abstract Service \\
\hline CFR & Code of Federal Regulations \\
\hline CIN & Container Identification Number \\
\hline DOT & Department of Transportation \\
\hline DW & Dangerous Waste \\
\hline EPA & U.S. Environmental Protection Agency \\
\hline ERDF & Environmental Restoration Disposal Facility \\
\hline FVR & Field Verification Requirements \\
\hline HEIS & Hanford Environmental Information Systems \\
\hline HW & Hazardous Waste \\
\hline LDR & Land Disposal Restriction \\
\hline MSDS & Material Safety Data Sheet \\
\hline MT & Maintenance \\
\hline OWTF & Onsite Waste Tracking Form \\
\hline PCB & Polychlorinated Biphenyls \\
\hline PDA & Personal Digital Assistant \\
\hline PE & Project Engineer \\
\hline PIN & Package Identification Number \\
\hline PIP & Process Improvement Project \\
\hline $\mathrm{RCC}$ & River Corridor Closure \\
\hline RDC & Records and Document Control \\
\hline RFID & Radio Frequency Identification \\
\hline RMIS & Records Management Information System \\
\hline SA & System Administrator \\
\hline SDD & Software Design Description \\
\hline SWITS & Solid Waste Information Tracking System \\
\hline TSD & Treatment, Storage, and Disposal \\
\hline TSCA & Toxic Substances Control Act of 1976 \\
\hline WAC & Washington Administrative Code \\
\hline WCF & Waste Certification Form \\
\hline WCH & Washington Closure Hanford \\
\hline WCH LAN & Local Area Network \\
\hline WDS & Waste Designation Specialist \\
\hline WIDS & Waste Information Data System \\
\hline WIS & Waste Inventory Sheet \\
\hline WITS & Waste Information Tracking Specialist \\
\hline WMIS & Waste Management Information System \\
\hline WTS & Waste Transportation Specialist \\
\hline
\end{tabular}


WCH-138

Rev. 2 


\subsection{INTRODUCTION}

The design and development of WMIS incorporates the automation of waste management processes and data collection, with the generation and routing of waste-related forms into an integrated and retrievable format. This guide describes methods to effectively use the Waste Management Information System (WMIS).

The WMIS web-based user interface allows access to the system from any Local Area Network (WCH LAN) workstation by multiple, concurrent users. This system provides a versatile method for waste management personnel to enter and capture data through a web site.

All WMIS data loads will occur in an accurate, timely manner. In the unlikely event that WMIS is offline, or otherwise unavailable, personnel are directed to use the methodology found in the WMT-1 procedures. Upload of any resultant data to WMIS will occur as soon as practicable by the responsible parties.

Access control specifications are identified in the WCH-114, Cyber Security Program Plan. This includes local area network users who are required to employ password protected screen savers when leaving their computers and also, user access to the system is the responsibility of the program sponsor.

At the time of this writing, the WMIS is designated as a level "B" use, due to the functionality regarding the Environmental Restoration Disposal Facility (ERDF) Field Verification

Requirement (FVR). The FVR provides a limit on the radionuclide concentrations received at the ERDF over a 24-hour period. If the limit is exceeded, waste with appropriately low concentrations needs to be accepted to offset the higher concentrations.

The safety function that WMIS performs occurs when a shipper creates an On-Site Waste Transfer Form (OWTF) to ship waste to the ERDF. The WMIS will compare the radionuclide concentrations against the FVR limits. If any radionuclide concentration is exceeded, the shipper is warned and the OWTF description is changed with a FVR limit warning.

\subsection{SCOPE}

This guide provides information on work processes, step-by-step instructions on data entry and retrieval, and general system usage to WMIS users.

\subsection{SYSTEM DESCRIPTION}

WMIS allows users to initiate, track, and close waste packages. The modular design supports integration and utilization of data through the various stages of waste management. The phases of the waste management work process include generation, designation, packaging, container management, procurement, storage, treatment, transportation, and disposal. Detailed descriptions of the modules are in Section 1.4, Module Interrelations and Process Flow, of this guide. 
Table 1-1. WMIS Modules and Targeted Audience. (2 Pages)

\begin{tabular}{|l|l|}
\hline \multicolumn{1}{|c|}{ WMIS Module } & \multicolumn{1}{c|}{ Targeted Audience (Users) } \\
\hline Administration & SA \\
\hline \multirow{4}{*}{ Designation } & PE \\
\cline { 2 - 2 } & WDS \\
\cline { 2 - 2 } & WSL \\
\hline \multirow{4}{*}{ Storage } & WDS \\
\cline { 2 - 2 } & WITS \\
\cline { 2 - 2 } & WTS \\
\cline { 2 - 2 } & WSL \\
\hline \multirow{5}{*}{ Transportation/ERDF } & ERDF Users \\
\cline { 2 - 2 } & WITS \\
\cline { 2 - 2 } & WTS \\
\cline { 2 - 2 } & WSL \\
\hline Purchase Orders & MT \\
\cline { 2 - 2 } & WITS \\
\hline Reporting & All users \\
\hline
\end{tabular}

\subsection{SYSTEM USER ADMINISTRATION}

The WMIS application is available to all users of the WCH Local Area Network (WCH LAN), and to users on all other networks with access to WCH LAN and current WMIS access privileges and passwords. The WMIS System Administrator (SA) interfaces with Information Systems and Technology as the point-of-contact and administers the system as follows:

- Define security user roles and restrict data available to users and user groups down to the individual data-element level.

- Authorize and activate user's access to WMIS. This may include assignment of multiple user groups.

- Access the system across the network to perform routine functions (e.g., monitoring logs, performing backups and restores, and restarting the system), as necessary.

Table 1-2. WMIS Security User Roles. (2 Pages)

\begin{tabular}{|l|l|}
\hline \multicolumn{1}{|c|}{ Defined WMIS User Roles } & \multicolumn{1}{c|}{ Access to WMIS Tools and Functions } \\
\hline ERDF User & $\begin{array}{l}\text { The ERDF USER has the capability to edit any form in the } \\
\text { Transportation/ERDF Module. }\end{array}$ \\
\hline MT - Maintenance & $\begin{array}{l}\text { The Role doesn't provide any edit capabilities in WMIS, but is } \\
\text { used to Filter the list of Users for the PDAs. This is used to } \\
\text { both Disposal and Container Maintenance. }\end{array}$ \\
\hline
\end{tabular}


Table 1-2. WMIS Security User Roles. (2 Pages)

\begin{tabular}{|l|l|}
\hline \multicolumn{1}{|c|}{ Defined WMIS User Roles } & \multicolumn{1}{c|}{ Access to WMIS Tools and Functions } \\
\hline PE - Project Engineer & Can approve and change the status of designations. \\
\hline System Administrator (WMIS) & Has access to edit all forms under the Administration Module. \\
\hline WDS - Waste Designation Specialist & $\begin{array}{l}\text { Edit any form in the Designation Module. In the storage } \\
\text { module this role can change the Packaging Components, } \\
\text { remove a constituent from a profile for a waste container } \\
\text { using the Constituents tab, and assign a designation to a } \\
\text { waste container that has a status of closed. }\end{array}$ \\
\hline WSL - Waste Services Lead & $\begin{array}{l}\text { Same as WDS. Additionally can approve designations and } \\
\text { change the active status of a designation. This role has the } \\
\text { same access as WTS, plus the ability to change a waste } \\
\text { container's status to closed. }\end{array}$ \\
\hline WTS - Waste Transportation Specialist & $\begin{array}{l}\text { This role has access to the Storage Module. Any field } \\
\text { pertaining to filling the can is editable. In the } \\
\text { Transportation/ERDF module this role can create ERDF } \\
\text { shipments and change the estimated weights for an OWTF. }\end{array}$ \\
\hline $\begin{array}{l}\text { WITS - Waste Information Tracking } \\
\text { Specialist }\end{array}$ & $\begin{array}{l}\text { Same as WSL, but also has the ability to ship the waste } \\
\text { container. }\end{array}$ \\
\hline
\end{tabular}

\subsection{MODULE INTERRELATIONS AND PROCESS FLOW}

Figure 1-1 provides a high-level illustration of the functionality that is contained within WMIS. The system design is available in the WMIS Software Design Description (SDD) (BHI 2004a).

Figure 1-1. WMIS System Design 


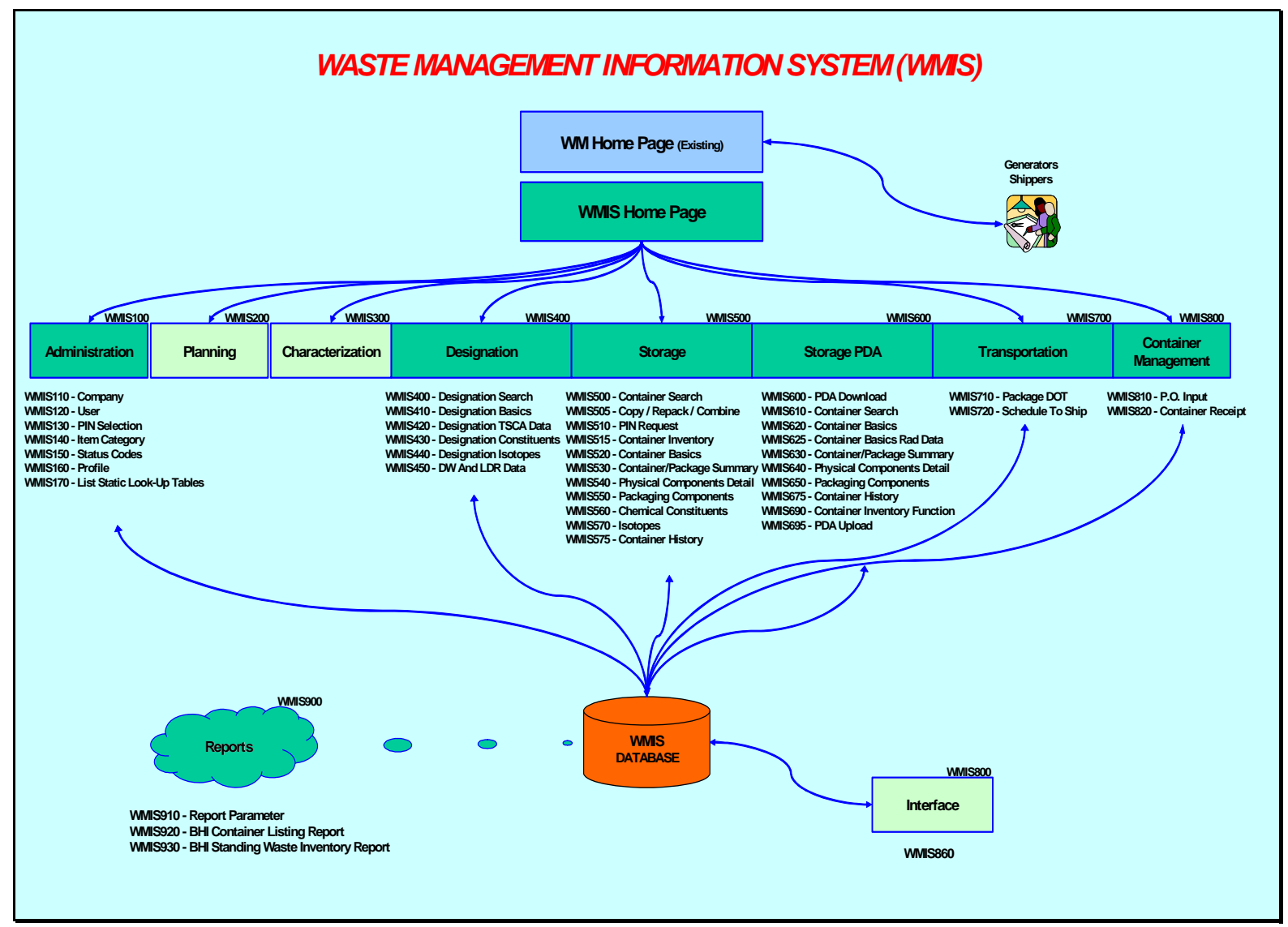

\subsubsection{Administration Module (WMIS100)}

The Administration Module contains the processes that the SA uses for the everyday functioning of the system. Validation table input screens, user table screens, and the security functionality are in this module.

\subsubsection{Designation Module (WMIS400)}

The Designation Module collects and analyzes the results of the characterization process and relates it to the specific waste placed in containers. A WMIS Import Tool is in place to retrieve data from the Waste Designation spreadsheet to create a new or revise an existing designation in WMIS. This module is limited to input of the final designation information from hard copy, which allows for the elimination of duplicate data entry steps among the different waste functions.

\subsubsection{Storage Module (WMIS500)}

The Storage Module involves the receiving of containers and the actual placement of waste within them. This process captures inventory of contents, a full description of the container, and other pertinent data. This module captures the information contained in the hard copy data forms which gather information for the containers. 


\subsubsection{PDA Storage Module (WMIS600)}

The Personal Digital Assistant (PDA) Storage Module allows remote collection of field information and inventory tracking by use of bar codes applied to ERDF cans. Figure 1-2 illustrates the data flow.

Figure 1-2. PDA Electronic Data Flow

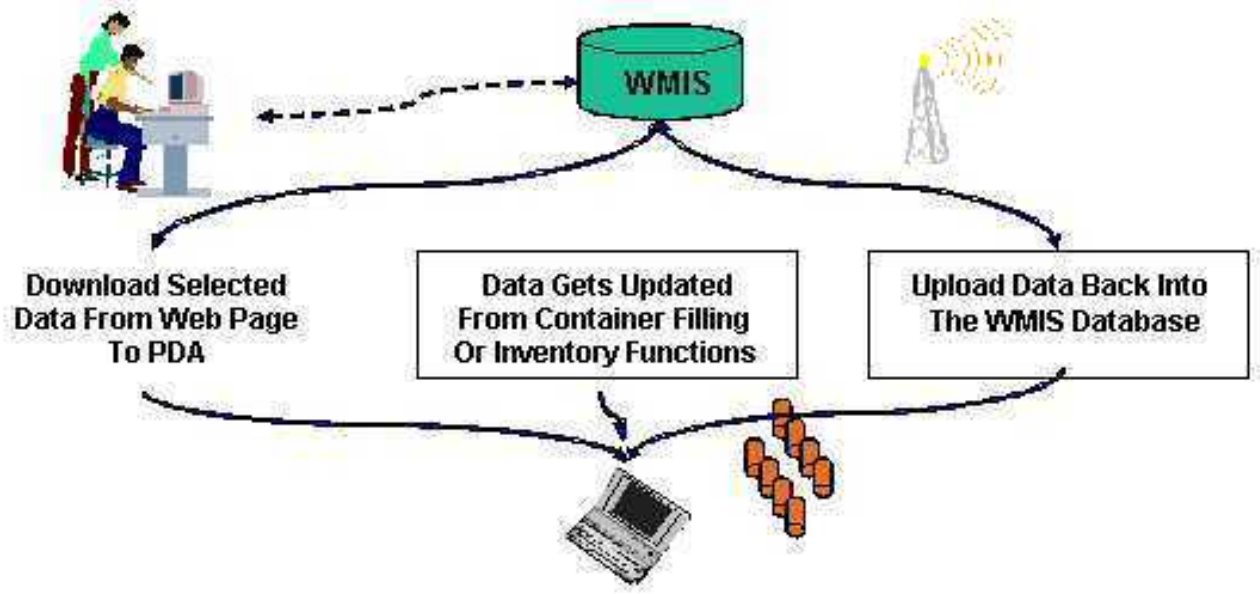

\subsubsection{Transportation/ERDF Module (WMIS790)}

The Transportation/ERDF Module includes the support of on-site shipments of waste in relation to the ERDF, as well as the shipments of containerized drums to ERDF. This module consists of some innovative methods of tracking shipments with radio-frequency identification (RFID) tagging capabilities.

\subsubsection{Container Management Module (WMIS800)}

The Container Management Module allows for more detailed assignment and tracking of containers by the primary identification number (Container Identification Number [CIN]) including those containers purchased by the RCC contractor or other Hanford contractors. The module tracks the containers from Request to Disposal, allows re-use of containers multiple times, and one-time use and disposal.

\subsubsection{Reporting Module (WMIS900)}

All pre-defined reports are within this module. Pre-defined reports consist of several formatted layouts of information, with a search screen that lets the user select and narrow the search grid.

\subsection{SOFTWARE QUALITY ASSURANCE}

WMIS has been evaluated as Level B software from a software quality perspective per the requirements of DOE Order 414.1C (Quality Assurance), WCH-186 [Washington Closure Hanford Information Technology System Configuration Management Plan (SCMP)/July 2007], and WCH-192 (Washington Closure Hanford Software quality Assurance Program Plan). The requirements for 
software quality assurance are document in WCH-213 [Waste Management Information System (WMIS) Software Project Management Plan (SPMP)].

\subsection{TRAINING}

Prior to being granted access to WMIS (aside from read-only access), each user shall be trained on WMIS operations. This training is a required reading of $\mathrm{WCH}-138$, "Waste Management Information Services (WMIS) User Guide" and SWTD-0011, "Waste Management Information System Training" and shall be documented prior to initial use. 


\subsection{DEFINITIONS}

Container: May include, but is not limited to, drums, boxes, bulk trailers, tankers, plastic wrap, banded units and bags. Does not include tanks, waste piles or other storage/treatment units. An ERDF can is an example of a roll-off box style container. Every container has a unique number associated with it, which shall remain the same for the life of the container.

Container Identification Number (CIN): A unique identifier assigned to a waste container at the time of acquisition/use for container tracking purposes. It is the primary tracking number when referenced with a package identification number (PIN). The following are three ways to identify the CIN on a container. First, each CIN on ERDF cans consists of a hardened, environmentally-resistant ABS plastic, embedded RFID. Second, a barcode is affixed to the container, for scanning purposes to retrieve the CIN. Third, the CIN number is in English format as a failsafe for options one and two. A CIN number may appear multiple times in the WMIS database in relation to a re-usable container.

Dangerous Waste: Solid waste designated as dangerous, extremely hazardous or mixed waste. Washington Administrative Code (WAC) 173-303.

Dangerous Waste Constituents: Constituents listed in WAC 173-303-9905 and other constituents that have caused a waste to be a dangerous waste under WAC 173-303.

Dose-Equivalent Curie: A method of normalizing the ratio of various radionuclides within a profile to plutonium-239 for use in establishing that an operations program remains within approved safety basis at certain Hanford Site waste management units. The basis for normalization is on the relative committed effective dose equivalent from inhalation of each radionuclide to that of plutonium-239 using the conversion factors from Federal Guidance Report No. 11, "Limiting Values of Radionuclide Intake and Air Concentration and Dose Conversion Factors for Inhalation, Submersion, and Ingestion".

Environmental Restoration Disposal Facility: A CERCLA landfill located within the Hanford Reservation where approximately $95 \%$ of all Hanford site waste will ultimately be disposed.

Fissile Material: Consists of nuclides which sustain a chain reaction through thermal (slow) neutron-induced fission. For the Hanford Site criticality safety program, uranium-233, uranium235, plutonium-239, and plutonium-241 are the primary nuclides of interest. In addition, plutonium-238 is considered fissile material for transportation under 49 CFR 173.

Fissionable Materials: Substances which contain nuclides capable of sustaining a nuclear fission chain reaction (regardless of neutron energy). Such material could be fissionable only by nature of its form, configuration, or environment. This includes, but is not limited to, uranium-233, uranium-235, plutonium-238, plutonium-239, plutonium-240, plutonium-241, neptunium-237, americium-241, and curium-244.

Hazardous waste: Solid waste designated by 40 CFR 261 and regulated as a hazardous and/or mixed waste by the EPA.

Lab Pack: A packaging method where more than one inner containers of waste are packaged into an outer drum as specified in 49 CFR 173.12(b). 
Land Disposal Restrictions: The restrictions and requirements for land disposal of hazardous or dangerous waste as specified in 40 CFR 268 and WAC 173-303-140. (Refer to definitions for RCRA Land Disposal Restrictions and Washington State Land Disposal Restrictions.)

Low-Level Mixed Waste: Waste that meets both the definition of low-level and hazardous/dangerous waste.

Low-Level Waste: Non-high-level radioactive waste, spent nuclear fuel, transuranic waste, byproduct material (as defined in Section 11e.(2) of the Atomic Energy Act of 1954, as amended), or naturally occurring radioactive material. (DOE M 435.1-1)

Manifest Record: EPA required form detailing the contents of a shipment for over-the-road purposes.

Mixed Waste: A dangerous, hazardous, or acutely hazardous waste that contains both a nonradioactive hazardous component and, as defined by 10 CFR 20.1003, source, special nuclear, or by-product material subject to the Atomic Energy Act of 1954 (42 U.S.C. 2011 et seq.).

(WAC 173-303-040)

Mobile Radionuclides: Radionuclides that tend to migrate readily through Hanford soil and pose the highest risk of impact to groundwater resources: tritium (hydrogen-3), carbon-14, chlorine-36, selenium-79, molybdenum-93, technetium-99, iodine-129, rhenium-187, uranium (all isotopes), and neptunium-237.

Onsite Waste Tracking Form: The standard form containing all of the information, both isotopes and chemical constituents, of a particular ERDF can. This form must be attached to the ERDF can in storage or located inside the driver's compartment of the hauling truck in transport.

Package Identification Number (PIN): The WTS assigns the PIN, a unique number, on all waste packages for tracking. The PIN identifies the source facility and the year initial tracking of the waste began. The PIN belongs to the waste inside the container, and identifies the waste, not the container. (Cradle to Grave). If transfer of the waste to another container occurs, the PIN goes with the waste. In the event of destruction or disposal of the container, with the waste inside, the CIN/PIN record shows as "D" (Disposed) in the WMIS database. When the container is simply emptied, the database record for that CIN/PIN combination shows disposed, but the container is available for re-use, and appears in the WMIS database as many times as it is reused, with different PINs for each use.

Plutonium-Equivalent Curie (PE-Ci): A method of normalizing the radio toxicity in transuranic waste to plutonium-239 for use in establishing the approved safety limits at the Waste Isolation Pilot Plant (WIPP) located near Carlsbad, New Mexico. The basis of normalization is the relative committed effective dose equivalent from inhalation of a radionuclide to that of plutonium-239 using the conversion factors from DOE/EH-0071, "Internal Dose Conversion Factors for Calculation of Dose to the Public", as described in Appendix B of DOE/WIPP-02-3122.

Plutonium-239 Fissile Gram Equivalent (FGE): A method of normalizing fissile and fissionable isotopes to plutonium-239 for use in establishing criticality safety limits for the Hanford Site Solid Waste Program. This is consistent with the method found in the safety 
analysis reports for the TRUPACT-II and 72-B casks for plutonium-239, uranium-233, and uranium-235 and in ANSI/ANS 8.15 for other fissile, fissionable, and special actinide elements.

Polychlorinated biphenyl or PCB: Any chemical substance that is limited to the biphenyl molecule that has been chlorinated to varying degrees or any combination of substances that contains such substance (40 CFR 761.3).

Process Knowledge: Knowledge the generator applies to a solid waste to determine if it is a dangerous or mixed waste in light of the materials or the processes used, when demonstration of such knowledge is sufficient for determining whether a solid waste is designated properly. Process knowledge includes information on waste obtained from existing published or documented waste analysis data or studies conducted on mixed waste from processes similar to that, which generated the waste. Process knowledge for mixed waste also could include information obtained from surrogate material.

Profile: A product of the characterization process by which all radiological isotopes and chemical constituents are identified for a waste stream.

Percent of Profile: Adjustment factor applied to a profile in order to compensate for variations in concentrations of radiological isotopes and chemical constituents within a given waste stream.

Radio Frequency Identification (RFID): A plastic tag, which emits a unique identification number in order to track a container remotely.

Radioactive Waste: Any garbage, refuse, sludge, and other discarded material, including solid, liquid, semisolid, or contained gaseous material that must be managed for its radioactive content.

RCRA land disposal restrictions or RCRA LDR: The requirements and restrictions for land disposal of hazardous waste codified in 40 CFR 268.

Requirement: A condition or capability that must be met by a system (or system component) to satisfy a contract, standard, or specification. The set of all requirements forms the basis for subsequent development of the system or system component.

Software Design Description (SDD): A document that represents the software product. The SDD is used as a medium for communicating software design information, and may be thought of as a blueprint or model of the system.

Specific Activity: The radiological activity (disintegrations per unit of time) of a radionuclide per unit mass of that nuclide. The specific activity of a material in which the radionuclide is essentially uniformly distributed is the radiological activity per unit mass of the material.

System Change Request (SCR): A document that identifies a proposed change to a system. A system change request may ask for the preparation of a new function or modify an existing function. 
System Configuration Management: A set of management disciplines, within the context of the system engineering process, which identifies and documents the functional and physical characteristics of a product and controls changes to those characteristics.

System Test Plan: The document that is used for the formal testing acceptance of all revisions to a system.

Template: A system of screens whereby a user can save various models of shipment information and quickly create new shipments based on parameters set in the template.

Test Environment: An environment for the formal testing and verification of software changes is maintained and controlled by the developer. Software is moved to this area by the developer after it has been judged ready for formal testing. Access to this environment is restricted to the developers and the user representatives responsible for acceptance buy-off.

Toxic: Having the properties to cause or significantly contribute to death, injury, or illness of humans or wildlife. (WAC 173-303-040)

Toxic Substances Control Act (TSCA): PCB waste or TSCA PCB waste. Any PCBcontaining waste that is regulated under the TSCA requirements codified in 40 CFR 761 .

Transuranic Mixed Waste, Or TRU-Mixed Waste: Waste that meets both the definitions of transuranic waste and hazardous/dangerous waste.

Transuranic Waste: Transuranic waste is radioactive waste containing more than 100 nanocuries (3700 becquerels) of alpha-emitting transuranic isotopes per gram of waste, with half-lives greater than 20 years, except for: (1) high-level radioactive waste; (2) waste that the Secretary of Energy has determined, with the concurrence of the Administrator of the Environmental Protection Agency, does not need the degree of isolation required by the 40 CFR Part 191 disposal regulations; or (3) waste that the Nuclear Regulatory Commission has approved for disposal on a case-by-case basis in accordance with 10 CFR 61 (DOE M 435.1-1).

Waste Stream: A waste or group of wastes from a process or a facility with similar physical, chemical, or radiological properties. (DOE M 435.1-1) 


\subsection{WMIS110 - ADMINISTRATION MODULE}

The Administration Module contains validation table input screens, user table screens, and security functionality. The SA is responsible for user security roles and maintenance of the system validation tables.

\subsection{WMIS110 COMPANY DATA ADMINISTRATION}

\section{Screen 3-1. Administration - Companies}

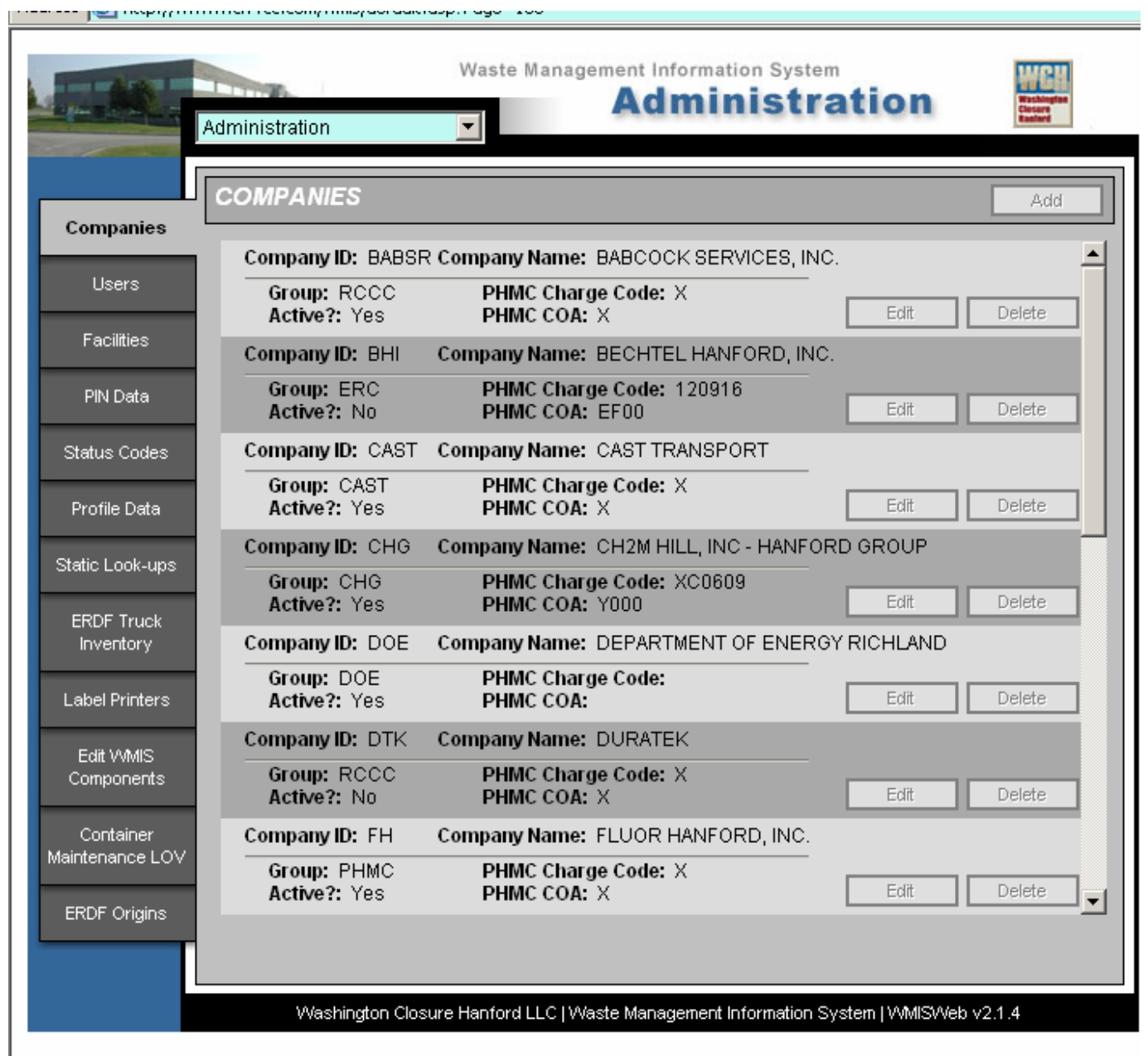

NOTE: The screens presented in this document revision are still valid for software version 2.1.6. The Transportation section may still refer to ILSI as the transporter. The transporter contractor is now Washington Closure Hanford.

- $\quad$ Select "Add" to add new company, see Screen 3-2.

- $\quad$ Select "Edit" to edit existing company, see Screen 3-3. 


\section{Add Company}

\section{Screen 3-2. Administration - Add Company}

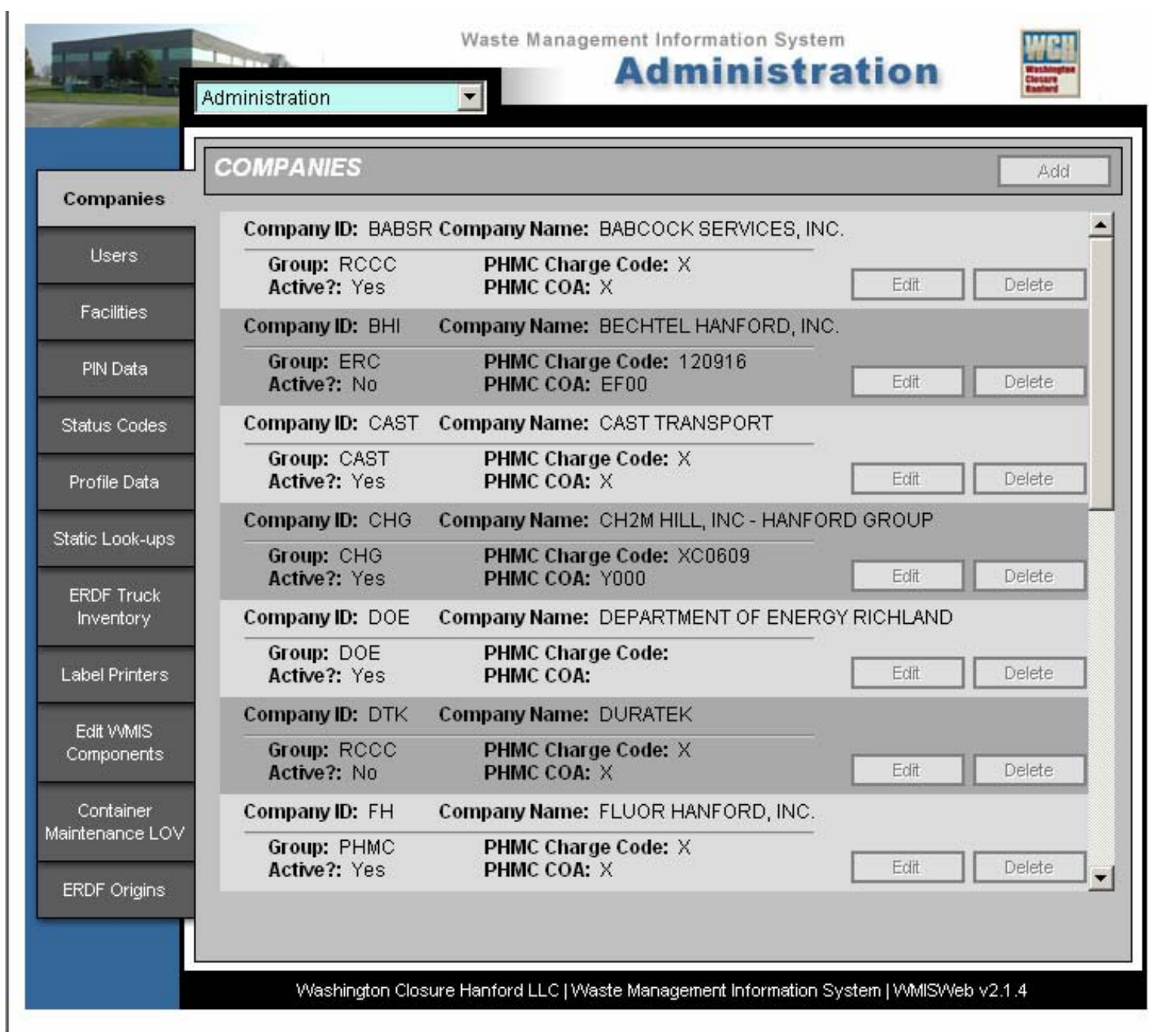

- Enter data to create new company.

- Mark the checkbox to activate the company, or leave blank to leave the company inactive in WMIS.

- $\quad$ Press "Save."

- Press "Reset" to reset field values to <NULL>. 


\section{Edit Company}

Screen 3-3. Administration - Edit Company

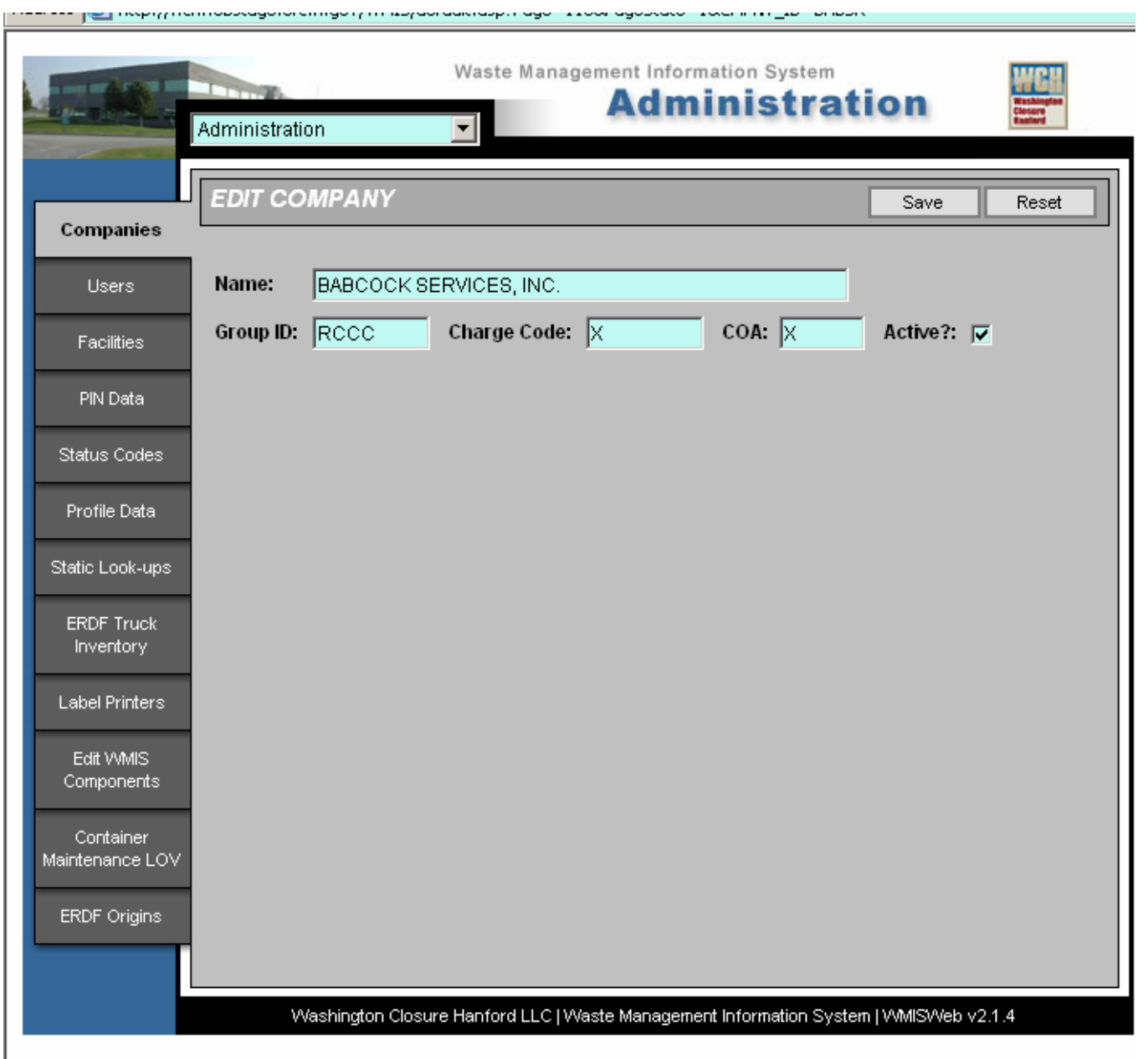

- Edit the company information as needed.

- Mark the checkbox to activate the company, or leave blank to leave the company inactive in WMIS.

- Press "Save."

- Press "Reset" to reset field values to the pre-existing values.

\section{Delete Company}

- This function is not in use. 


\subsection{WMIS120 USER DATA ADMINISTRATION}

The user table lists any users who have additional rights other than read-only.

\section{Screen 3-4. Administration - Users}

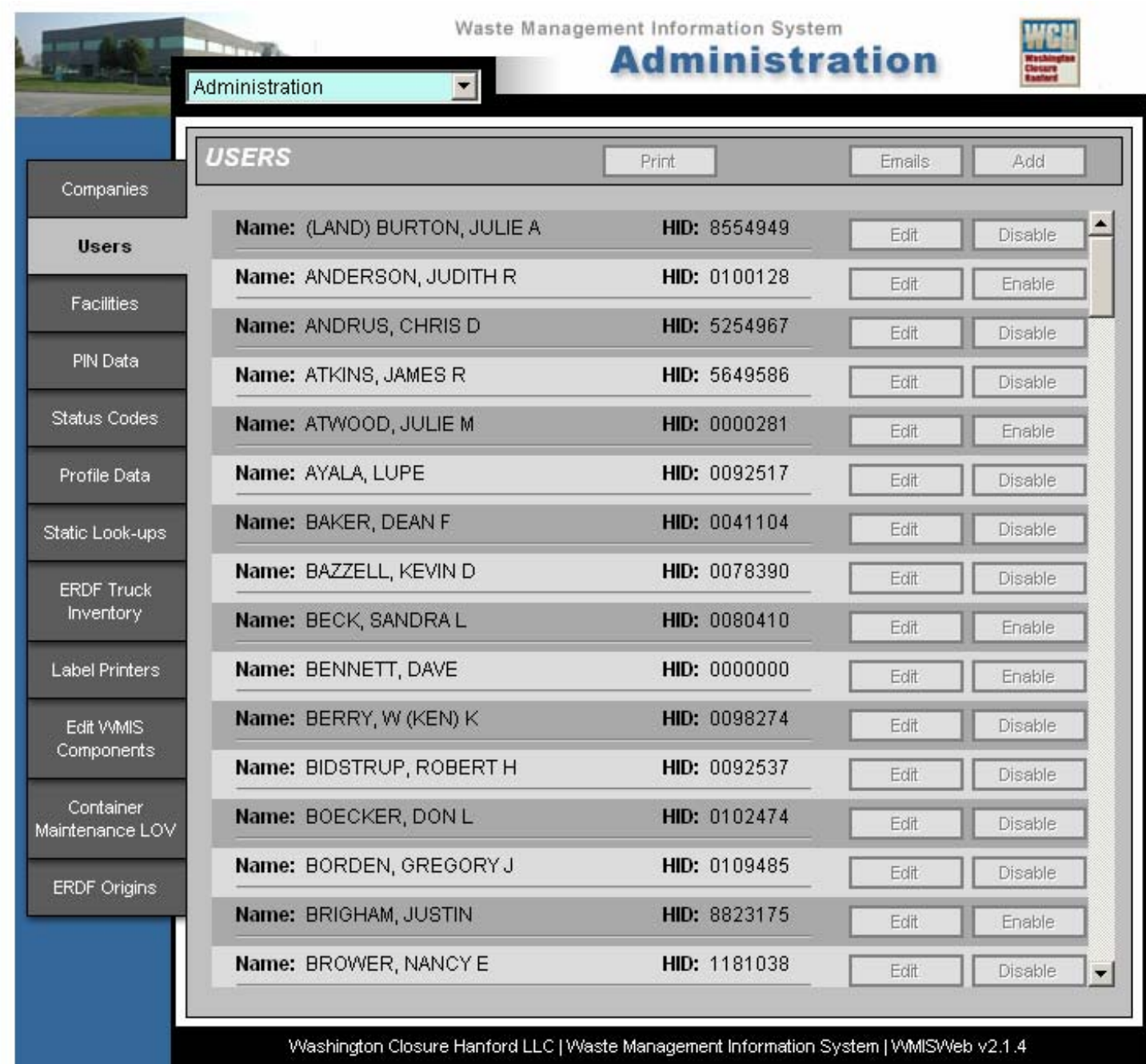

- $\quad$ Select "Add" to add new WMIS user, see Screen 3-5.

- $\quad$ Select "Edit" to edit user security role permissions, see Screen 3-6.

- $\quad$ Select "Enable/Disable" to activate or deactivate user permissions in WMIS. 


\section{Add User}

\section{Screen 3-5. Administration - Add User}

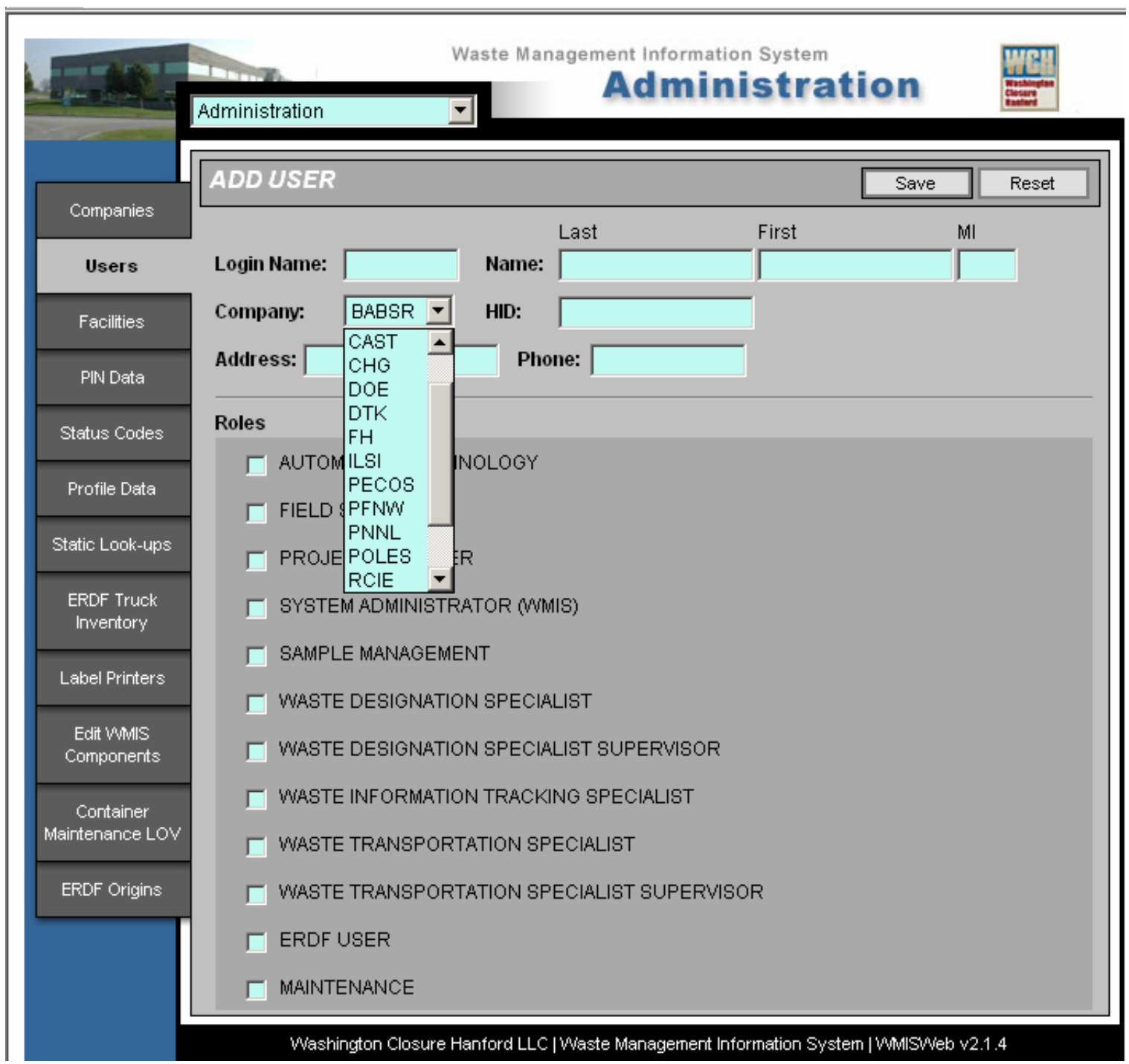

- Enter new user information:

- Login Name: WCH LAN User Name (BUN) (i.e., IMSmithe)

- Name: Last/First/MI (i.e., Smithers/lvan/M)

- Company: Select appropriate company from drop-down (Company table)

- HID: Hanford identification number (i.e., 0990999, no leading "h")

- Address: Bldg/Area/MSIN (i.e., MO607/600 Area/T2-04)

- Phone: Cell or Office number (i.e., 509.555.0009).

- $\quad$ Press "Save."

- Press "Reset" to reset field values to <NULL> Edit User. 


\section{Edit User}

\section{Screen 3-6. Administration - Edit User}

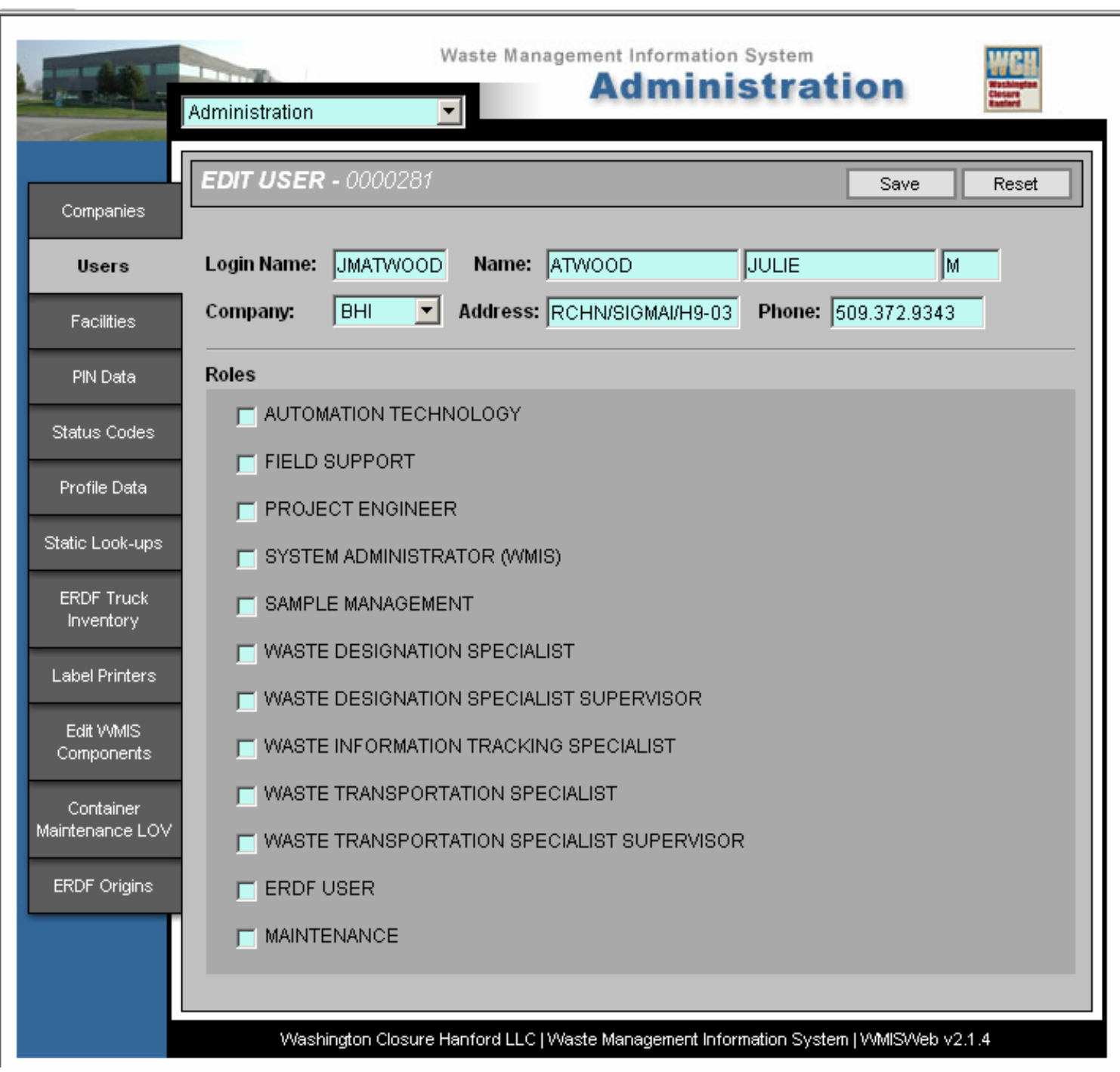

- Edit WMIS user information and modify security role permissions as needed.

- Press "Save."

- $\quad$ Press "Reset" to reset field values to the pre-existing values. 


\subsection{WMIS130 FACILITY DATA ADMINISTRATION}

\section{Screen 3-7. Administration - Facilities}

\begin{tabular}{|c|c|c|c|c|}
\hline$v_{1-x+2}=$ & \multicolumn{3}{|c|}{$\begin{array}{l}\text { Waste Management Information System } \\
\text { A Administration }\end{array}$} & Wid \\
\hline Companies & \multicolumn{3}{|l|}{ HACILIVIES } & Add \\
\hline Users & $A R E A$ & $100 \quad \square$ & & \multirow[b]{2}{*}{$\Delta$} \\
\hline \multirow{2}{*}{ Facilities } & Facility: $116-\mathrm{B}-4$ & NAME: $116-\mathrm{B}-4$ & Edit & \\
\hline & Facility: $116-\mathrm{DR}-1$ & NAME: 116 -DR-1 TRENCH & Edit & \\
\hline PIN Data & Facility: $116-\mathrm{DR}-2$ & NAME: $116-D R-2$ TRENCH & Edit & \\
\hline Status Codes & Facility: $116 \mathrm{~B} 6 \mathrm{~A}$ & NAME: $116 \mathrm{~B} 6 \mathrm{~A}$ & Edit & \\
\hline Profile Data & Facility: $116 \mathrm{C} 2 \mathrm{~A}$ & NAME: $116 \mathrm{C} 2 \mathrm{~A}$ & Edit & \\
\hline Static Look-ups & Facility: $116 \mathrm{C} 5$ & NAME: $116 \mathrm{C} 5$ & Edit & \\
\hline \multirow{2}{*}{$\begin{array}{l}\text { ERDF Truck } \\
\text { Inventory }\end{array}$} & Facility: $116 \mathrm{D} 1 \mathrm{~A}$ & NAME: $116 \mathrm{D} 1 \mathrm{~A}$ & Edit & \\
\hline & Facility: 116D1日 & NAME: $116 \mathrm{D} 1 \mathrm{~B}$ & Edit & \\
\hline Label Printers & Facility: $116 \mathrm{D} 7$ & NAME: $116 \mathrm{D} 7$ & Edit & \\
\hline \multirow{2}{*}{$\begin{array}{l}\text { Edit WMIS } \\
\text { Components }\end{array}$} & Facility: $116 \mathrm{DR} 12$ & NAME: $116 \mathrm{DR} 12$ & Edit & \\
\hline & Facility: 116DR9 & NAME: 116DR9 & Edit & \\
\hline $\begin{array}{c}\text { Container } \\
\text { Maintenance LOV }\end{array}$ & Facility: $116 \mathrm{~F} 14$ & NAME: $116 \mathrm{~F} 14$ & Edit & \\
\hline \multirow{2}{*}{ ERDF Origins } & Facility: $116 \mathrm{~F} 1 \mathrm{~A}$ & NAME: $116 \mathrm{~F} 1 \mathrm{~A}$ & Edit & \\
\hline & Facility: $116 \mathrm{~F} 2$ & NAME: $116 \mathrm{~F} 2$ & Edit & \\
\hline
\end{tabular}

- $\quad$ Select "Add" to add new facility, see Screen 3-8.

- $\quad$ Select "Edit" to edit existing facility, see Screen 3-9. 


\section{Add Facility}

\section{Screen 3-8. Administration - Add Facility}

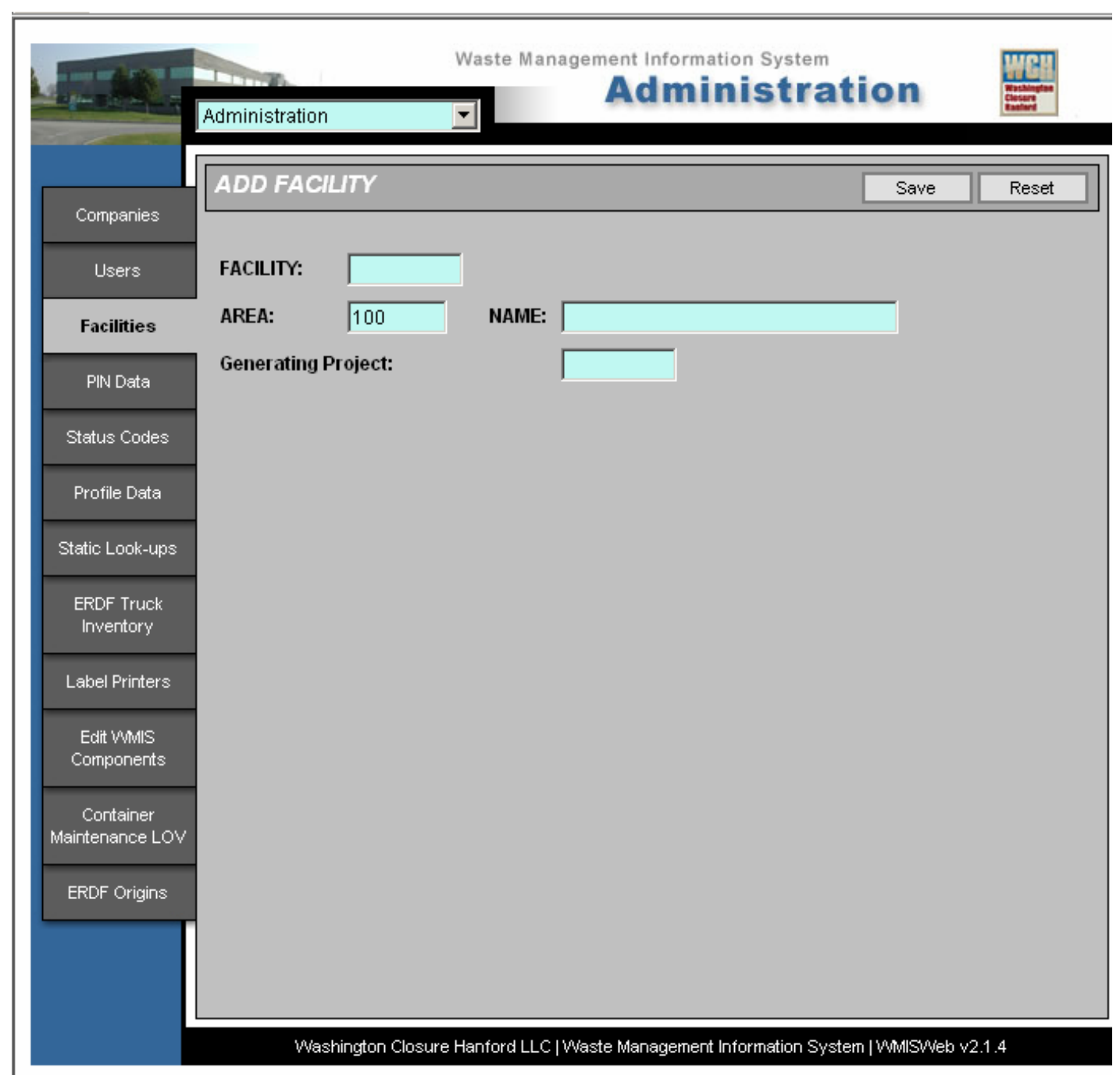

- Enter data to create new facility.

- Press "Save."

- Press "Reset" to reset field values to <NULL>. 


\section{Edit Facility}

Screen 3-9. Administration - Edit Facility

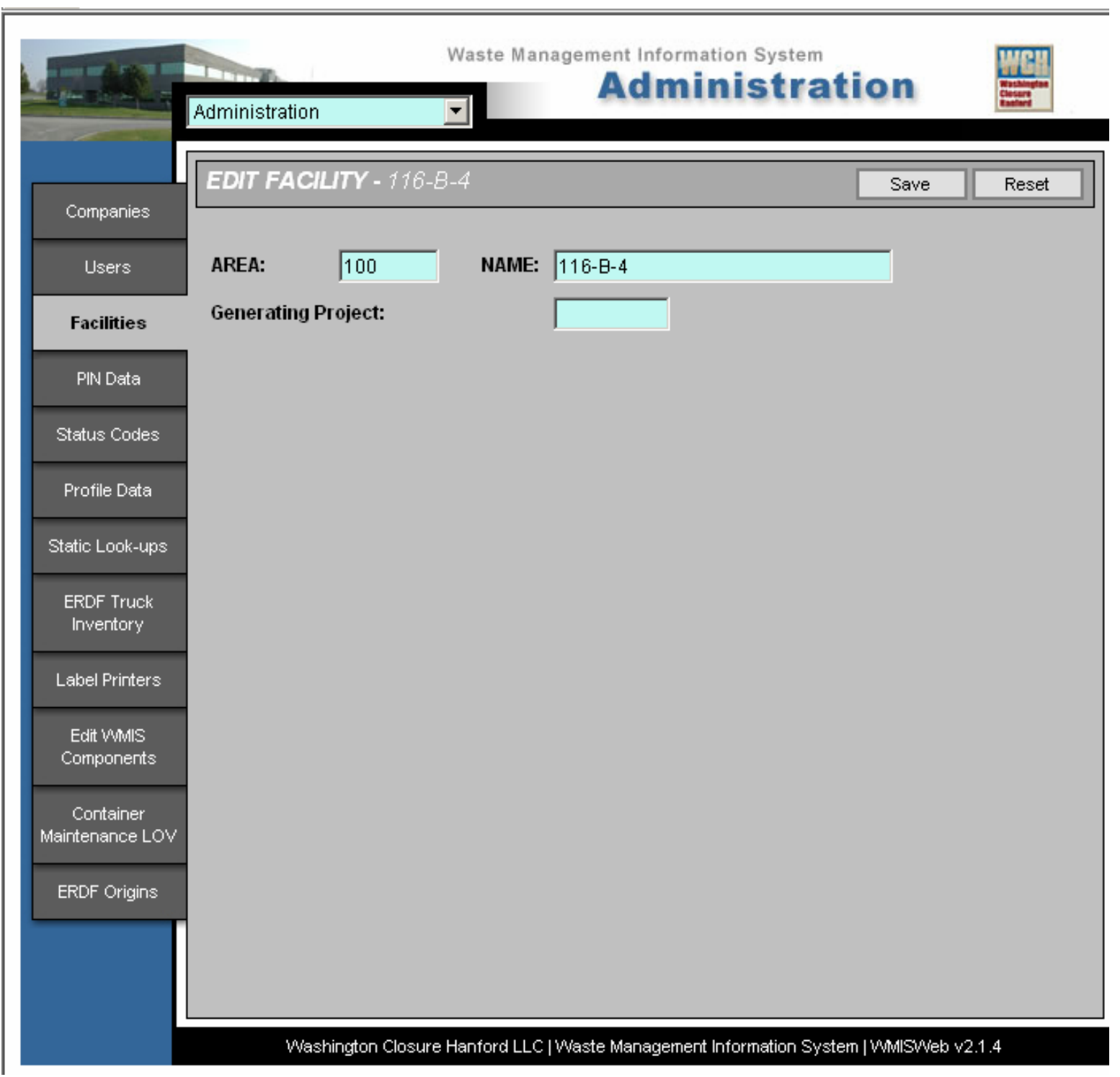

- Edit the facility information as needed.

- Press "Save."

- Press "Reset" to reset field values to the pre-existing values. 


\subsection{WMIS140 PIN SELECTION DATA ADMINISTRATION}

This look-up table contains the information a user needs to make a proper PIN assignment. The table provides the look-up data for the WMIS user when requesting PIN Numbers in the Storage Module.

\section{Screen 3-10. Administration - PIN Selection Data}

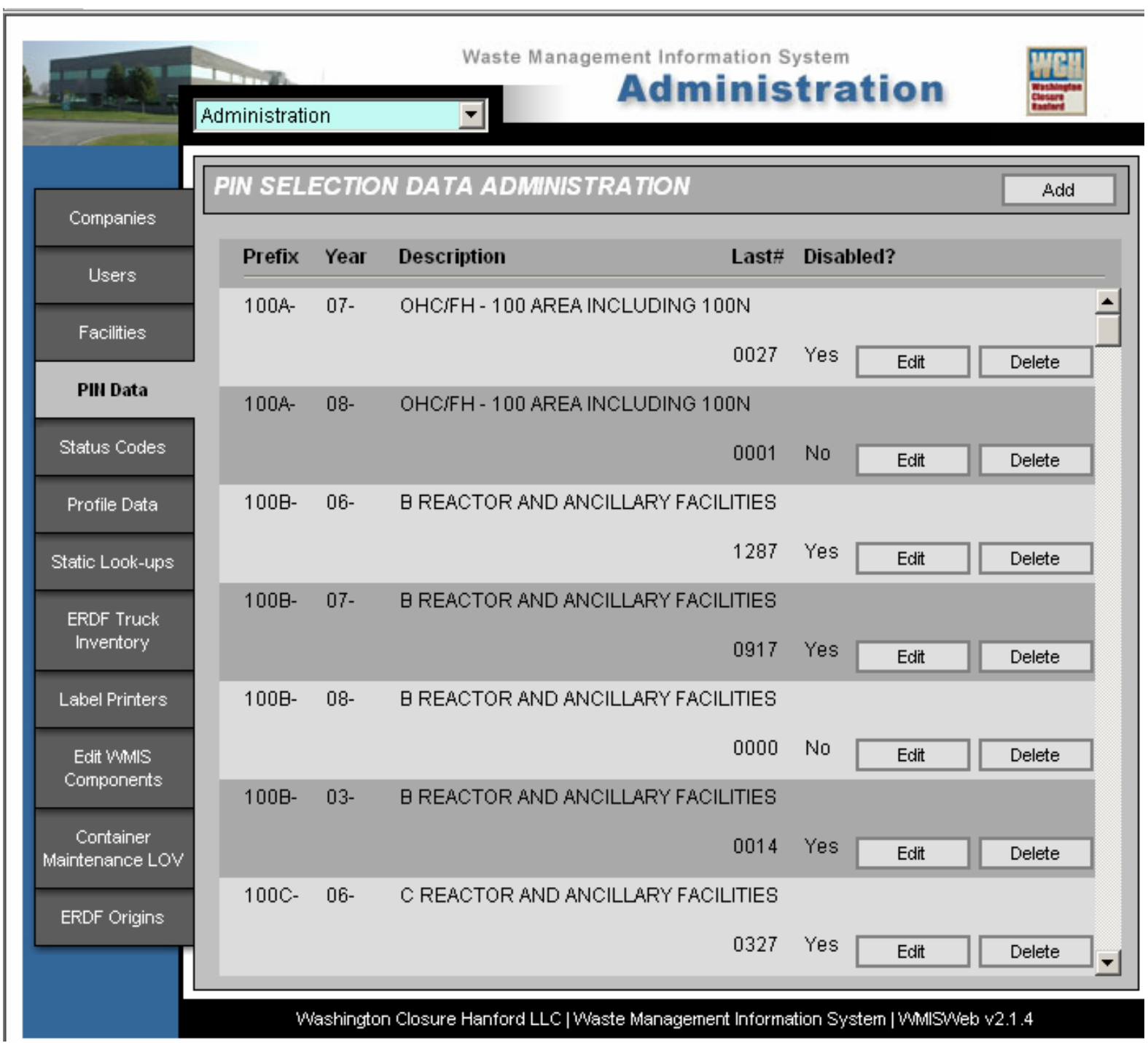

- $\quad$ Select "Add" to add new PIN prefix, see Screen 3-11.

- $\quad$ Select "Edit" to edit existing PIN prefix, see Screen 3-12.

- $\quad$ Select "Delete" to delete PIN prefix. 


\section{Add PIN Selection Data}

\section{Screen 3-11. Administration - Add PIN Selection Data}

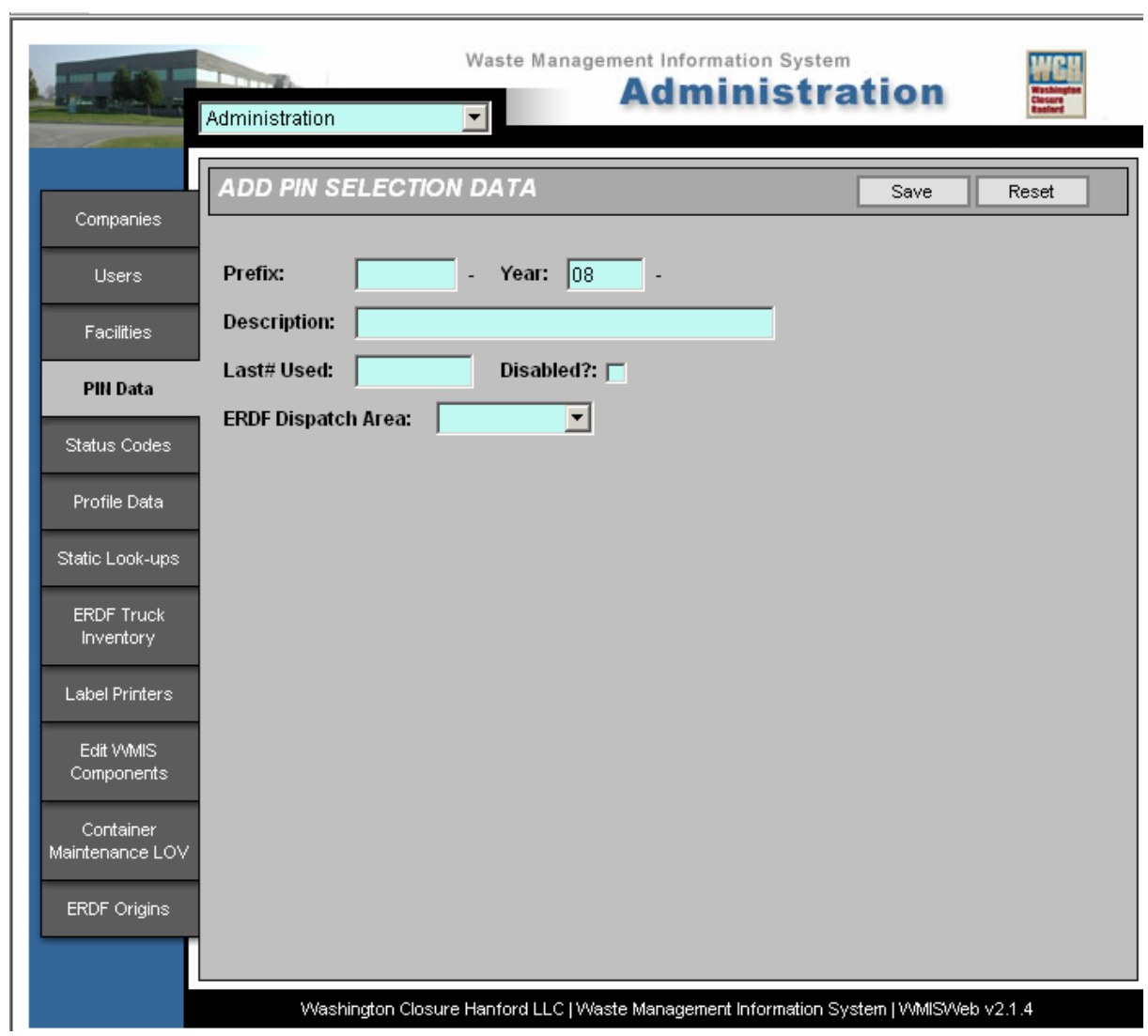

- Enter new PIN information.

- Prefix: Source site/area of waste generation (i.e., 100B)

- Year: Auto-filled by system calendar

- Description: Site/area description (i.e., B Reactor and ancillary facilities)

- Last\# Used: Set to "0" when entering new PIN prefixes, updates automatically as PINs are requested.

- Disabled?: Set to disabled when project associated with a specific PIN is completed/ terminated.

- $\quad$ Press "Save."

- Press "Reset" to reset field values to <NULL>. 


\section{Edit PIN Selection}

Screen 3-12. Administration - Edit PIN Selection

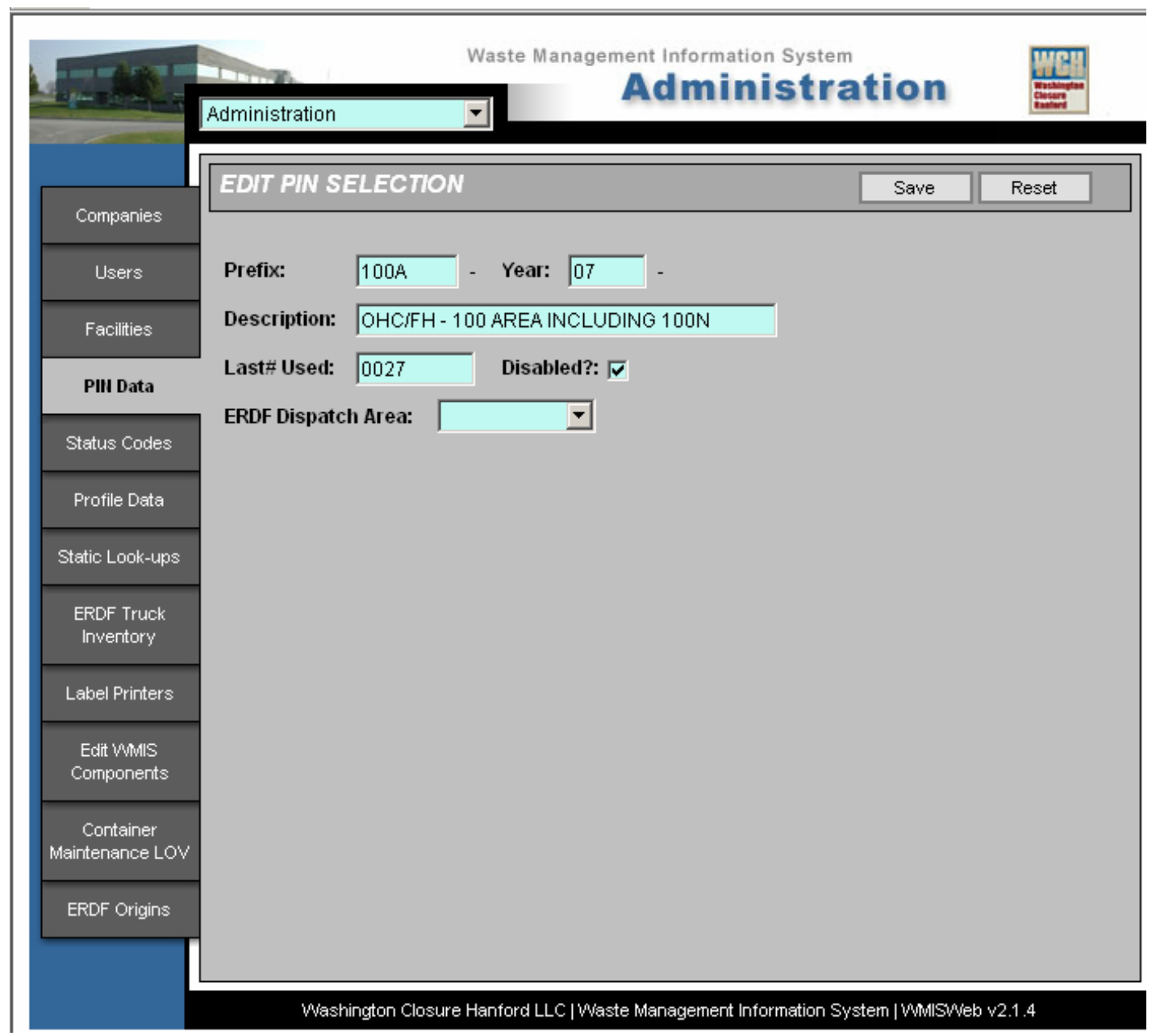

- Edit WMIS PIN selection information as needed.

- Press "Save."

- Press "Disabled?" to activate or deactivate PIN Selection Data in WMIS.

- Press "Reset" to reset field values to the pre-existing values.

\section{Delete PIN}

- Press "Delete" to delete PIN selection information in WMIS. 


\subsection{WMIS150 STATUS CODE DATA ADMINISTRATION}

\section{Screen 3-13. Administration - Status Code Data}

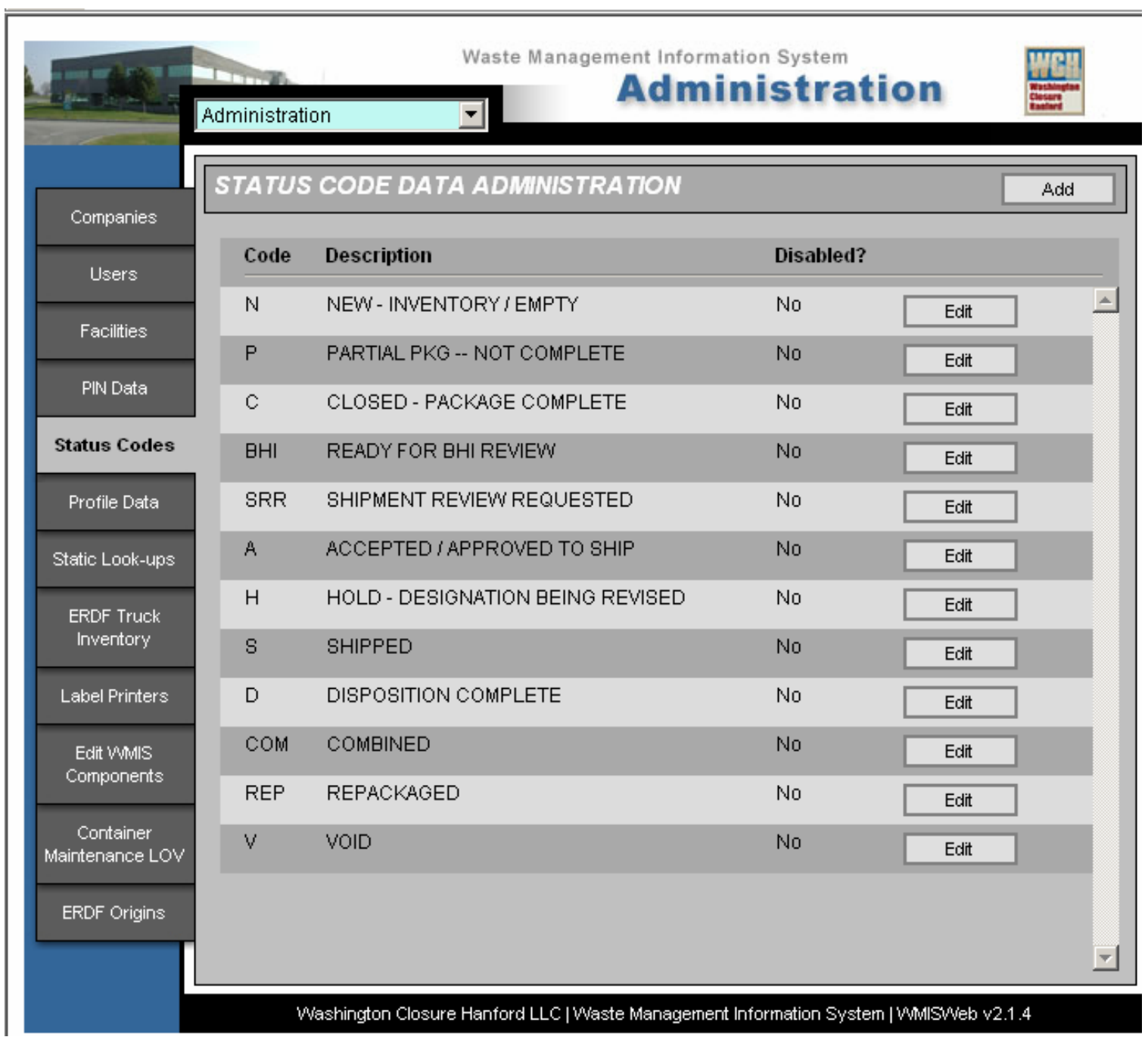




\section{Add Status Code Data}

This screen is used to add new status code data to the look-up table. All fields shown are required for input.

\section{Screen 3-14. Administration - Add Status Code Data}

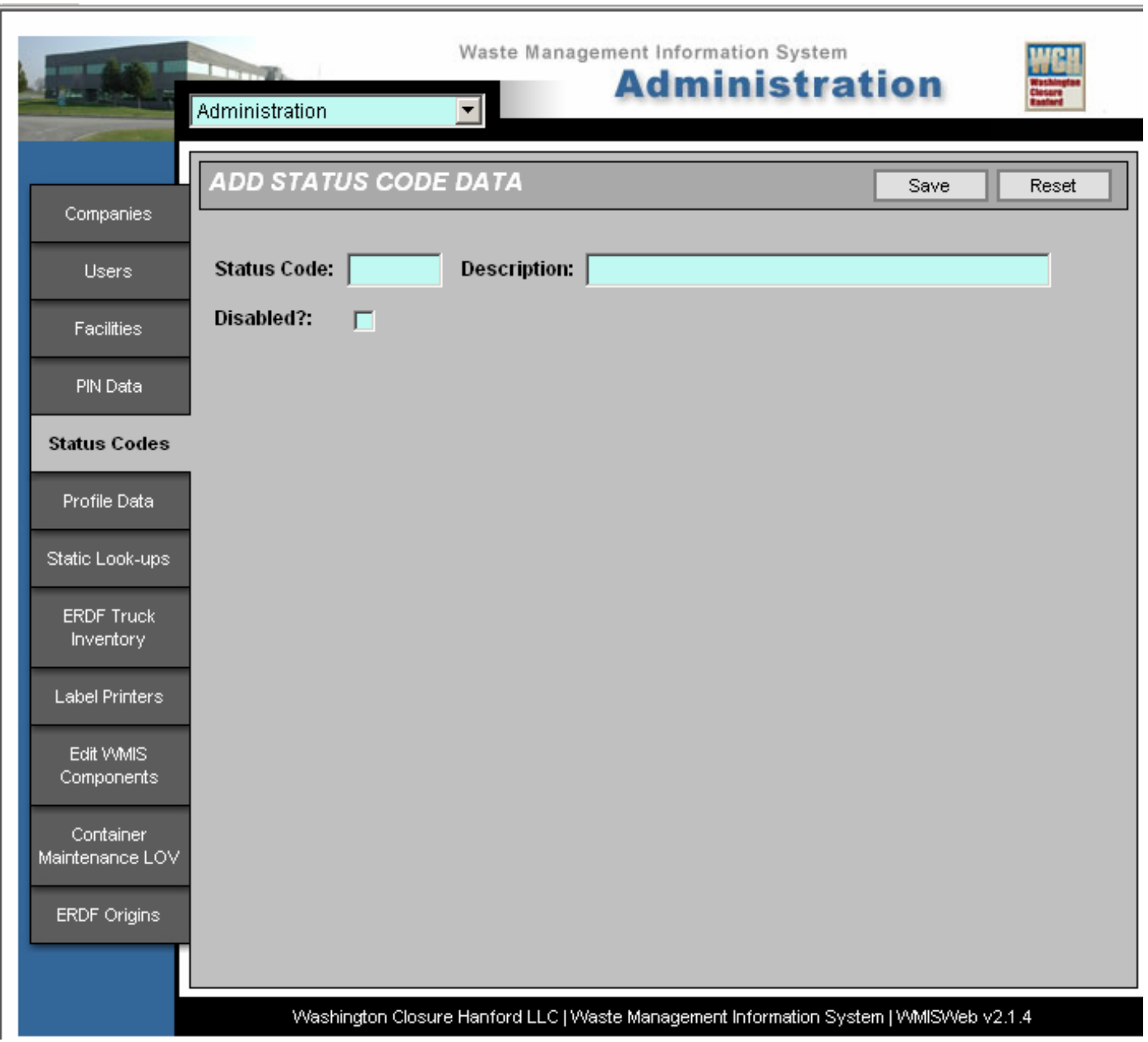

- Enter new status code data.

- Press "Save."

- Press "Disabled?" to activate or deactivate Status Code Data in WMIS.

- Press "Reset" to reset field values to <NULL>. 


\section{Edit Status Code Data}

\section{Screen 3-15. Administration - Edit Status Code Data}

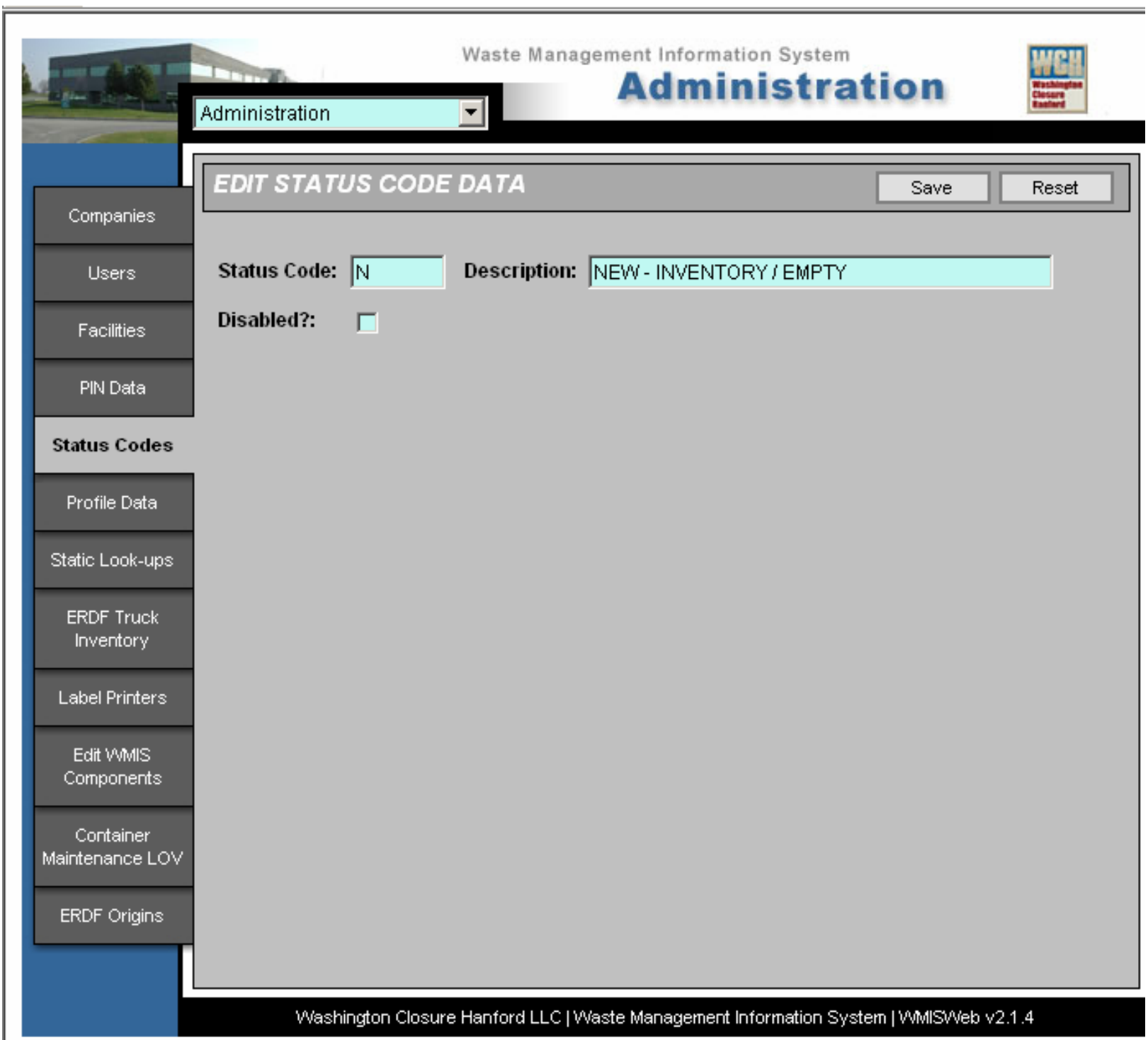

- Edit status code data as needed.

- Status Code: Single letter designator of waste package status.

- Description: Description of status code.

- Disabled?: Disable status code if no longer in use.

- $\quad$ Press "Save."

- $\quad$ Press "Reset" to reset field values to be reset the pre-existing values. 


\subsection{WMIS160 PROFILE DATA ADMINISTRATION}

The profile table has a record for each PHMC profile that waste is generated under. All ERDF profiles are captured in the Designation module.

\section{Screen 3-16. Administration - Profile Data}

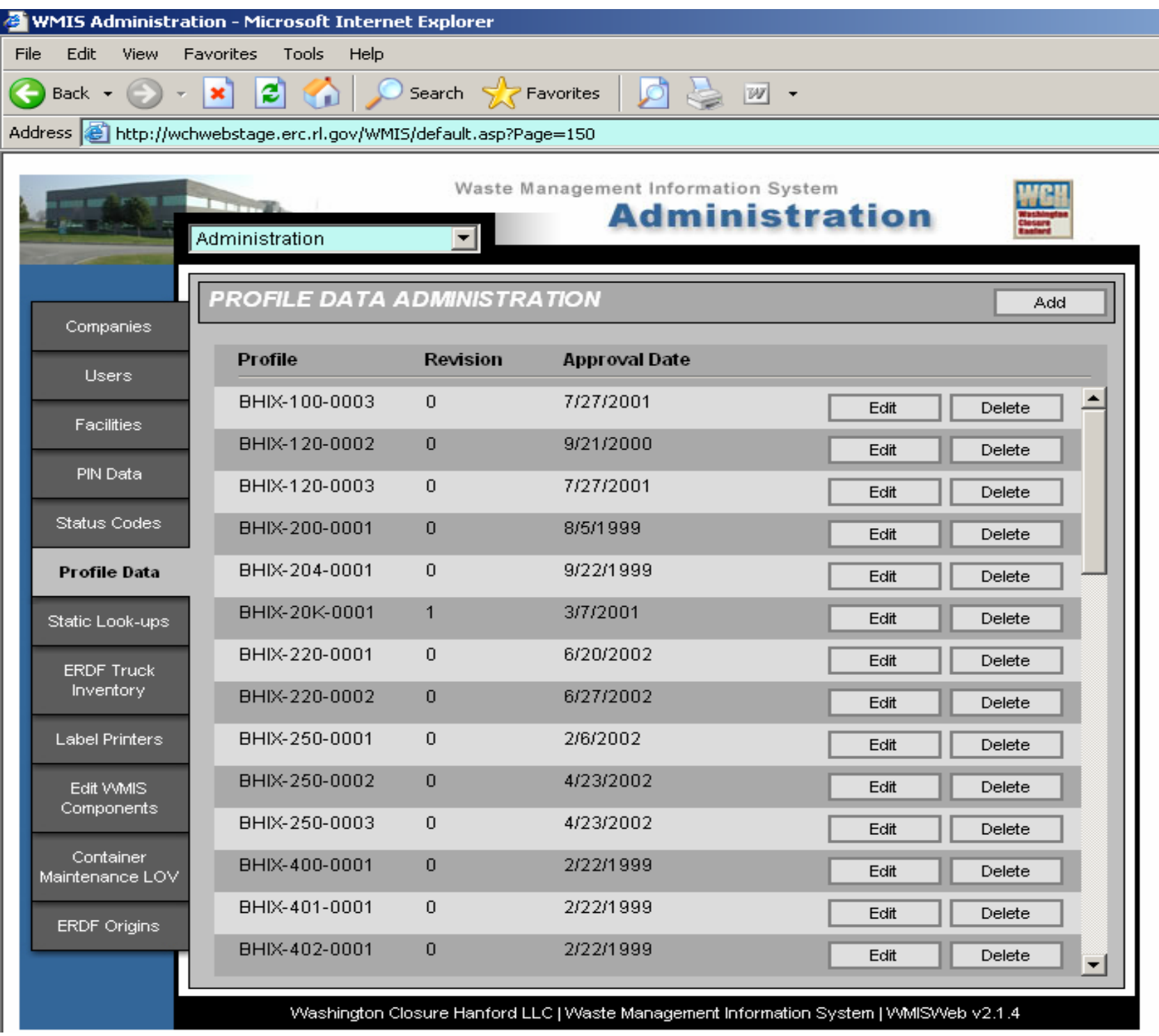




\section{Add Profile Data}

\section{Screen 3-17. Administration - Add Profile Data}

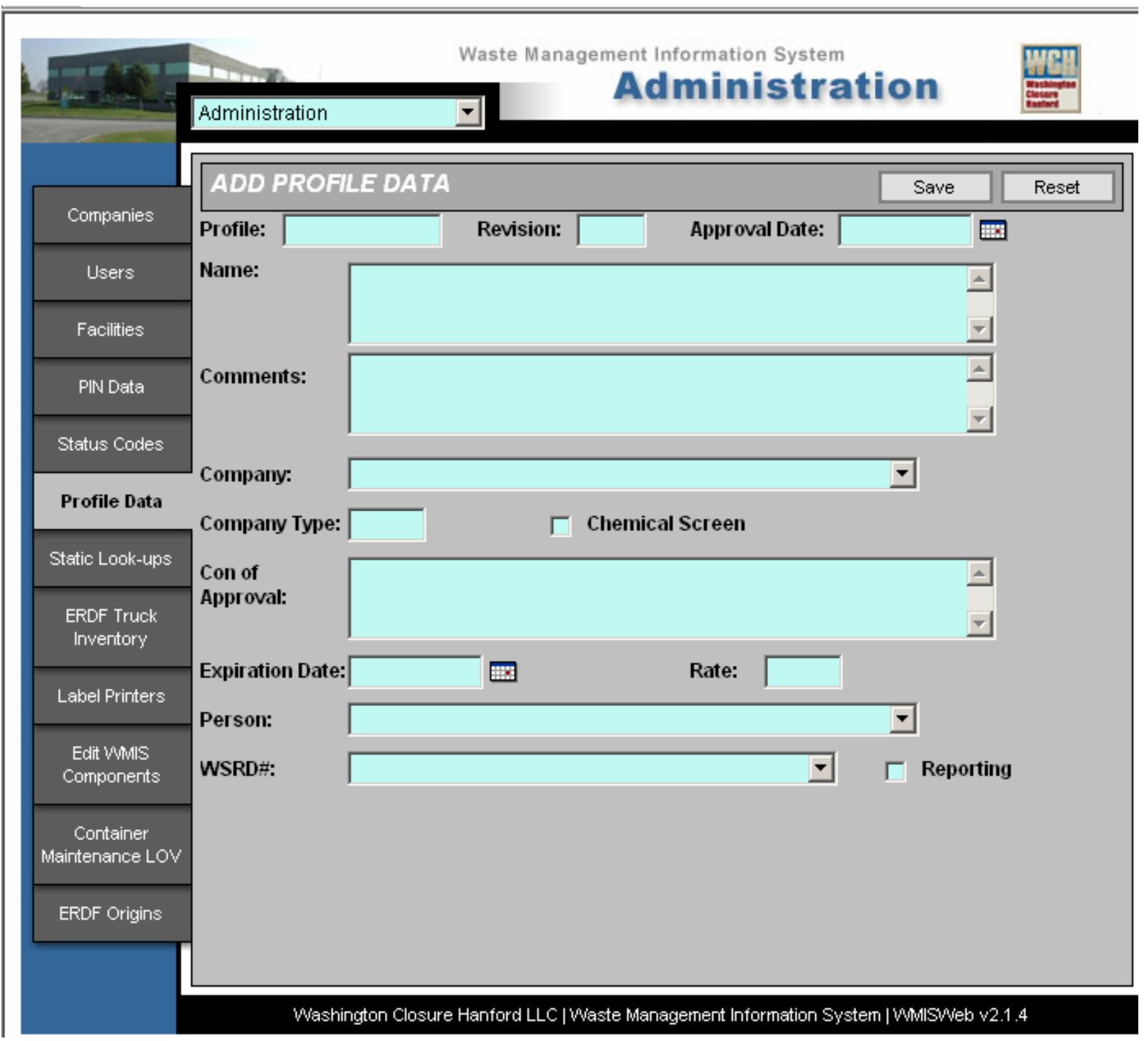

- Enter new PHMC profile information.

- $\quad$ Press "Save."

- Press "Reset" to reset field values to $<$ NULL $>$. 


\section{Profile Data Administration Edit}

\section{Screen 3-18. Administration - Profile Data Administration Edit}

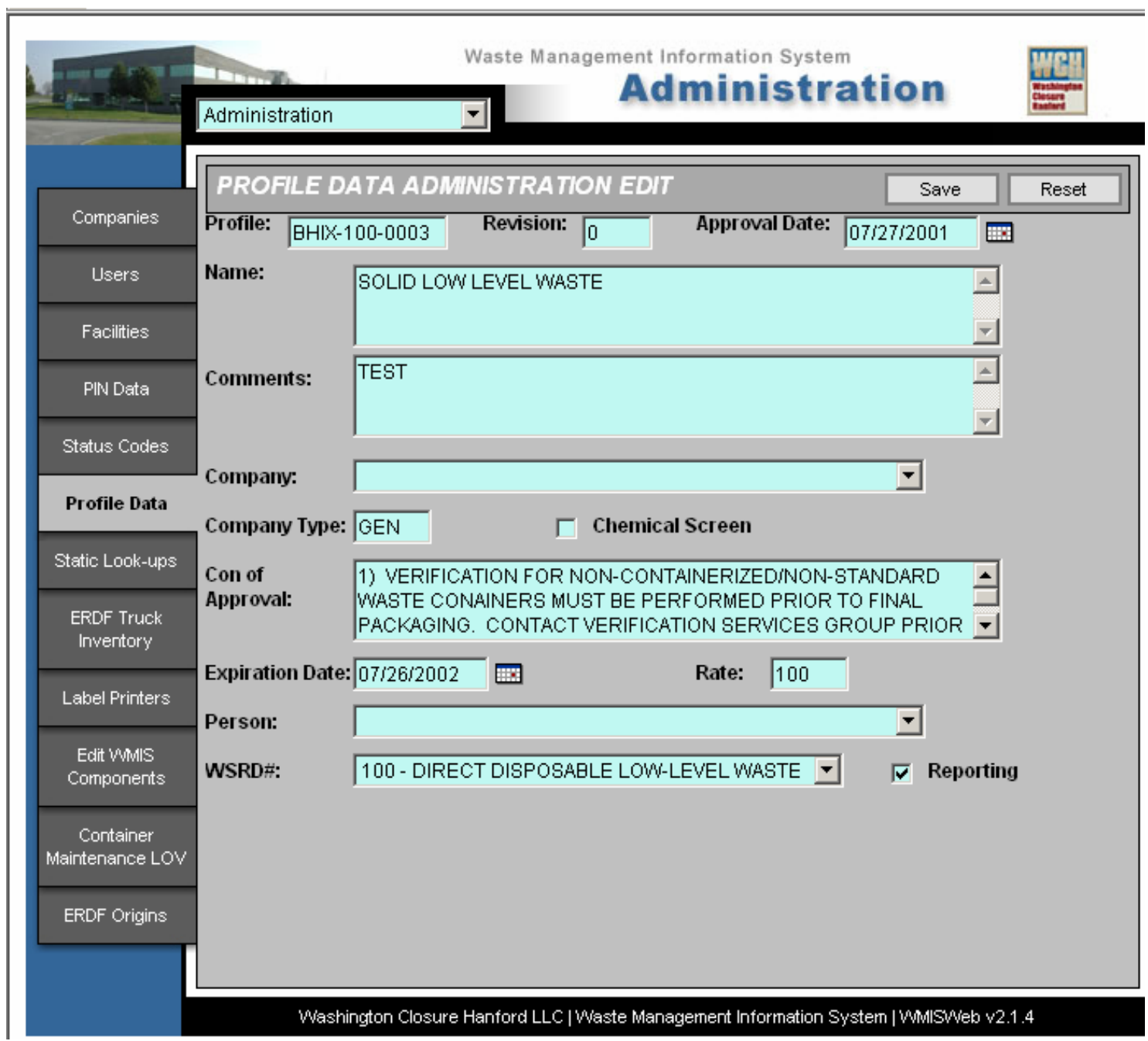

- $\quad$ Edit the existing profile as needed.

- Press "Save."

- $\quad$ Press "Reset" to reset field values to be reset the pre-existing values.

\section{Delete Profile Data}

- $\quad$ Press "Delete" to delete an existing profile in WMIS. 


\subsection{WMIS170 LIST STATIC LOOK-UP TABLES}

Static look-up tables for miscellaneous information (i.e., isotopes, DOT class, physical state, etc.) are on this screen. No insert or update functionality has currently been included.

\section{Screen 3-19. Administration - Static Lookup Lists}

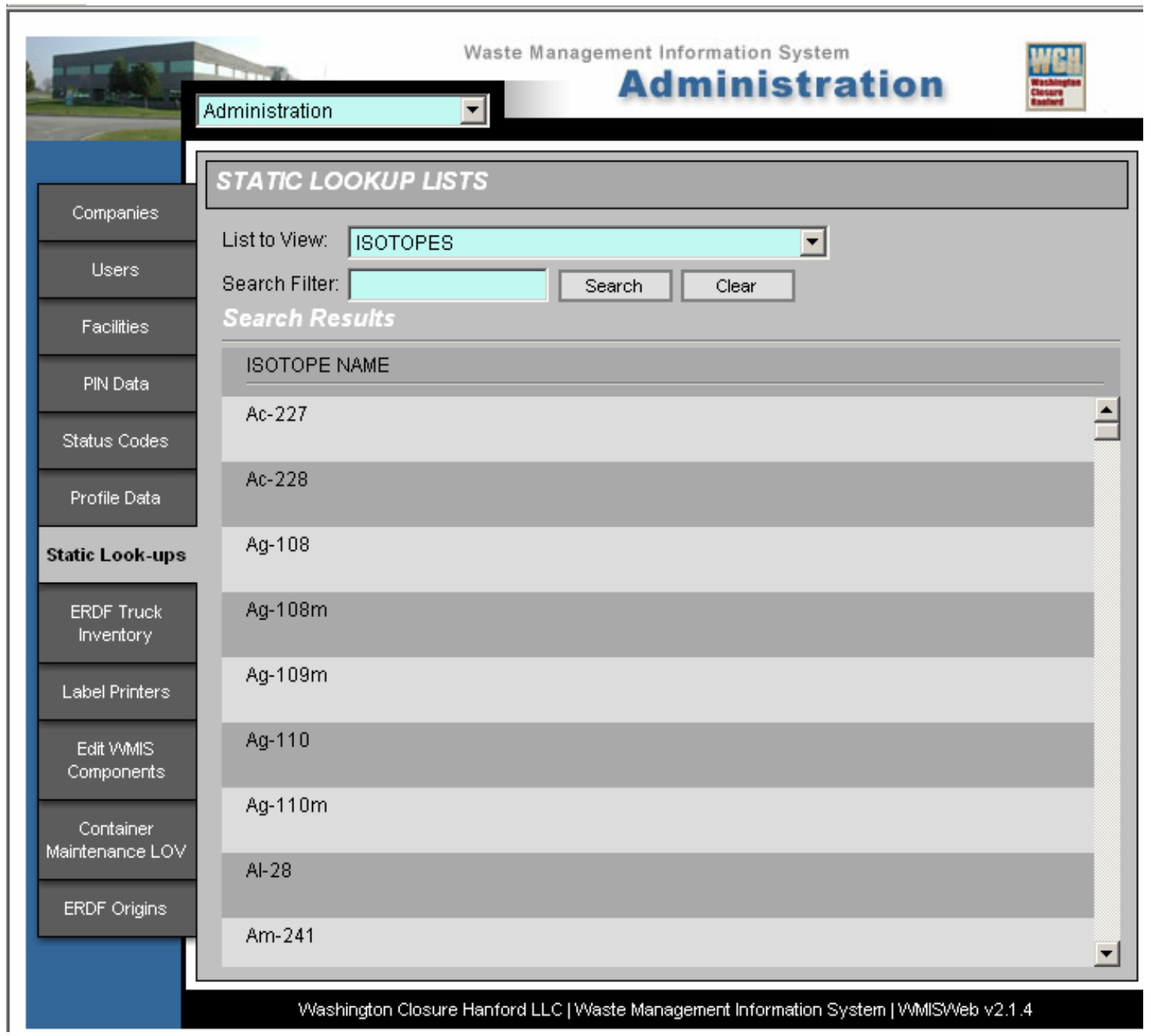

\section{Search Static Lookup List}

- Select appropriate list from the static lookup list to search as needed.

- The search filter function allows for refinement of the search parameters to optimize functionality. The syntax for the search pattern allows for truncated parameters.

- Press "Search." The screen will display all records that meet the query's criteria.

- $\quad$ To clear the search filter information, press "Clear." 


\subsection{WMIS180 ERDF TRUCK INVENTORY}

\section{Screen 3-20. Administration - ERDF Truck Inventory}

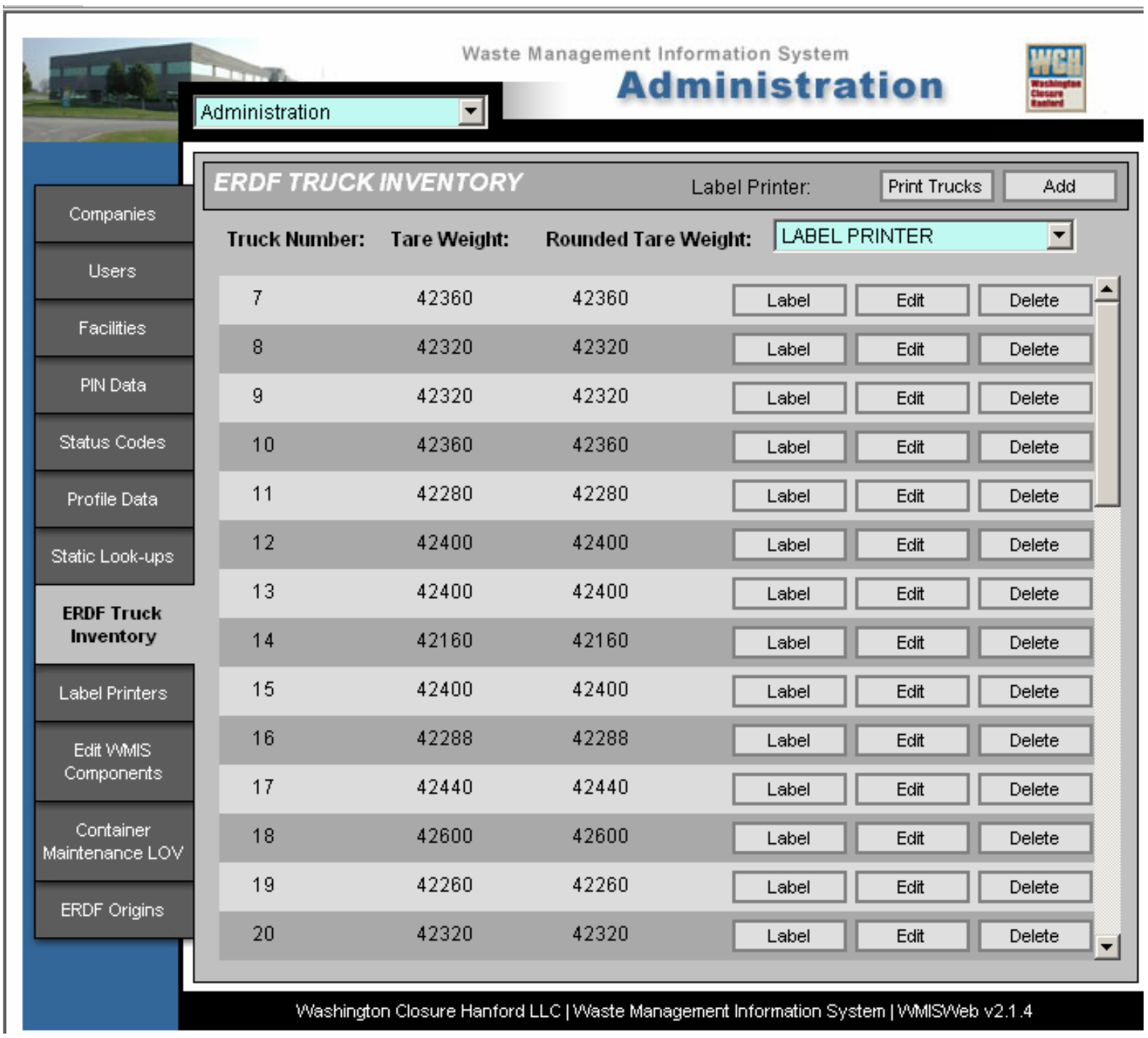

\begin{tabular}{|l|l|l|}
\hline Button & Screen Shot & Description \\
\hline Print Trucks & Screen 3-20 & \\
\hline Add & Screen 3-21 & Add new ERDF profiles \\
\hline Label & & \\
\hline Edit & Screen 3-23 & Edit existing ERDF profiles \\
\hline Delete & & Delete ERDF profiles \\
\hline
\end{tabular}

PRINT TRUCKS function- Reserved for future development 


\section{Screen 3-21. Administration - Add ERDF Truck}

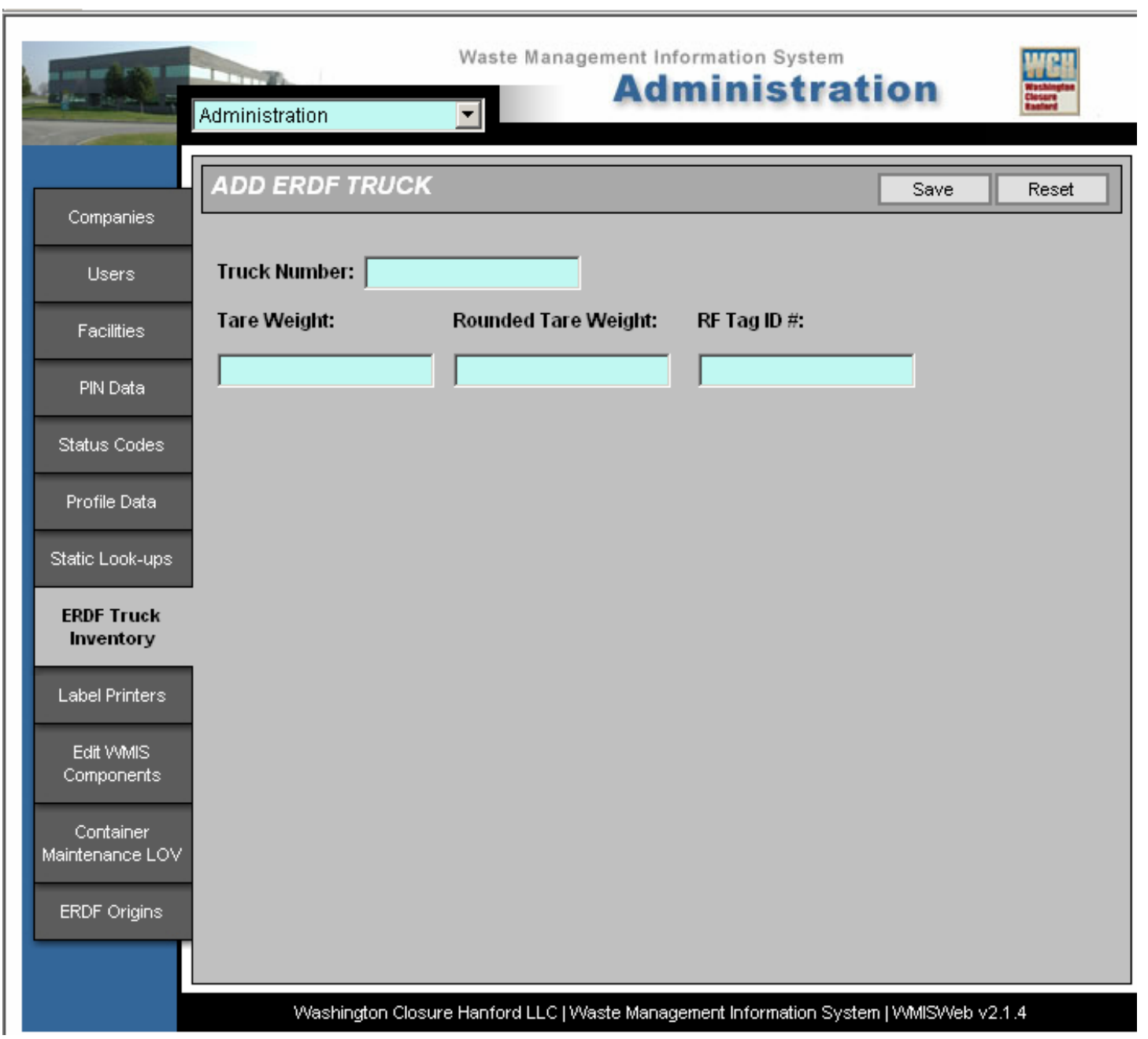

- Save. To add new ERDF truck information, enter the appropriate information in the required fields. Press the Save button.

- $\quad$ Reset. Press the reset button if the data is incorrect, which resets fields to $<$ Null $>$ values. Edit ERDF Truck. 


\section{Screen 3-22. Administration - Edit ERDF Truck}

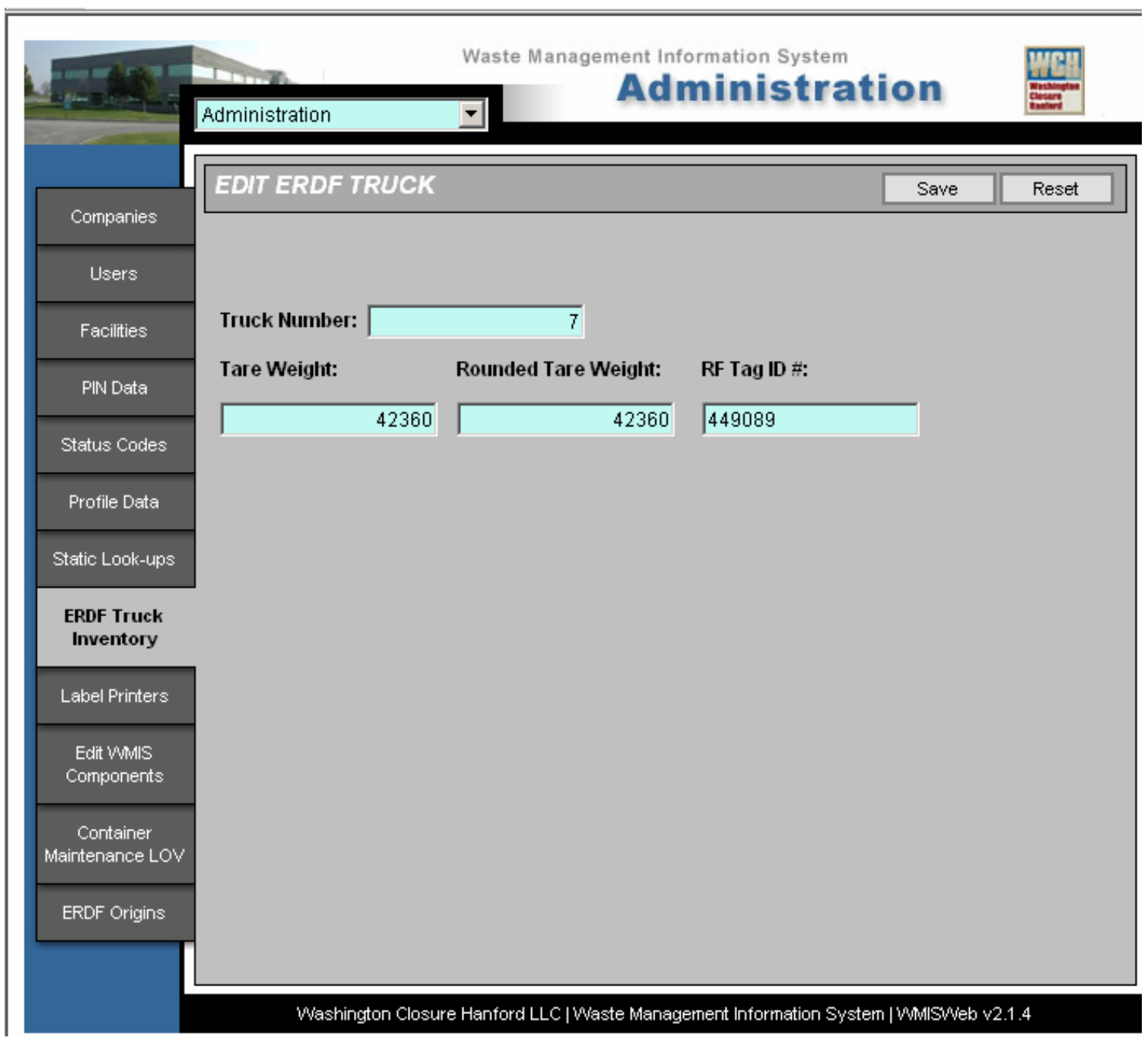

- Save. Edit existing ERDF trucks as needed. When changes are complete, Press the Save button.

- Reset. Press the reset button if the data entered into the required fields is incorrect and needs to be reset the pre-existing values. 


\subsection{WMIS190 LABEL FUNCTION ADMINISTRATION}

\section{Screen 3-23. Administration - Label Printers}

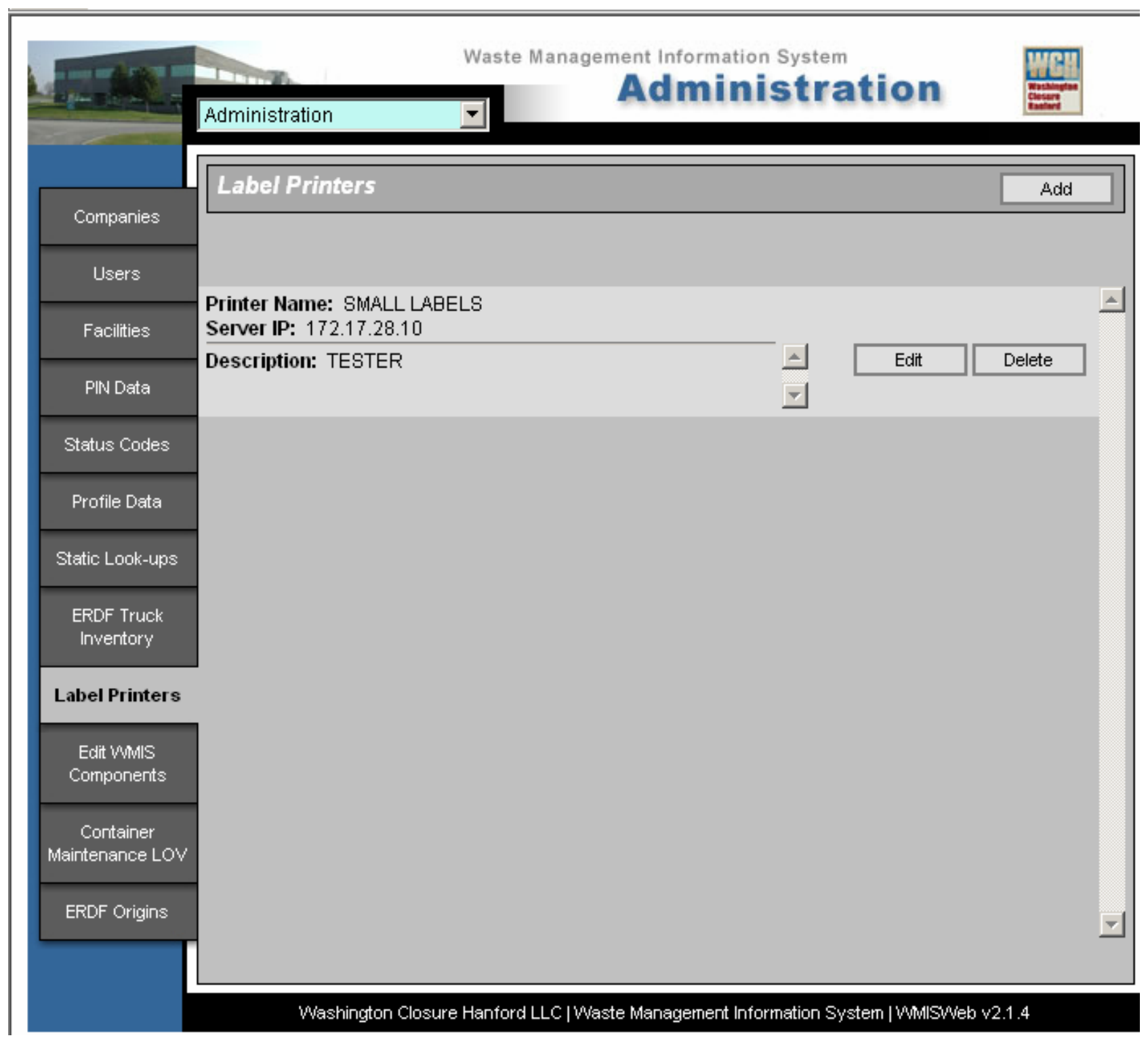




\section{Screen 3-24. Administration - Add Label Printer}

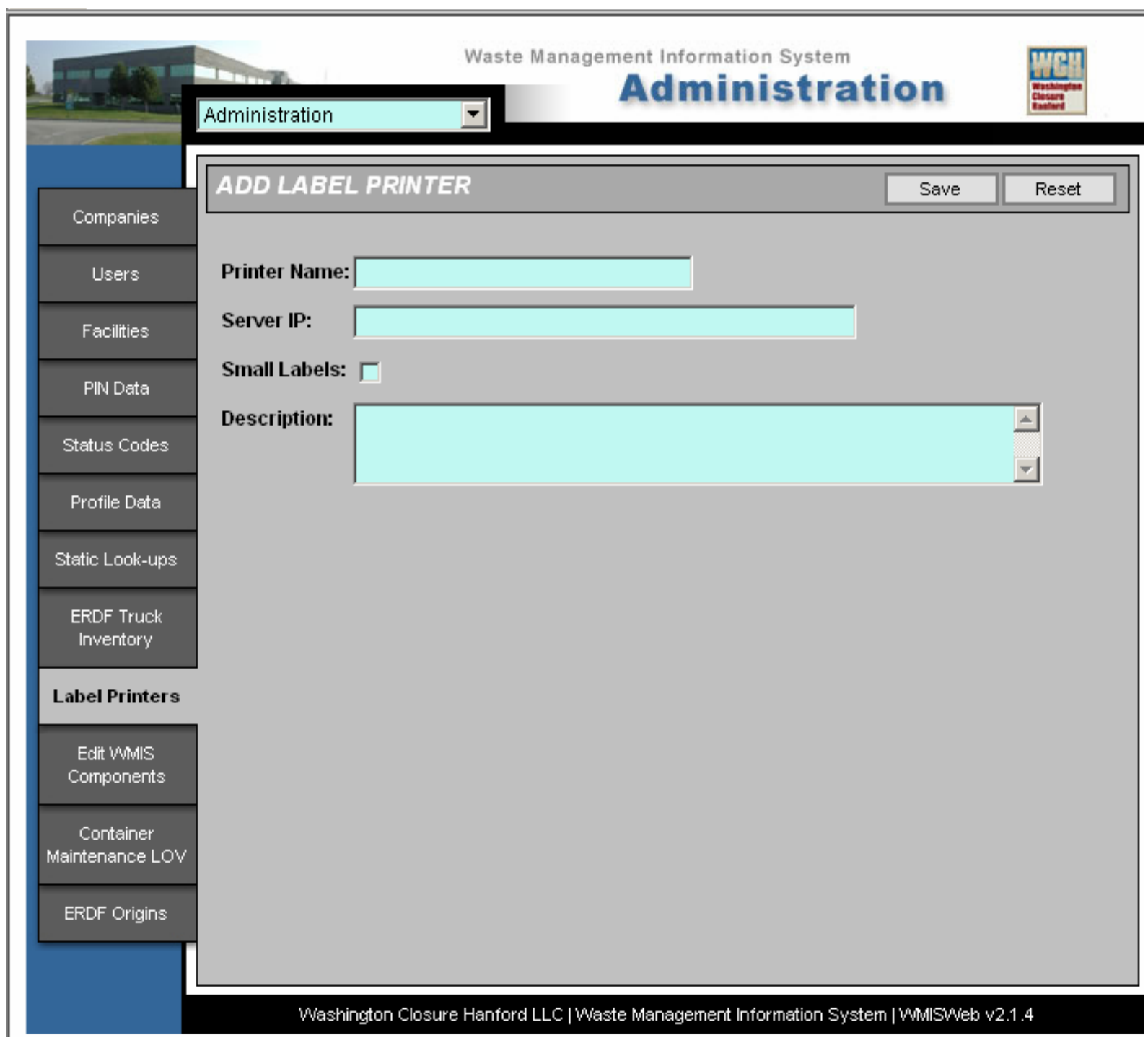




\section{Screen 3-25. Administration - Edit Label Printer}

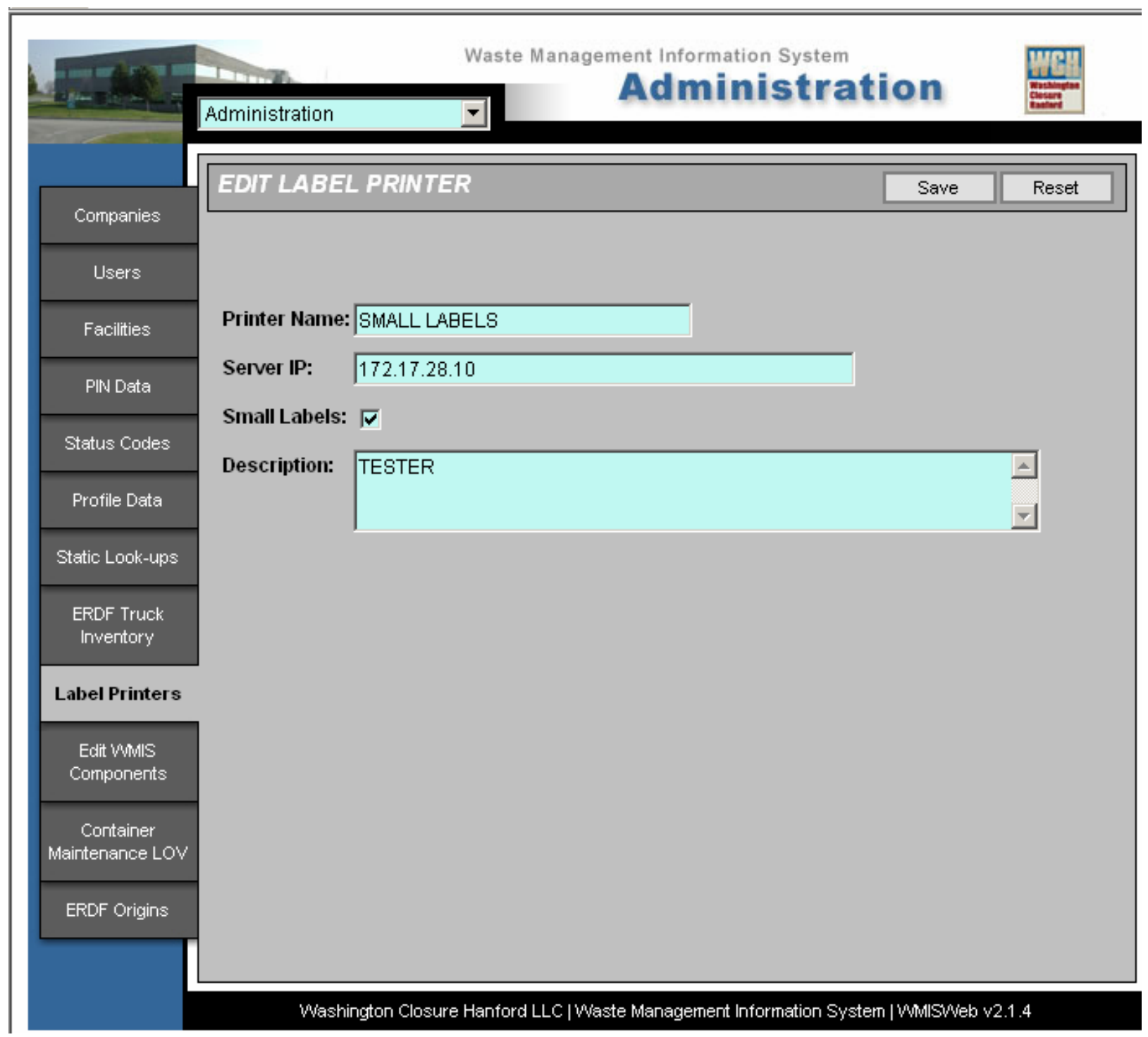




\subsection{WMIS200 WASTE COMPONENTS ADMINISTRATION}

\section{Screen 3-26. Administration - WMIS Waste Components}

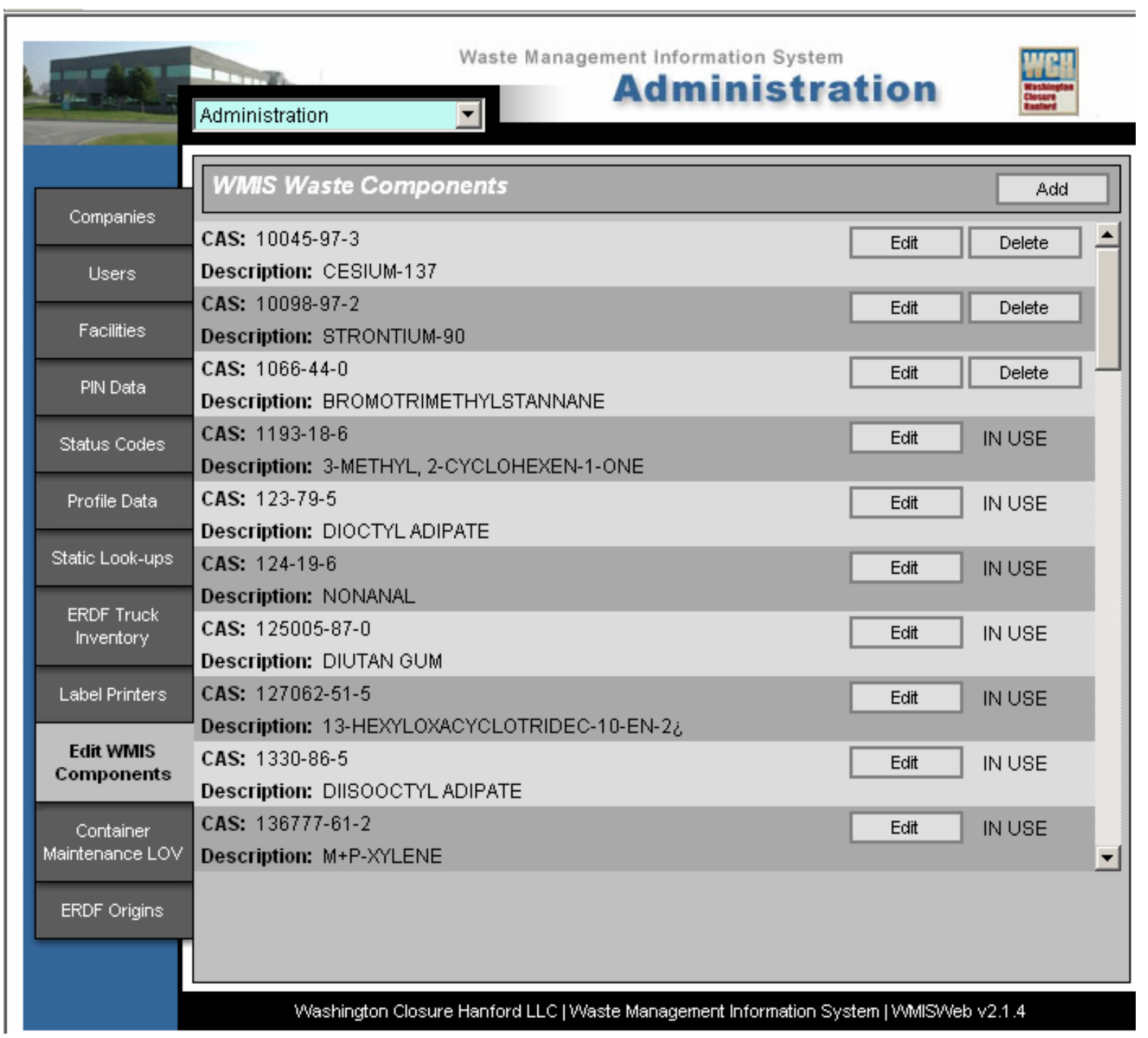

- $\quad$ Select "Add" to add new company, see Screen 3-27.

- $\quad$ Select "Edit" to edit existing company, see Screen 3-28. 


\section{Add WMIS Component}

Screen 3-27. Administration - Add WMIS Component

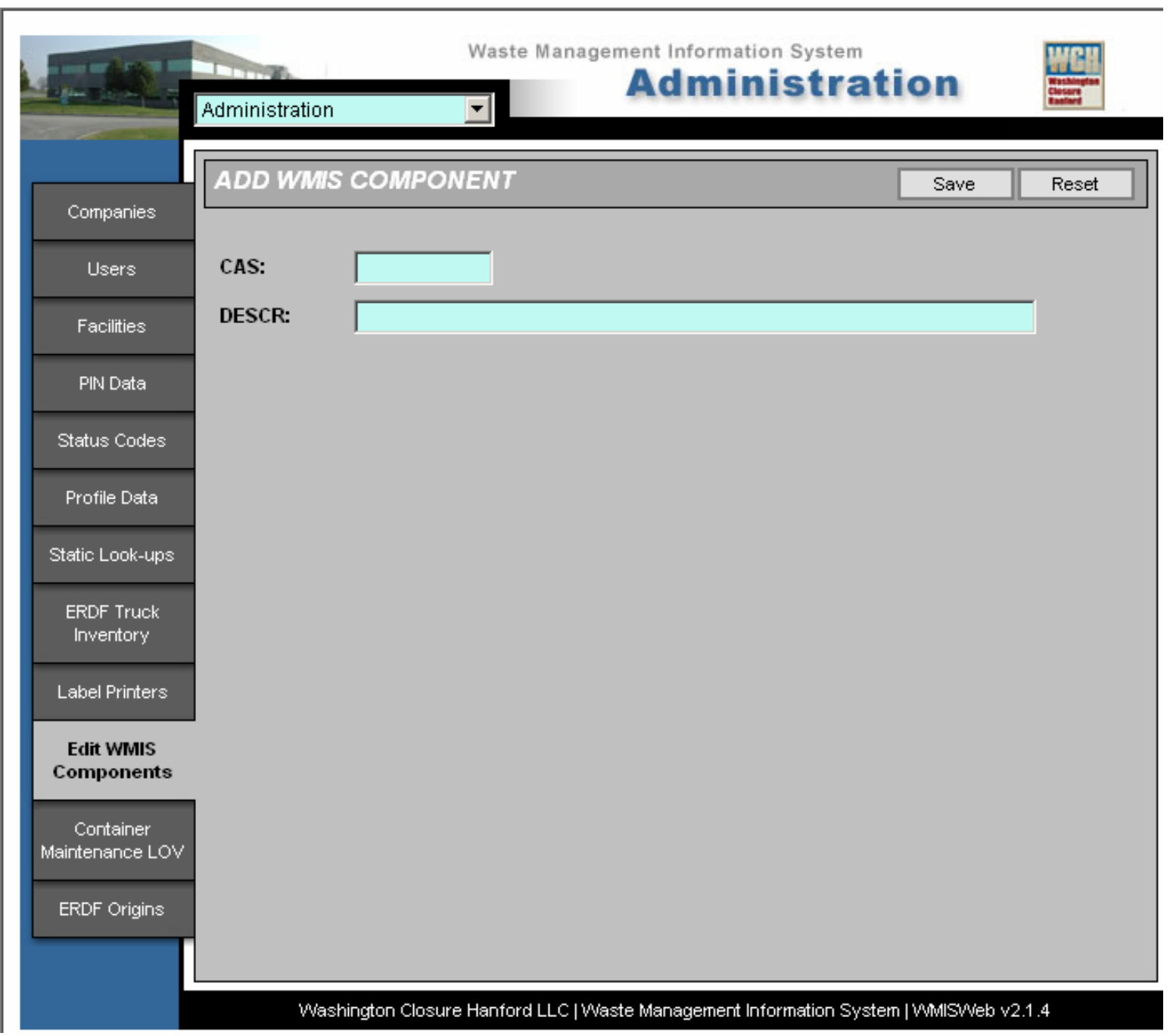

- Enter data to create new WMIS component.

- Press "Save."

- Press "Reset" to reset field values to <NULL>. 


\section{Edit WMIS Waste Component}

\section{Screen 3-28. Administration - Edit Waste Component}

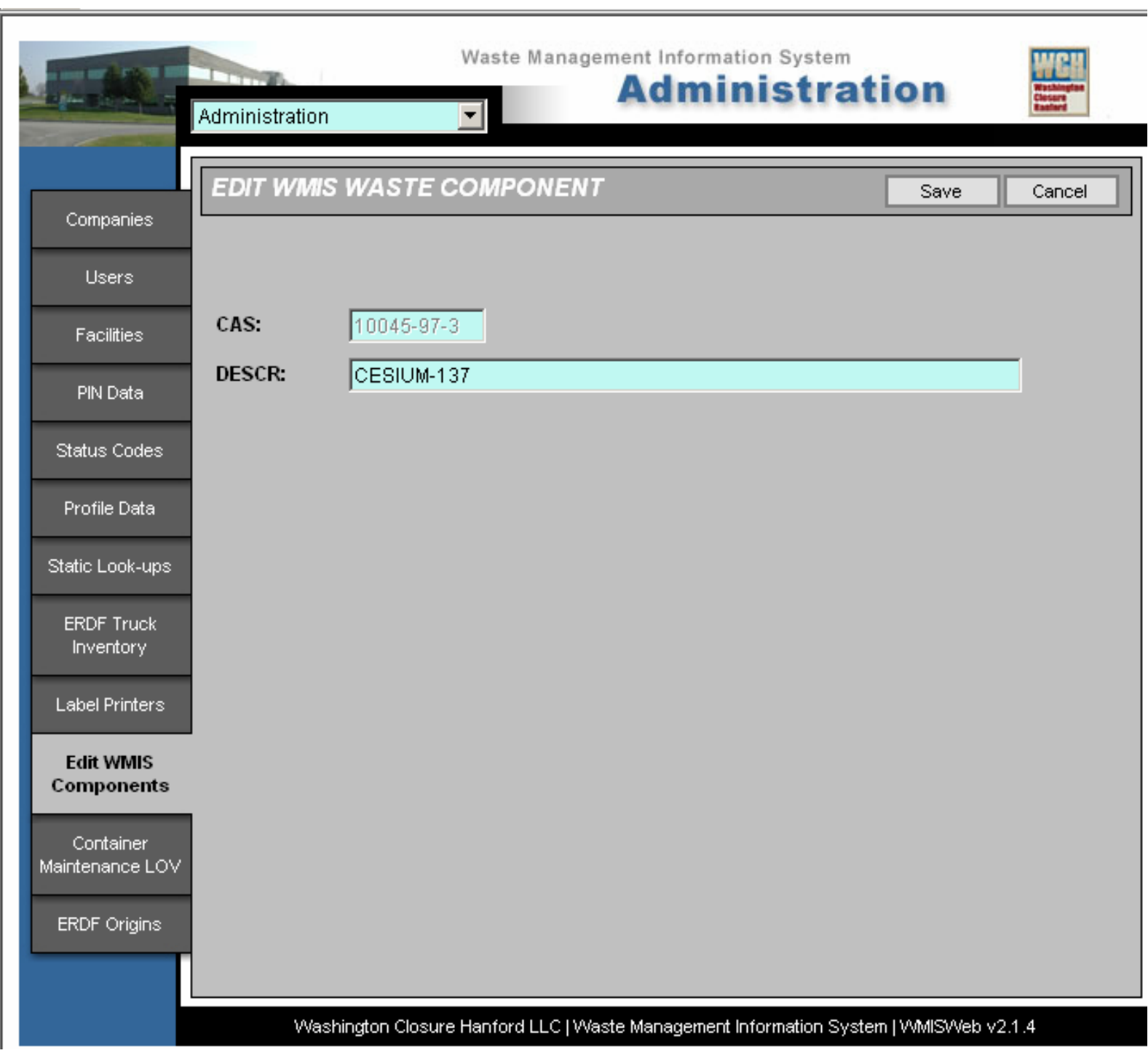

- Edit the waste component information as needed.

- Press "Save." 


\subsection{WMIS210 WMIS ERDF CONTAINER MAINTENANCE LOV ADMINISTRATION}

\section{Screen 3-29. Administration - Container Maintenance LOV}

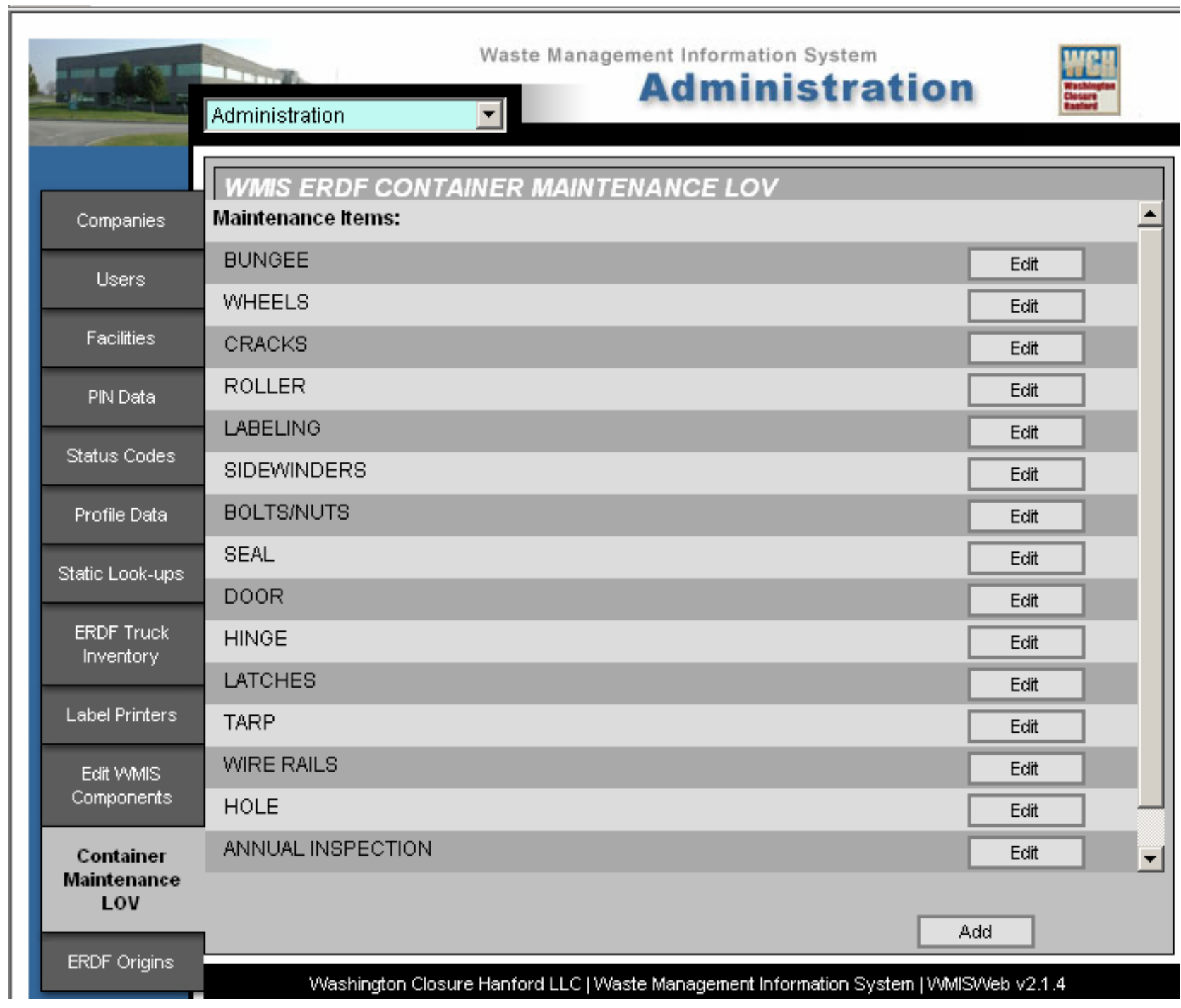

- Select "Add" to add new maintenance items, see Screen 3-30.

- Select "Edit" to edit existing maintenance items, see Screen 3-31. 


\section{Add Container Readiness Check List Item}

\section{Screen 3-30. Administration - Add Container Readiness Check List Item}

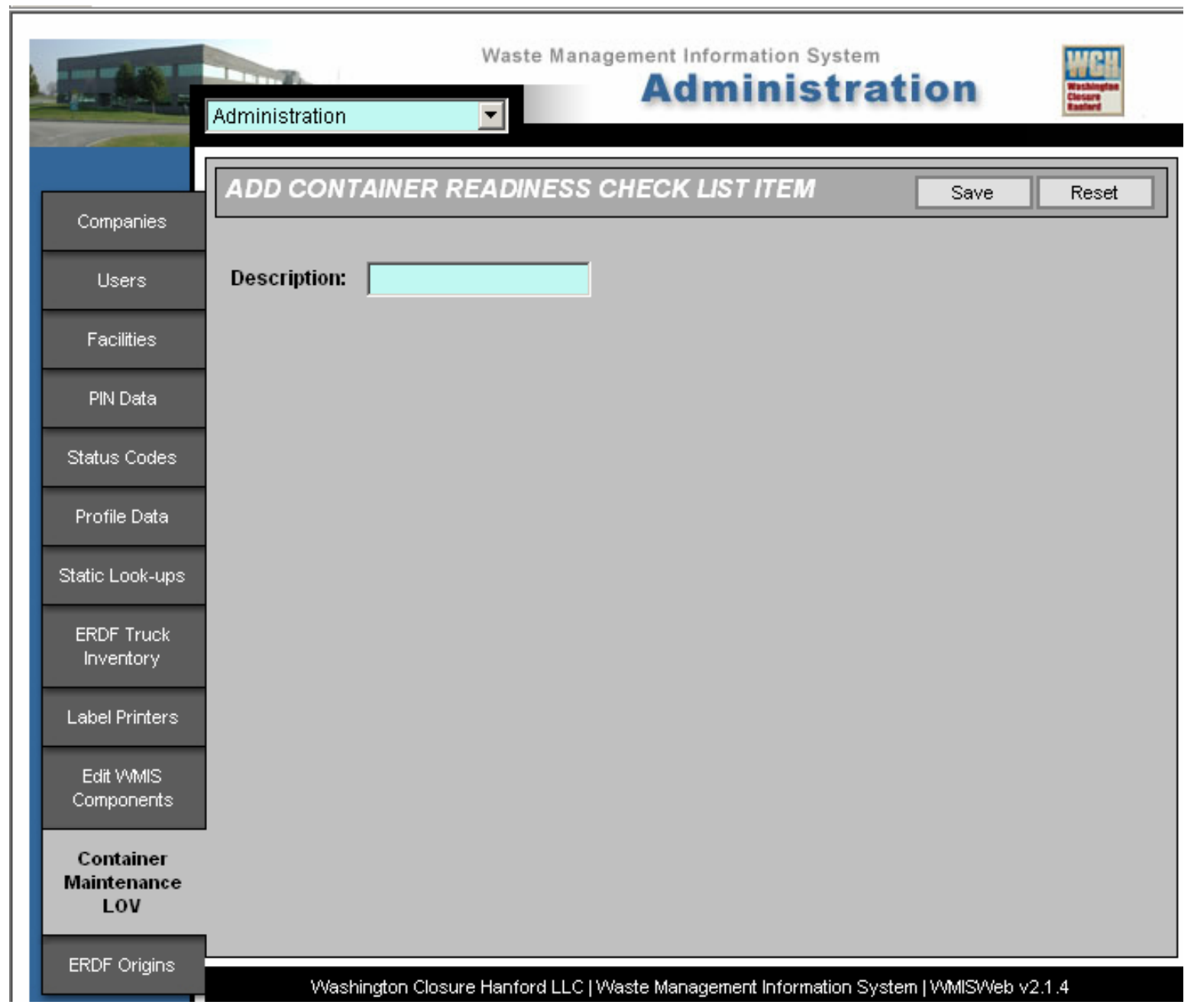

- Enter data to create new container readiness check list item.

- Press "Save."

- Press "Reset" to reset field values to <NULL $>$. 


\section{Edit Container Maintenance Items}

\section{Screen 3-31. Administration - Edit Container Maintenance Items}

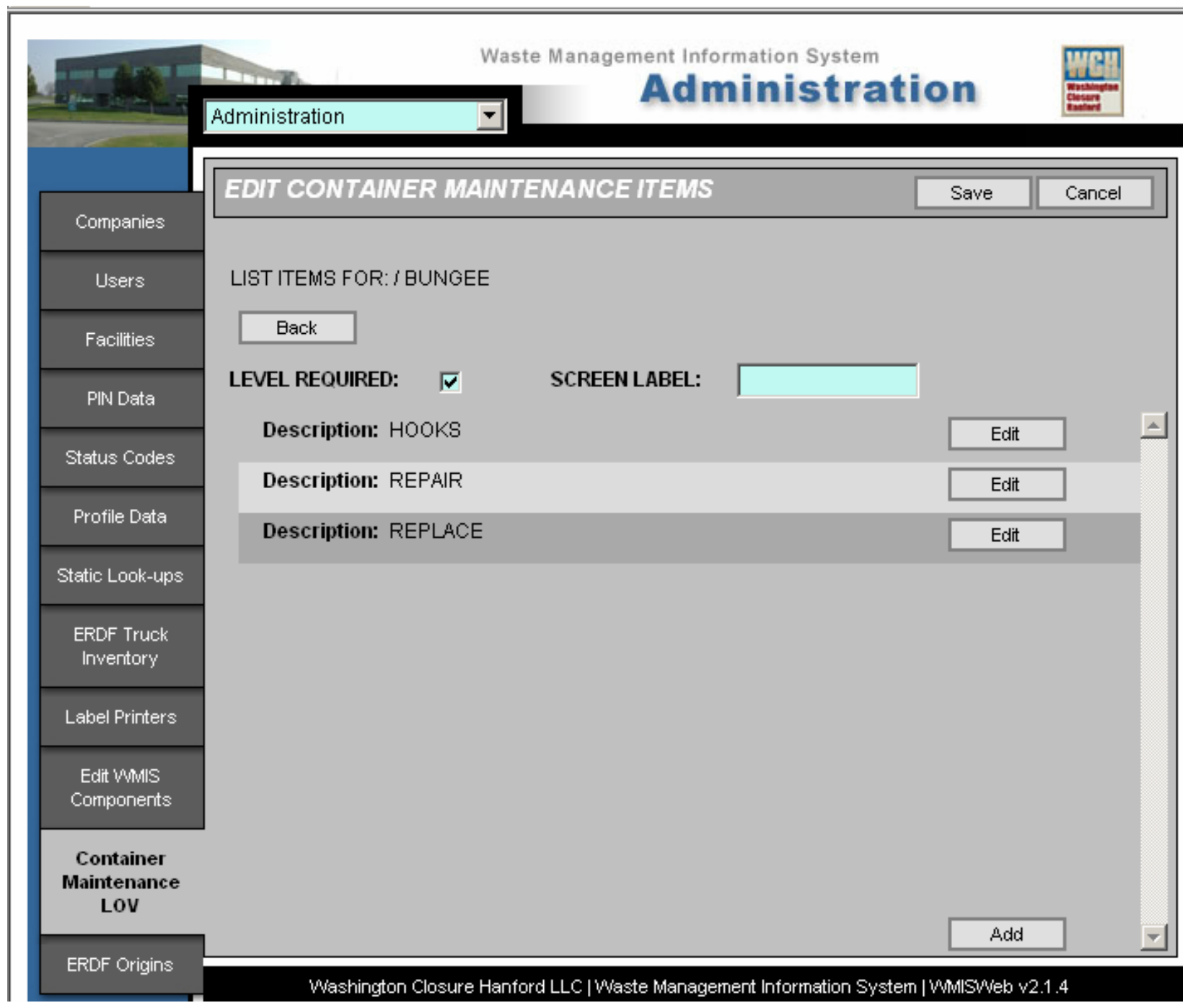

- Edit the container maintenance items information as needed.

- $\quad$ Press "Save." 


\subsection{WMIS220 WMIS ERDF ORIGINS}

Caution: ERDF Origins shall not be added, removed, or revised unless specifically authorized by the WMIS Subject Matter Expert

\section{Screen 3-32. Administration - WMIS ERDF Origins}

\begin{tabular}{|c|c|c|c|c|}
\hline Lif & \multicolumn{2}{|c|}{$\begin{array}{l}\text { Waste Management Information System } \\
\text { Administration }\end{array}$} & एक्र & \\
\hline \multirow{2}{*}{ Companies } & \multicolumn{2}{|l|}{ WMS ERDF ORICINS } & \multicolumn{2}{|l|}{ Add } \\
\hline & Origin: (B RX) HAZARD MITIGATION & Edit & Delete & $\Delta$ \\
\hline \multirow[t]{2}{*}{ Users } & Miles: 0 & & & \\
\hline & Origin: $100-\mathrm{B}-14$ & Edit & Delete & \\
\hline Facillies & Miles: 0 & & & \\
\hline \multirow{2}{*}{ PIN Data } & Origin: $100-\mathrm{B}-17$ & Edit & Delete & \\
\hline & Miles: 0 & & & \\
\hline \multirow[t]{2}{*}{ Status Codes } & Origin: $100-\mathrm{B}-18$ & Edit & Delete & \\
\hline & Miles: 0 & & & \\
\hline \multirow[t]{2}{*}{ Profile Data } & Origin: $100-\mathrm{B}-19$ & Edit & Delete & \\
\hline & Miles: 0 & & & \\
\hline Static Look-ups & Origin: $100-\mathrm{B}-21$ & Edit & Delete & \\
\hline \multirow{3}{*}{$\begin{array}{l}\text { ERDF Truck } \\
\text { Inventory }\end{array}$} & Miles: 0 & & & \\
\hline & Origin: $100-\mathrm{B}-22$ & Edit & Delete & \\
\hline & Miles: 0 & & & \\
\hline \multirow[t]{2}{*}{ Label Printers } & Origin: $100-\mathrm{B}-23$ & Edit & Delete & \\
\hline & Miles: 0 & & & \\
\hline \multirow{2}{*}{$\begin{array}{l}\text { Edit WMIS } \\
\text { Components }\end{array}$} & Origin: $100-\mathrm{B}-27$ & Edit & Delete & \\
\hline & Miles: 0 & & & \\
\hline \multirow{2}{*}{$\begin{array}{c}\text { Container } \\
\text { Maintenance LOV }\end{array}$} & Origin: $100-C-7$ & Edit & Delete & \\
\hline & Miles: 12.6 & & & $\nabla$ \\
\hline ERDF Origins & & & & \\
\hline
\end{tabular}

- $\quad$ Select "Add" to add new origins, see Screen 3-33.

- $\quad$ Select "Edit" to edit existing origins, see Screen 3-34. 


\section{Add WMIS ERDF Origin}

\section{Screen 3-33. Administration - Add WMIS ERDF Origin}

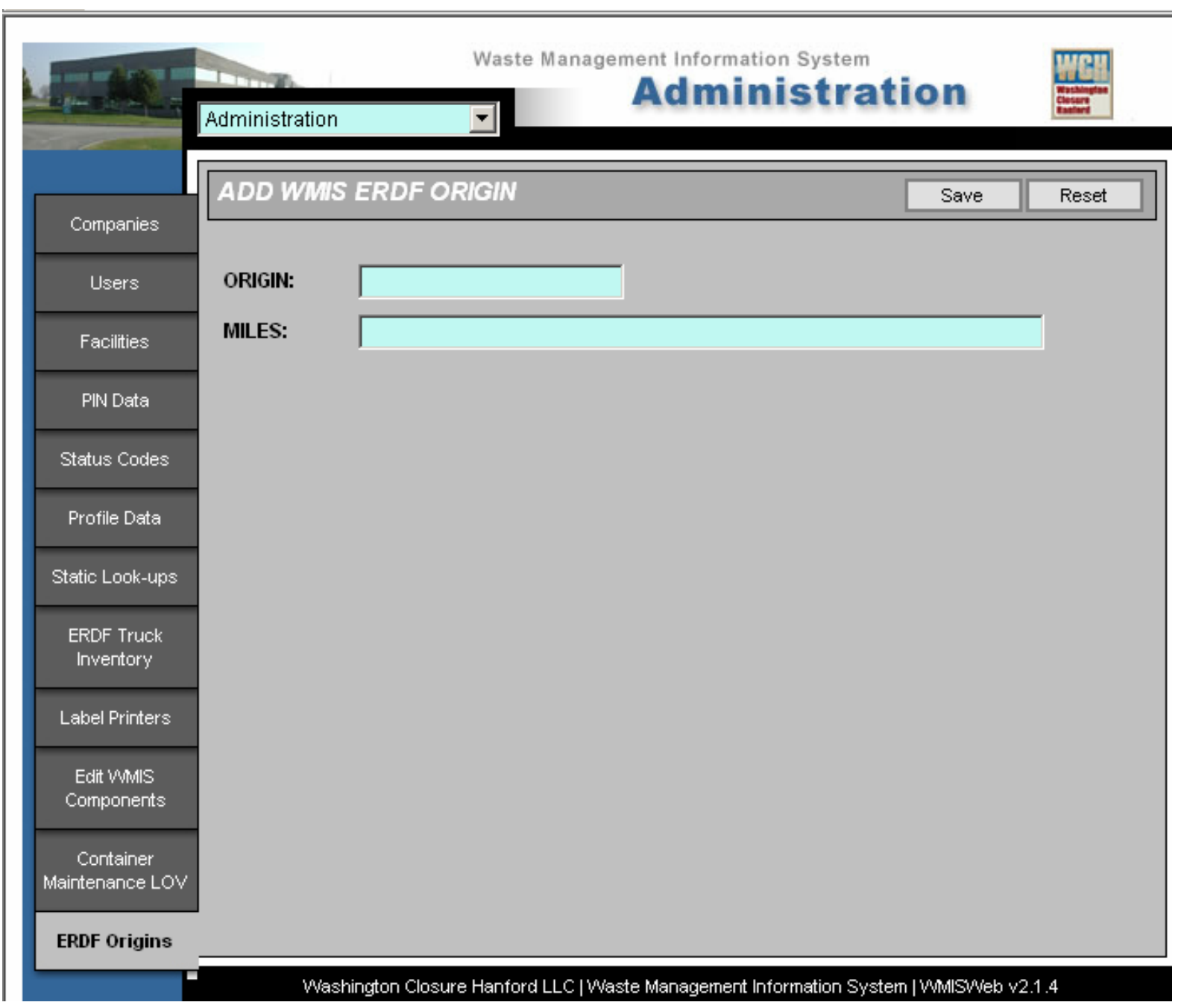

- Enter data to create a new origin.

- Press "Save." 


\section{Edit WMIS ERDF Origin}

\section{Screen 3-34. Administration - Edit WMIS ERDF Origin}

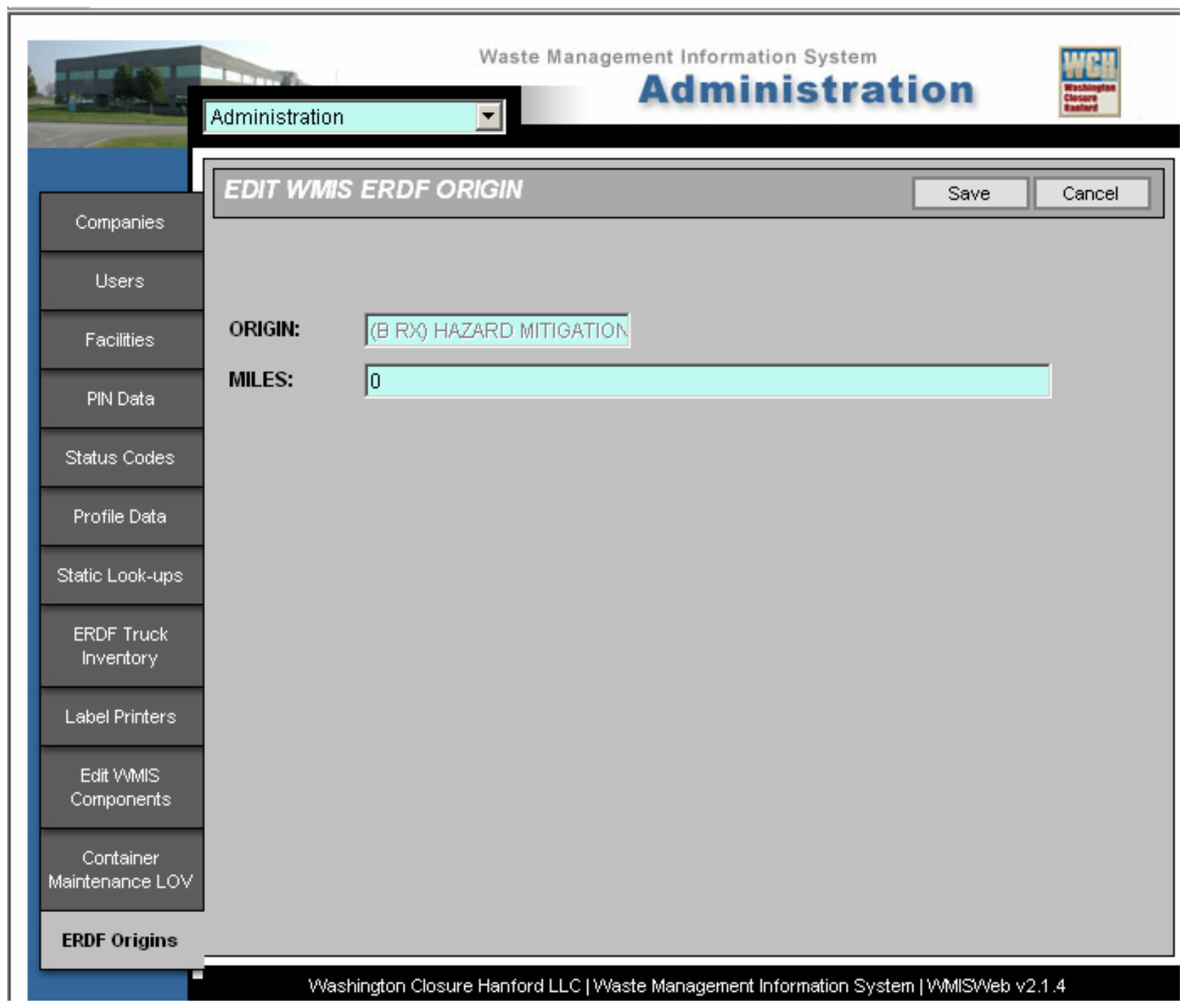

- Edit the origin information as needed.

- $\quad$ Press "Save." 


\subsection{WMIS400 - DESIGNATION MODULE}

The Designation Module contains the capability to create new designations, various search engines, constituent and isotope lookup tables, TSCA data screens, and dangerous waste and LDR screens. Users with WMIS security role permissions to this module have access to a wide variety of functions within this module.

\subsection{WMIS400 DESIGNATION SEARCH}

\section{Screen 4-1. Designation - Search}

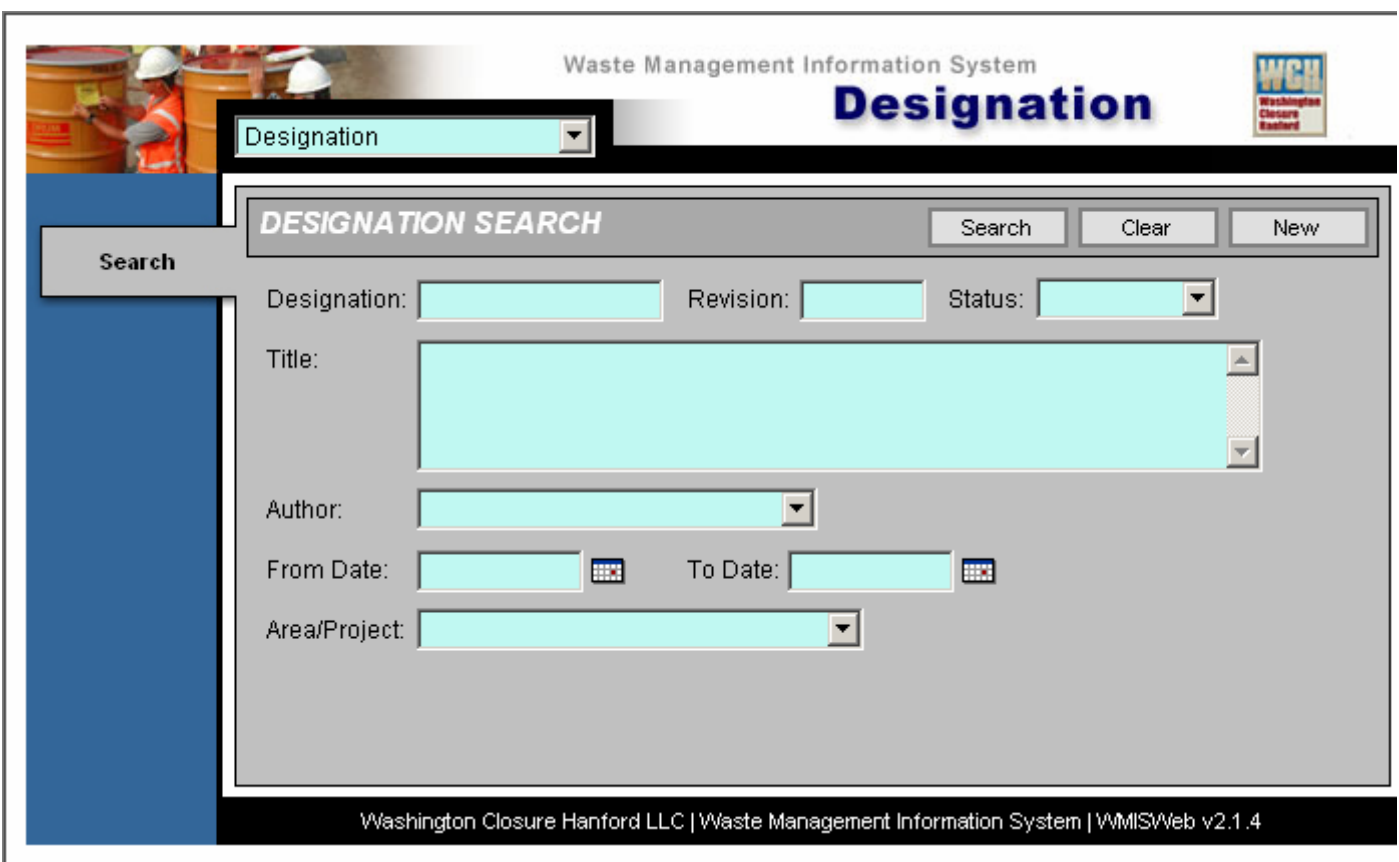

Designation: Waste profile (WP prefix), waste designation (WD prefix), or global designation (GD prefix) unique number. Waste profiles use a project/location-identifiable description for numbering with ending numbers for different waste streams at same project/location. Waste and global designations use the CCN as assigned by RDC.

Revision: Current revision.

Status: Draft, Approved, Revised

Title: Description of source location and waste stream.

Author: WDS

From Date/To Date: Allows search of designations within time frame. 


\begin{tabular}{|l|l|l|}
\hline Button & Screen Shot & Description \\
\hline Search & Screen 4-2 & Search existing designations \\
\hline Clear & Screen 4-1 & Clear search parameters \\
\hline New & Screen 4-3 & Create new designation \\
\hline
\end{tabular}

\section{Designation Search}

The Designation Search menu allows the user to query WMIS for designations to view or update. The results of the search appear in a list and the user can select a record for detailed viewing.

\section{Screen 4-2. Sample Search Results}

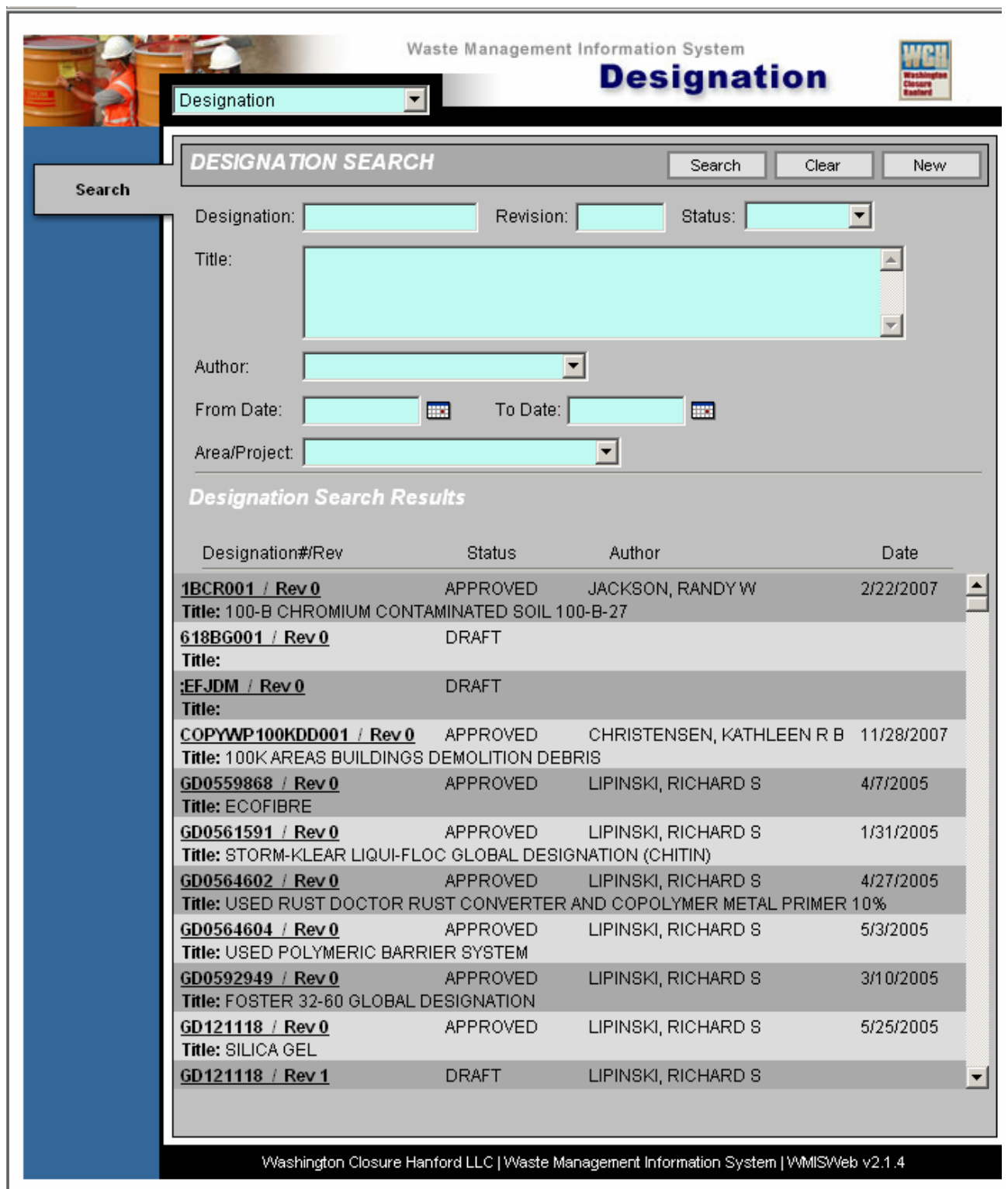




\section{Defining Search Parameters}

- Enter any combination of the following fields to build the search query (more fields narrow the search, fewer fields broaden the search).

- Designation number (truncate this field to maximize search)

- Revision number

- Title

- Status

- Author.

- Date fields are also available as search parameters. A pop-up calendar or manual entry of the date(s) is available.

- From date

- To date.

- $\quad$ Press the "Search" button at the top of the screen when search parameters are complete. Designations meeting the query criteria appear below the search parameters.

\section{Designation, Not Shown}

Press Clear to reset to $<$ NULL $>$.

Refine search parameters.

\section{Designation, Shown}

Press designation link to view. 


\section{Create New Designation}

The Create New Designation menu allows the user (WDS role authorization) to create a new designation in WMIS.

- Press "New" button in the top right of the screen (see Screen 4-1). The Create New Designation screen appears.

Screen 4-3. Designation - Create New

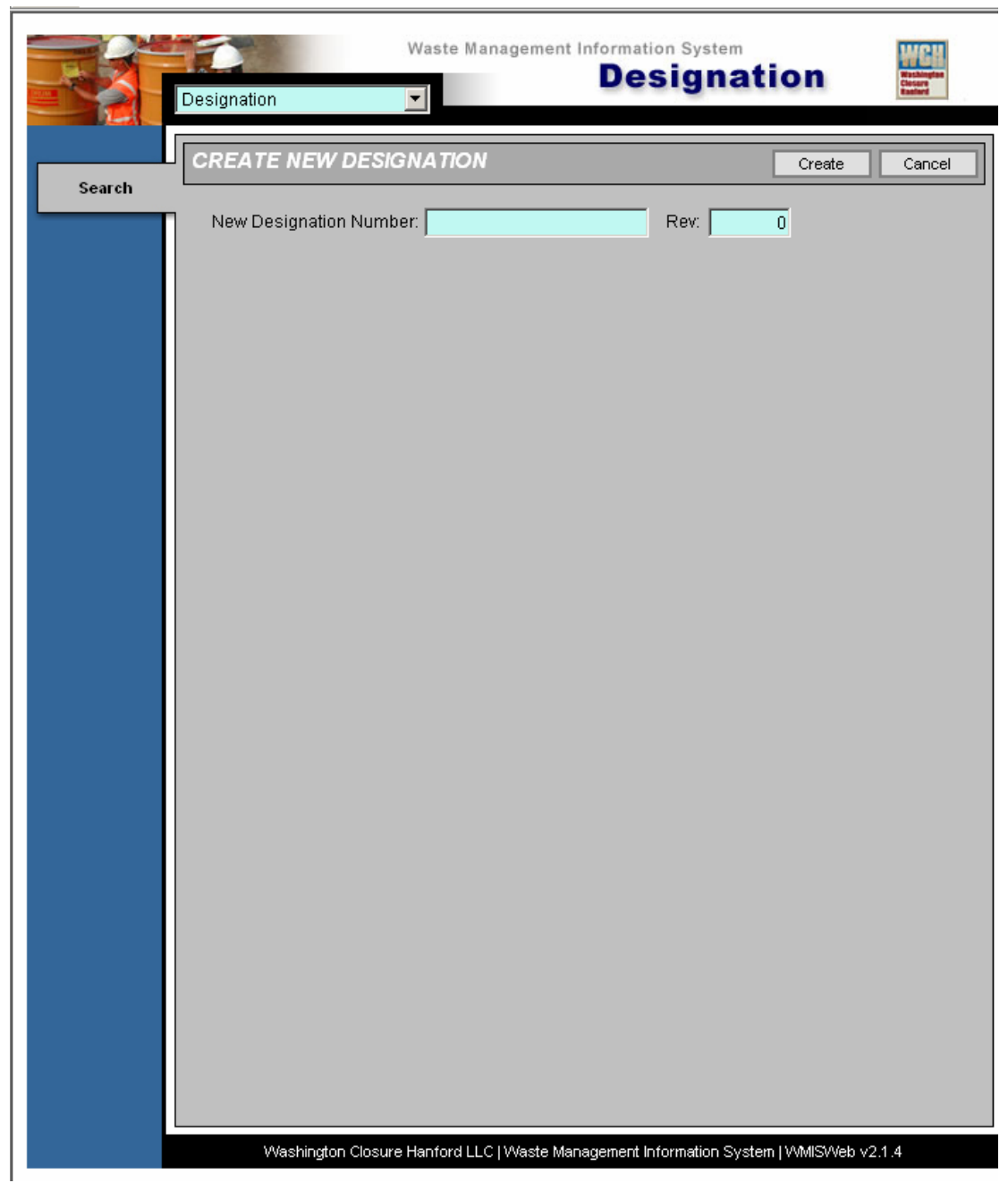

- Enter the new designation number and revision number (enter revision as 0 if new designation.). Use appropriate prefix for designation type; WP for waste profiles, WD for waste designations, and GD for global designations.

- Press "Create" - WMIS creates a new designation and opens the Designation Basics Screen (see Screen 4-4). Follow the steps in the following Section 4.1 for entering basic information. 


\subsection{WMIS410 DESIGNATION BASICS}

The Designation Basics screen allows the user to view and input the basic fields that define the general characteristics of the designation. Alternatively, a WMIS Import Tool is in place to retrieve this data to create a new or revise an existing designation in WMIS.

\section{Screen 4-4. Designation - Basics}

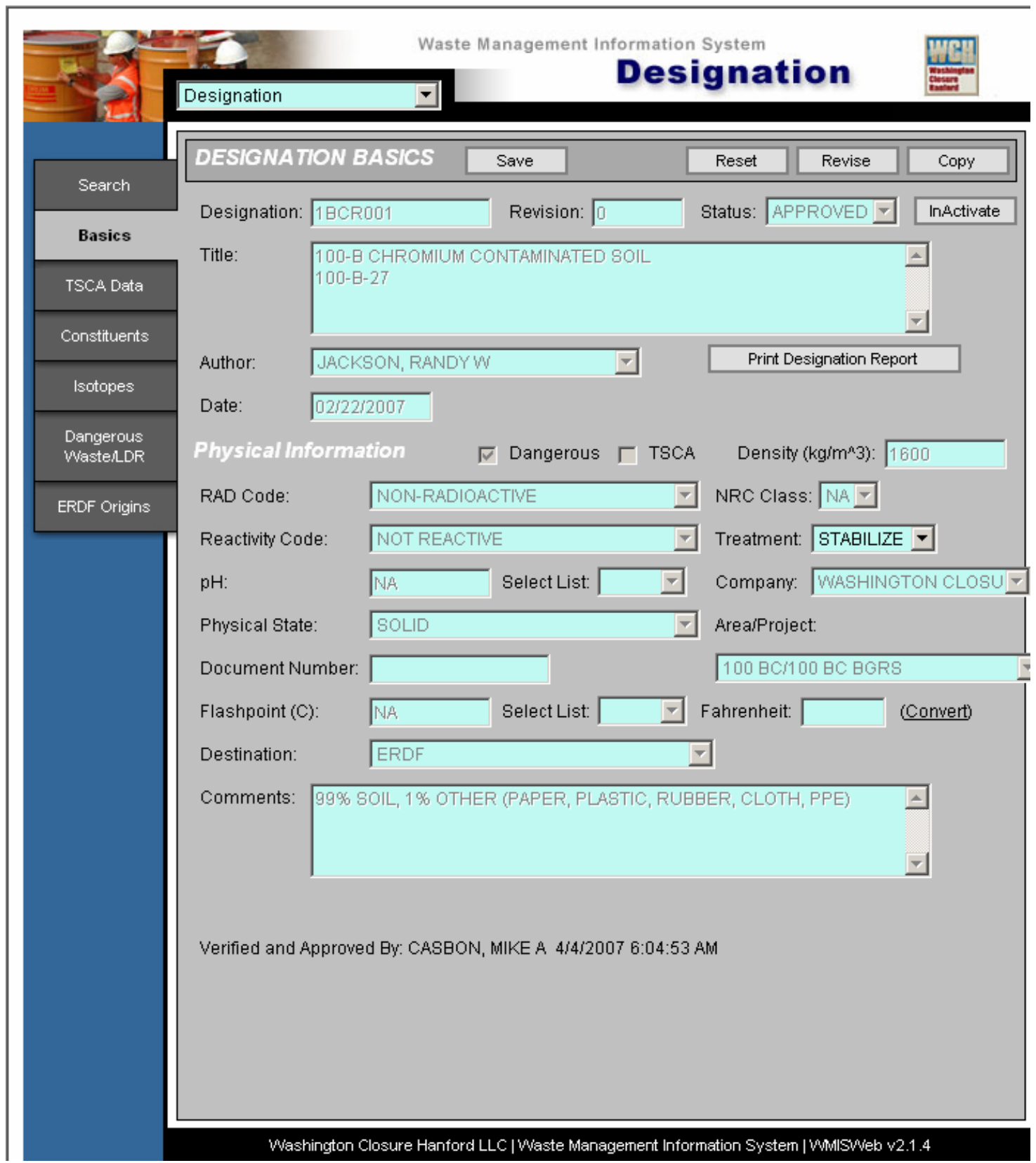


Table 4-1. Basic Designation Screen Fields.

\begin{tabular}{|l|c|l|c|}
\hline \multicolumn{1}{|c|}{ Field } & Entry & \multicolumn{1}{|c|}{ Description } & Req \\
\hline Designation & DEFAULT & Designation Number & $\mathrm{Y}$ \\
\hline Revision & DEFAULT & Revision Number & $\mathrm{Y}$ \\
\hline Status & DEFAULT & $\begin{array}{l}\text { Auto fill } \\
\text { "R" = Revised. "A" = Approved. } \\
\text { "D" = Draft. On Insert, "D" }\end{array}$ & $\mathrm{Y}$ \\
\hline Title & USER & Designation Title & $\mathrm{Y}$ \\
\hline Author & USER & Pick List from User table. & $\mathrm{Y}$ \\
\hline Date & USER & Date of Designation & $\mathrm{Y}$ \\
\hline Dangerous & USER & "Y," "N" Checkbox. & $\mathrm{Y}$ \\
\hline TSCA & USER & "Y," "N" Checkbox. & $\mathrm{Y}$ \\
\hline RAD Code & USER & "LLW," "TRU," "USG," "NON" & $\mathrm{Y}$ \\
\hline NRC Class & USER & A, B, C, >C, N/A & $\mathrm{Y}$ \\
\hline Reactivity Code & USER & Pick List & $\mathrm{Y}$ \\
\hline pH & USER & User entry & $\mathrm{Y}$ \\
\hline Physical State & USER & "G," "GL," "GLS," "GS," "L," "LS," "M," "S" & $\mathrm{Y}$ \\
\hline Document Number & USER & DocsOpen Number & $\mathrm{Y}$ \\
\hline Flash Point (Celsius) & USER & $\begin{array}{l}\text { If Celsius is entered, calculate and display } \\
\text { Fahrenheit = (Celsius * 1.8) + 32. }\end{array}$ & $\mathrm{Y}$ \\
\hline Flash Point (Fahrenheit) & USER & $\begin{array}{l}\text { If Fahrenheit is entered, calculate and } \\
\text { display Celsius = (Fahrenheit - 32) / 1.8. }\end{array}$ & $\mathrm{Y}$ \\
\hline Destination & USER & Pick List, Disposal Destination & $\mathrm{Y}$ \\
\hline Comments & USER & User entry & Optional \\
\hline None & UEFAULT & System Date & $\begin{array}{l}\text { Auto fill, inputs name of person logged on } \\
\text { to computer. }\end{array}$ \\
\hline Verified By & DEFAULT & $\begin{array}{l}\text { System Date/Auto fill. Sets Designation } \\
\text { Status to approved (A). If there is a } \\
\text { previous revision for this Designation, sets } \\
\text { that record's status to revised (R). }\end{array}$ & \\
\hline Verified Date & & & \\
\hline & & & \\
\hline
\end{tabular}




\section{Input Basic Designation Information}

The WDS creates a new or modifies an existing Waste Designation spreadsheet to characterize waste. Transfer of data into WMIS occurs either by the WMIS Import Tool or manually from the hardcopy. Please refer to Table 4-1 for detailed field requirements.

\section{Check Data}

- Press the "Check Data" button to verify that all required fields are complete.

\section{$\underline{\text { Reset Designation Criteria }}$}

- $\quad$ Press the "Reset" button to clear all fields.

\section{Create Revision to Existing Designation}

- Press the "Revise" button to create a new revision of an approved designation.

- $\quad$ Status of the new revision is automatically set to "D" (Draft).

- User must enter new Revision Number.

- Once the revision is approved, the status changes automatically to "A" (Approved), and the previous revision is denoted as "R" (Revised).

\section{Copy Existing Designation to a New Designation}

At times designations will have similar characteristics or are from adjacent areas. In these cases, to avoid duplication of effort the user may choose to copy the designation and manually modify the individual fields as necessary.

- Press the "Copy" button to copy the existing designation/revision records.

- $\quad$ Status of the new designation is automatically set to "D" (Draft).

- User must enter the new Designation Number and Revision Number.

- User revises fields as necessary.

\section{Print Designation Report}

- Press the "Print Designation Report" button to create the designation report.

\section{Verify and Change Status to Approved.}

Upon acceptance of waste profiles, Project Engineer to press the "Verify and Change Status to Approved" button. Within three business days of receipt of approved waste and global designations, the WITS will press the "Verify and Change Status to Approved" button. Once the "Verify and Change Status to Approved" button is pressed, designation record status will 
change to "A" (Approved). The system fills in the name, date, and time for the person who is logged in.

\subsection{WMIS420 TSCA DATA}

\section{Screen 4-5. Designation - TSCA Data}

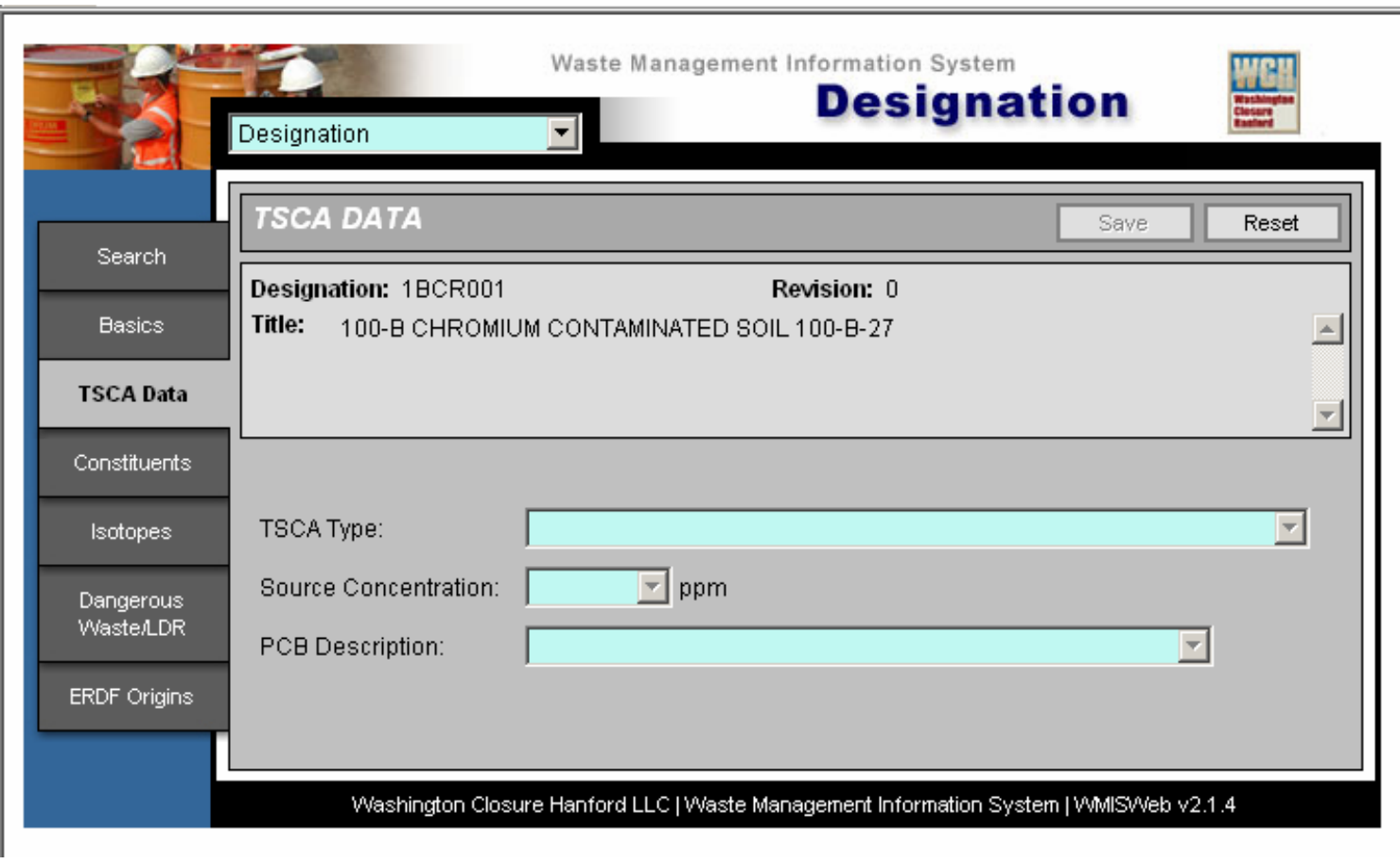

\section{Enter TSCA Data}

- Drop-down lists are available for the following data items:

- TSCA Type

- Source Concentration

- PCB Description.

\section{Reset TSCA Data}

- Press the "Reset" button to clear all fields. 


\subsection{WMIS430 DESIGNATION CONSTITUENTS}

The Designation Constituents Screen allows the user to input the individual chemical constituents that make up the waste for the designation. Alternatively, a WMIS Import Tool is in place to retrieve this data to create a new or revise an existing designation in WMIS.

Screen 4-6. Designation - Constituents

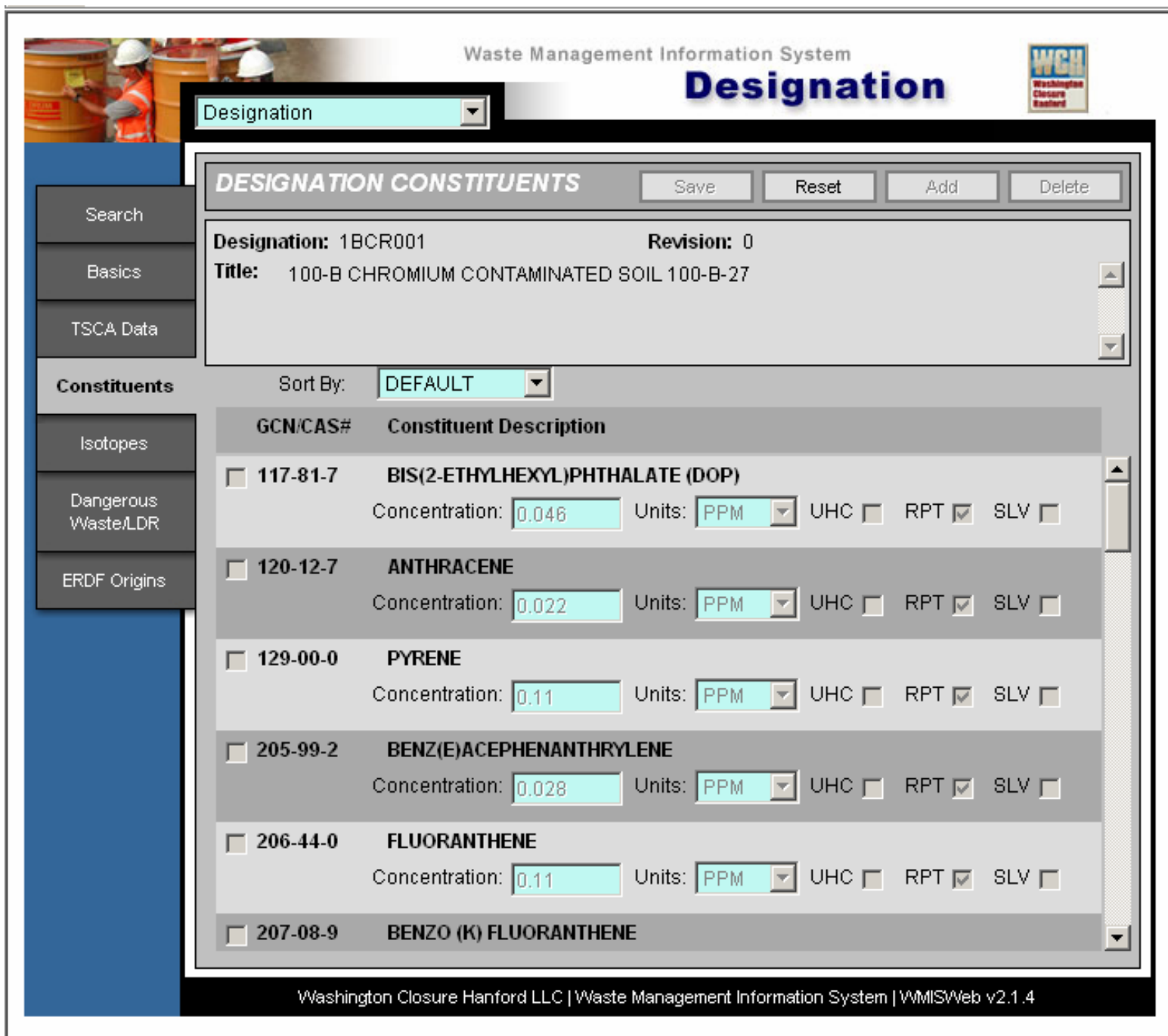

\section{Manually Add Chemical Constituents}

- $\quad$ Press the "Add" button in the top right corner of the screen.

- The Constituent Search screen appears. 


\section{Screen 4-7. Designation - Add Designation Constituents Search}

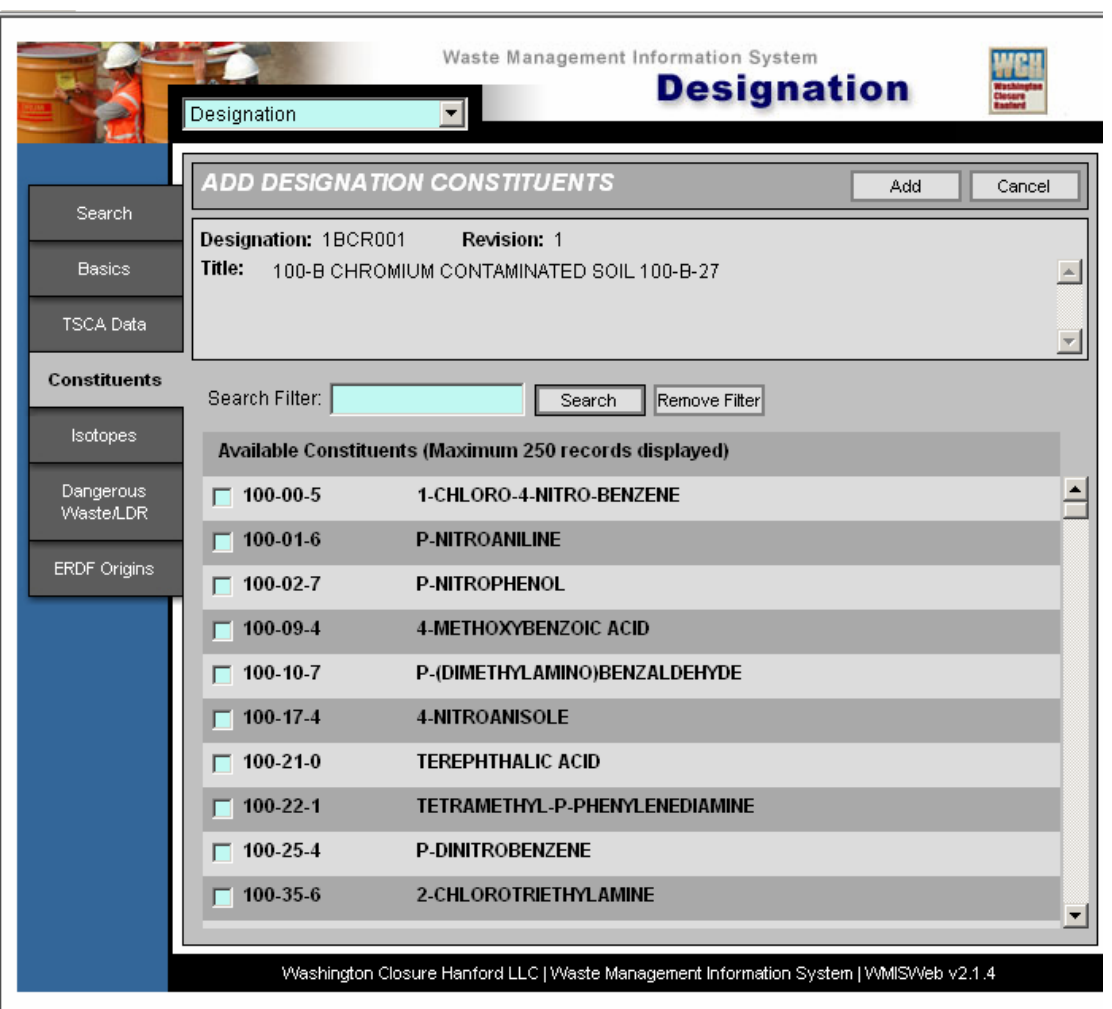

Enter a few characters of the constituent's name or the CAS number in the Search Filter.

- Press "Search" button.

- User must check the box next to the constituent to select (multiple constituents can be added concurrently).

- $\quad$ Once constituents are selected, press the "Add" button.

- User is returned to Screen 4-6. Designation - Constituents.

- $\quad$ After adding the constituents, press the "Save" button top right hand corner of Screen 4-6.

$\underline{\mathrm{OR}}$

- $\quad$ To end the search without adding constituents and return to Screen 4-6.

- Press "Cancel" button.

\section{Delete a Chemical Constituent}

- Press in the check boxes that appear to the left of each designation constituent to delete. Press on the "Delete" button, then the "Save" button. 


\section{$\underline{\text { Reset Constituent Data }}$}

- $\quad$ Press the "Reset" button to clear all fields.

\subsection{WMIS440 DESIGNATION ISOTOPES}

The Designation Isotopes Screen allows the user to input the individual isotopes and activity concentrations that make up the designation.

Screen 4-8. Designation - Isotopes

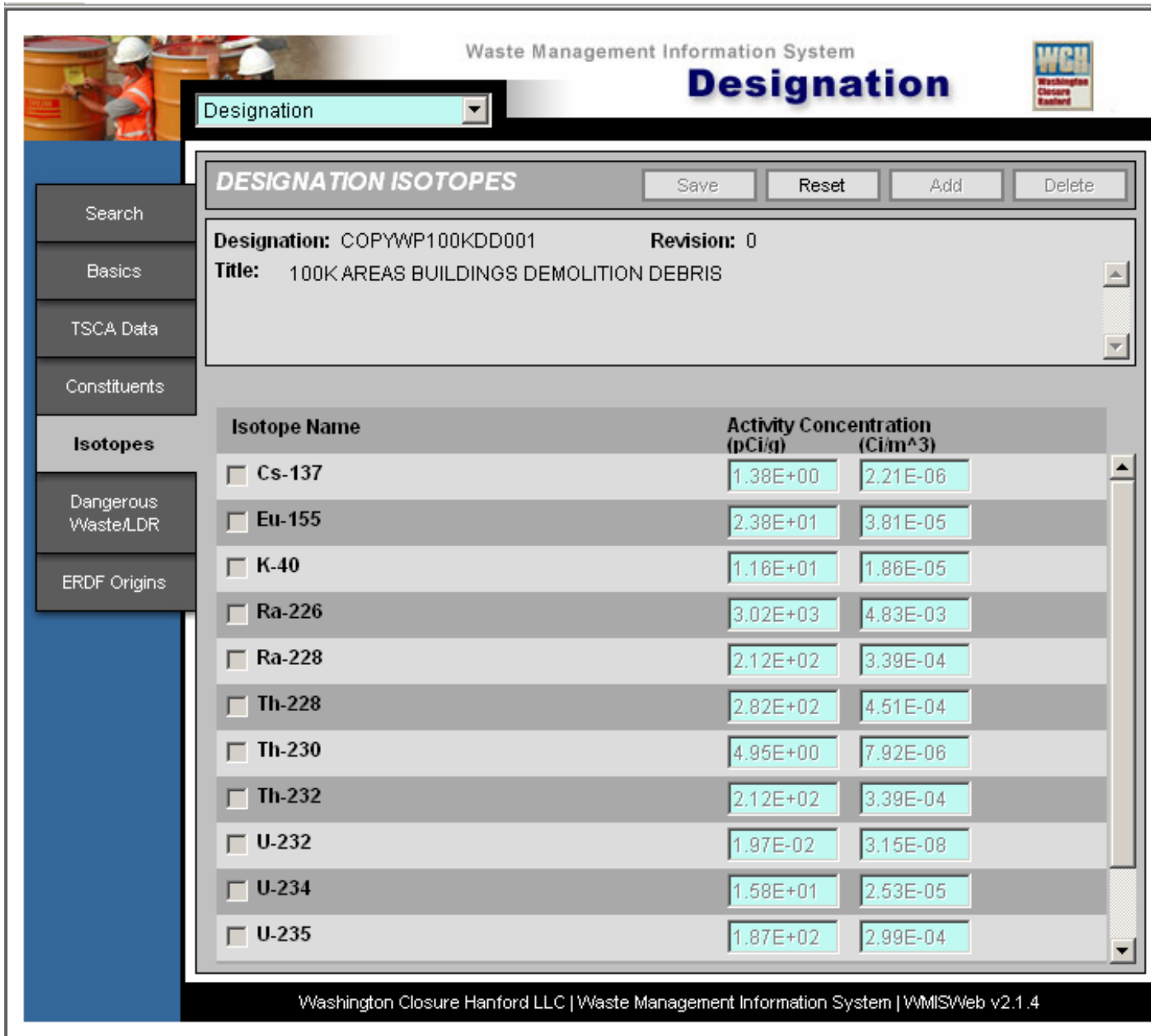

\section{Add an Isotope}

- Press the "Add" button in the top right corner of the screen.

The Isotope Search screen appears. 


\section{Screen 4-9. Designation - Add Designation Isotopes Search}

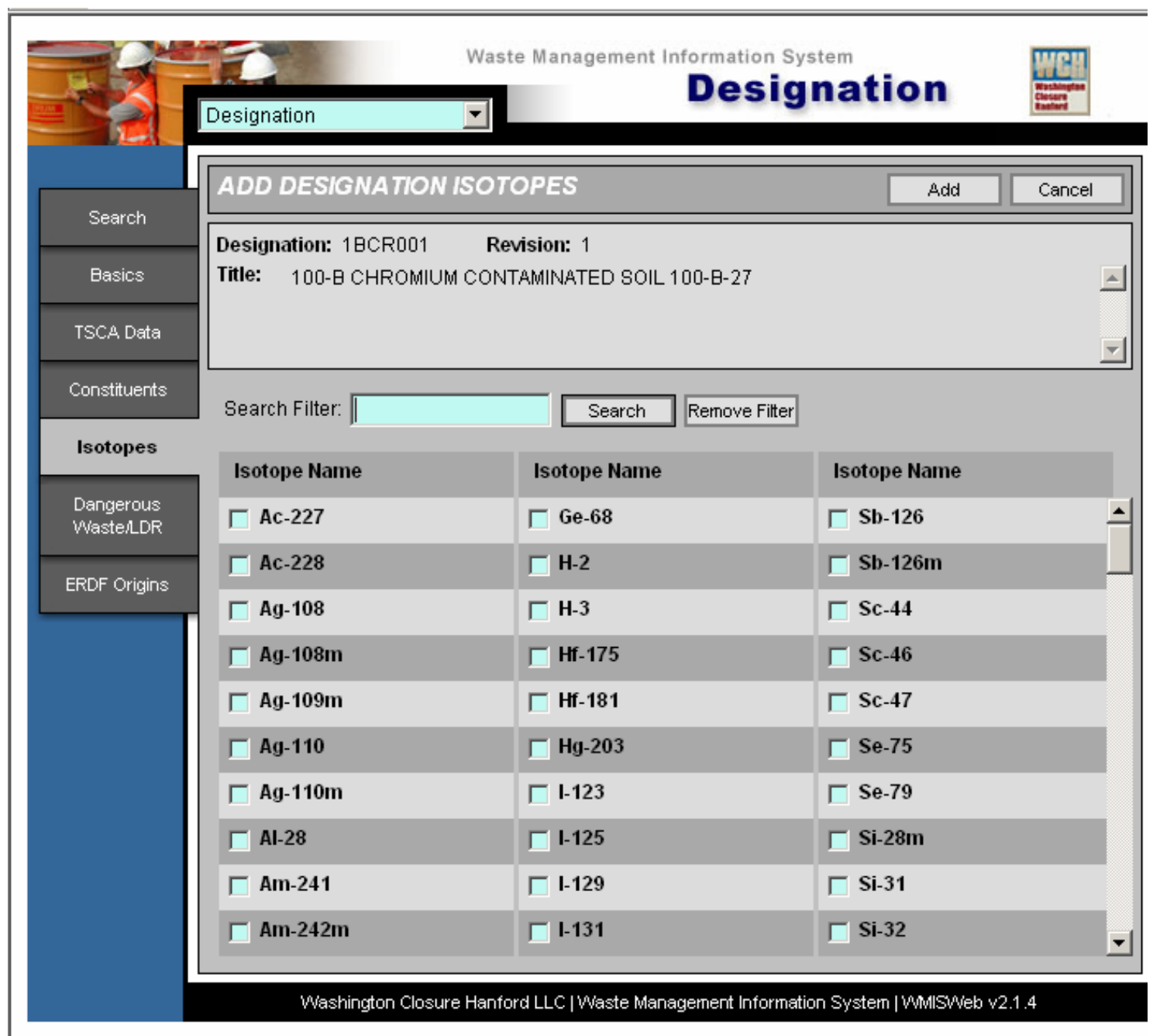

- Enter a few characters of the isotope's name in the Search Filter.

- Press the search button.

- Alternatively, user can scroll through the list and select the isotope by checking the box.

- The capability to add multiple isotopes concurrently is available.

- Once isotopes are selected, press the "Add" button.

- Press "Clear" to clear Search Filter.

- Press the "Cancel" button to end the search without adding isotopes and return to the Isotopes screen. 


\section{Delete an Isotope}

- Press in the check boxes that appear to the left of each isotope to delete. Press on the "Delete" button, then the "Save" button.

\section{Reset Isotope Data}

- Press the "Reset" button to clear all fields. 


\subsection{WMIS450 DANGEROUS WASTE AND LAND DISPOSAL RESTRICTION (LDR) DATA}

Enter all applicable dangerous waste codes and any applicable LDR information into WMIS in this screen.

\section{Screen 4-100. Designation - Dangerous Waste \& LDR}

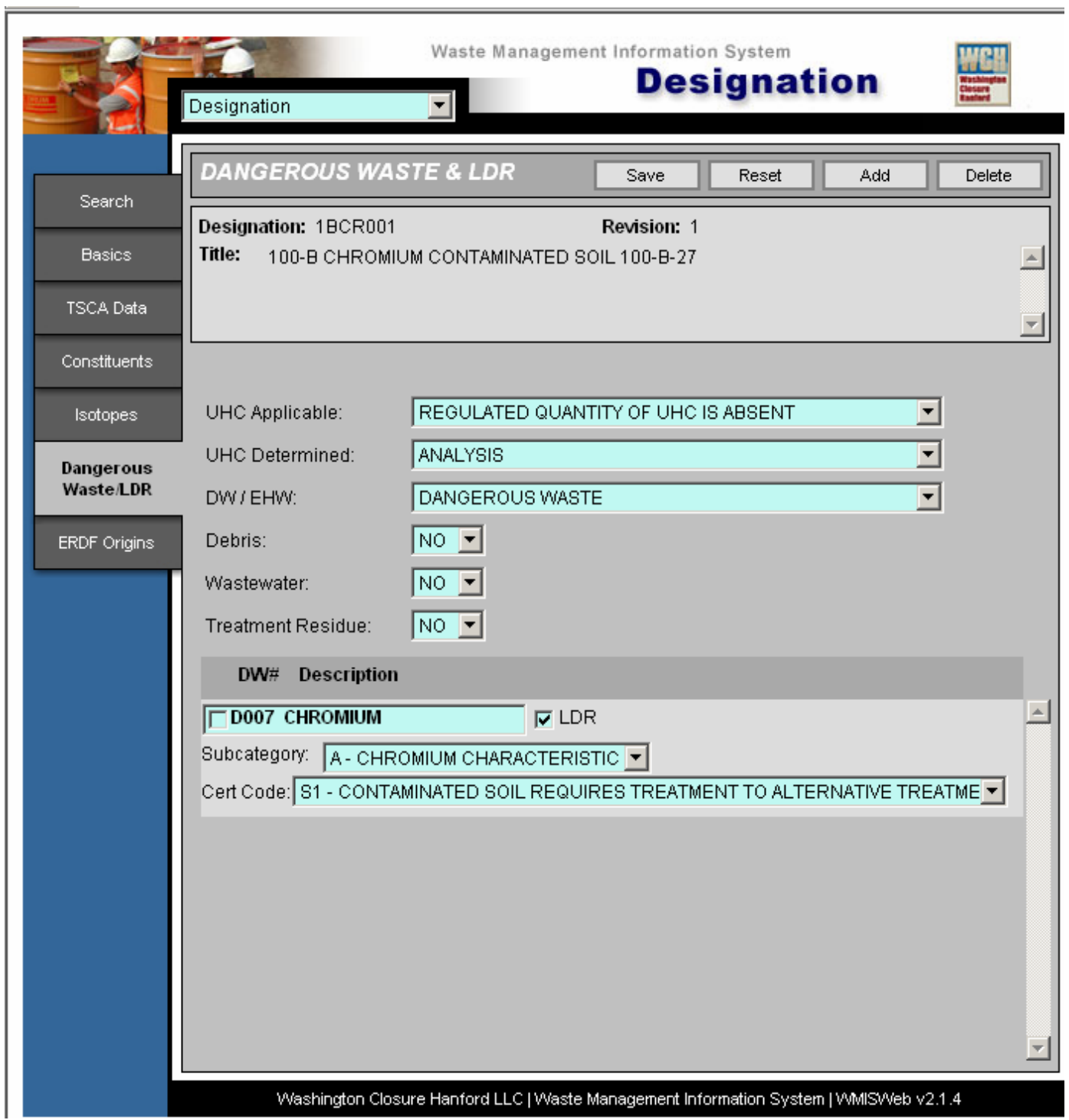

\section{Add a DW Number}

- Enter a few characters of the DW number in the Search Filter.

- $\quad$ Press the search button.

- Add multiple DW numbers concurrently in this screen. 
- $\quad$ Once DW numbers are selected, press the "Add" button.

- Press Save after DW's are added.

- $\quad$ Press "Clear" to clear Search Filter.

\section{Delete DW Number}

- $\quad$ Press the "Delete" button, to delete information.

\section{Reset DW Number Data}

- Press the "Reset" button to clear all fields.

\section{Save DW Number Data}

- $\quad$ Press the "Save" button to save DW Number data.

Screen 4-11. Designation - ERDF Origins

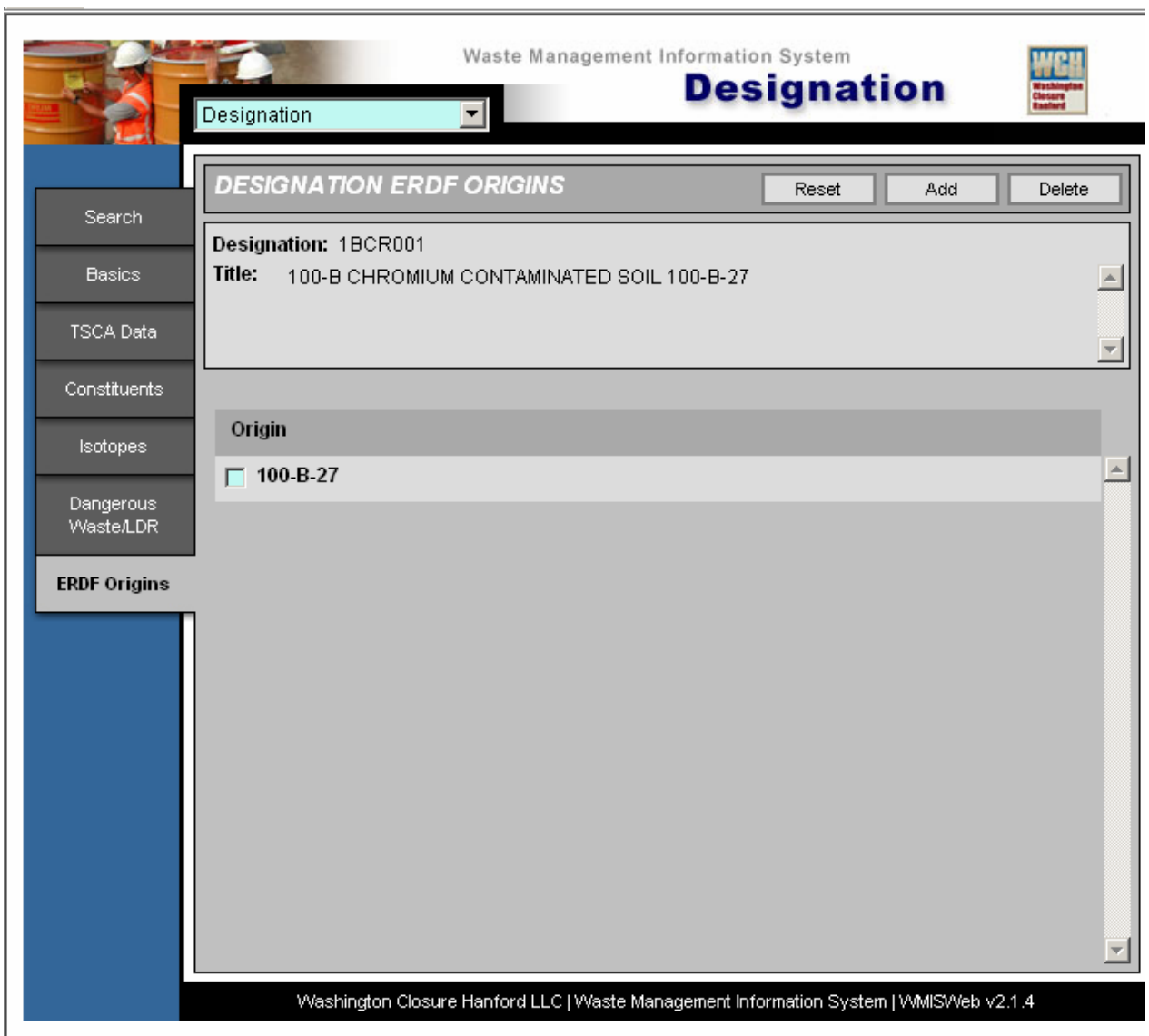




\subsection{WMIS500 - STORAGE MODULE}

\subsection{WMIS500 STORAGE CONTAINER SEARCH}

The Storage Module Search screen allows the user to enter a known CIN or PIN number to query the database for that record's information for viewing or update.

\section{Screen 5-1. Storage - Container Search}

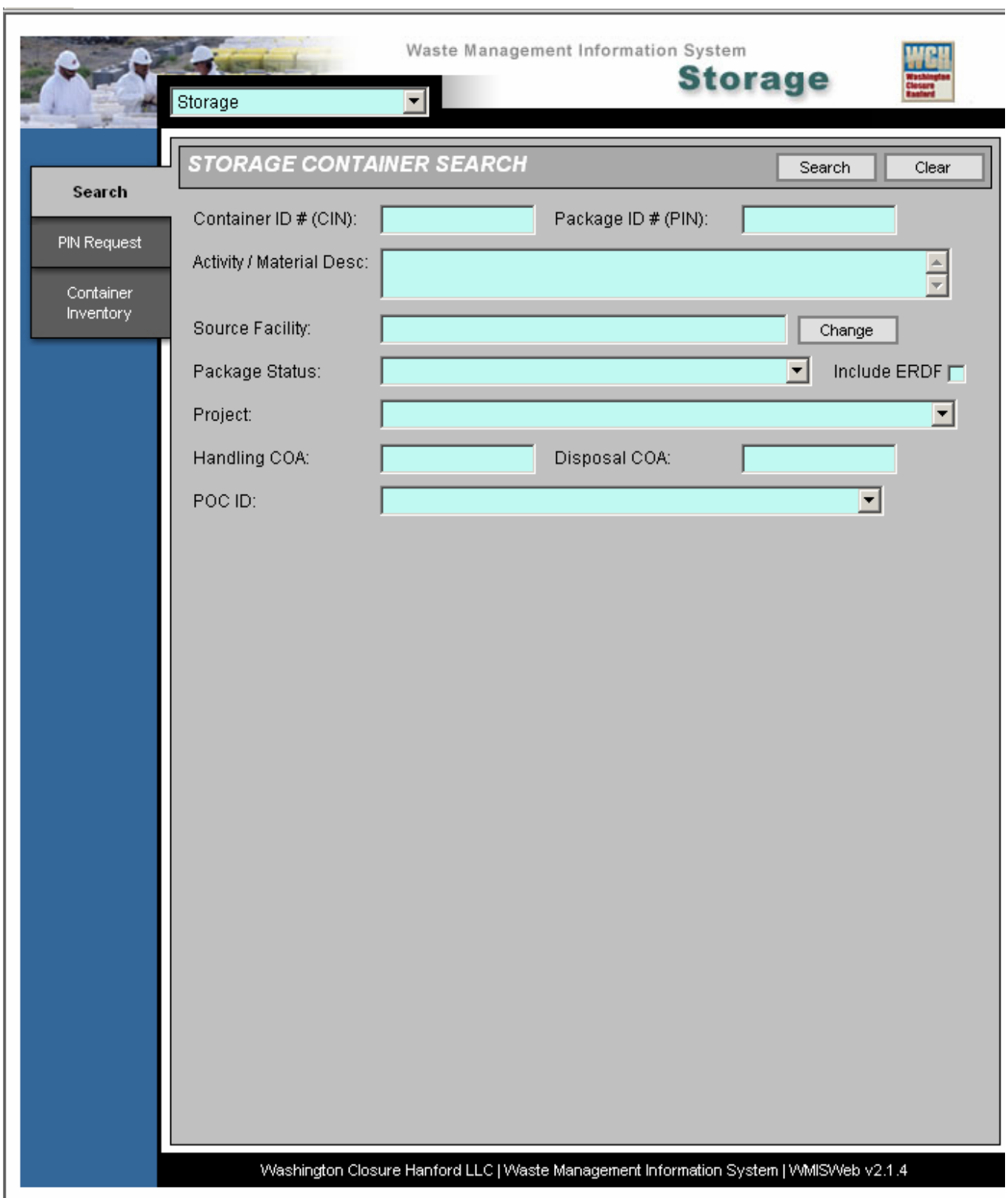




\section{Storage Container Search}

- Enter any combination of the following fields to build the search query.

NOTE: More fields narrow the search and fewer fields broaden the search.

$\begin{array}{ll}\text { Container ID \# (CIN) } & \text { Package ID \# (PIN) } \\ \text { Activity/Material Desc } & \text { Source Facility } \\ \text { Container Status } & \text { Include ERDF(cans/shipments) } \\ \text { Project } & \text { Handling COA } \\ \text { Disposal COA } & \text { POC ID }\end{array}$

- Select the "Search" button at the top of the screen, when the search parameters are complete. Containers meeting the query criteria appear below the search parameters (under "Storage Container Search Results" heading).

\section{Container, Not Shown}

Select the Clear to reset to $<$ NULL $>$.

\section{Container, Shown}

Double-click on PIN \# link to view container information.

Refine search parameters. 


\section{Screen 5-2. Example of Search Results}

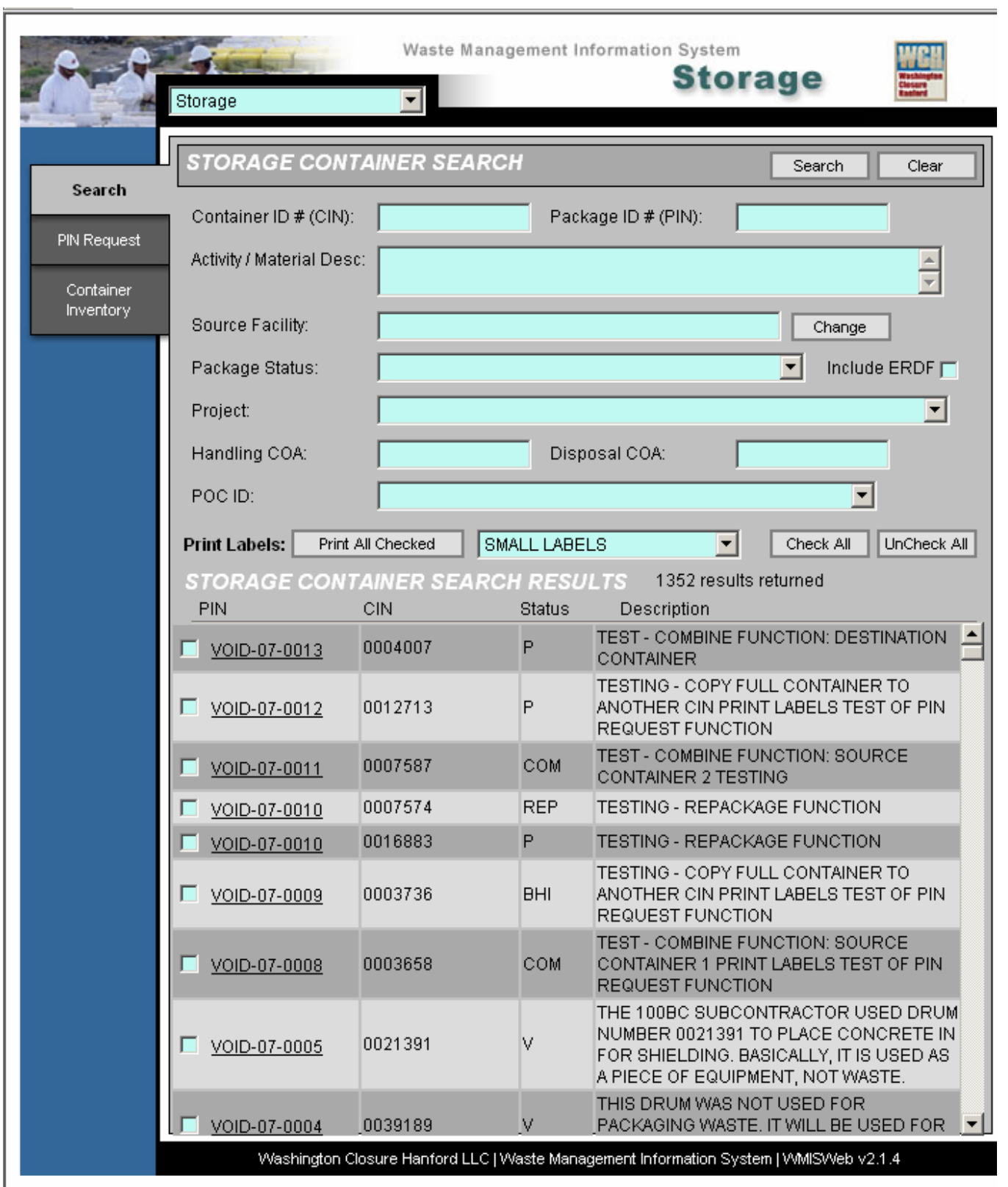

- When the user selects a link to a container, the main Container screen for the selected container appears, showing all the basic information for that container.

\section{Clear Function}

Strike the "Clear" button to clear all fields. 


\subsection{WMIS505 COPYIREPACKICOMBINE}

This screen is accessible upon retrieval of an available container. The term "Available" container means a container that has previously been identified with a CIN. This function copies, repacks, or combines an existing container into an "Available" container from inventory.

\section{Container Copy-Repack-Combine}

\section{Screen 5-3. Storage - Container Copy Repack Combine}

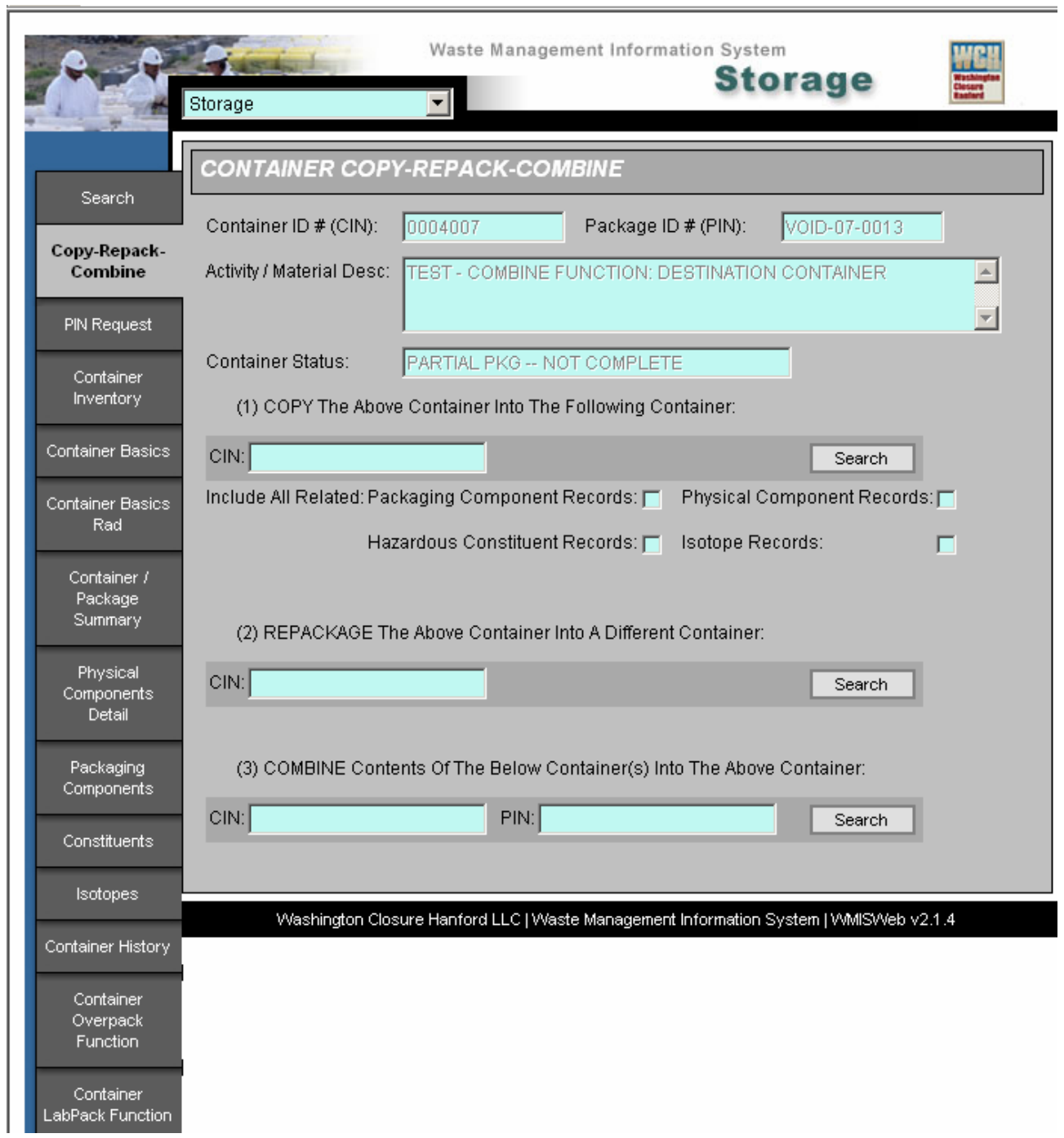

\section{Copy into the Following Container.}




\section{Screen 5-4. Example of Search Results}

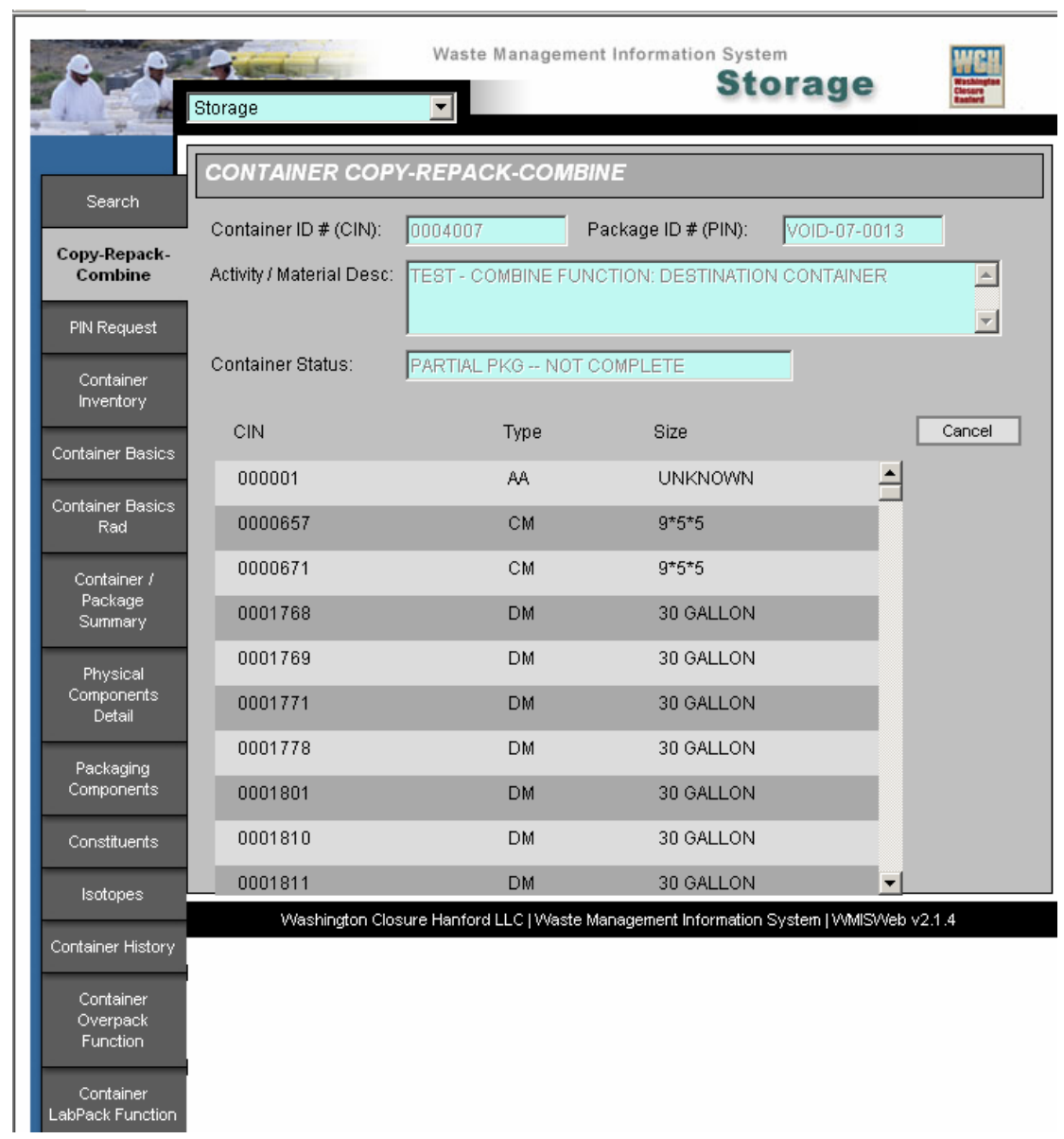

- Selection of this option creates a copy of the container shown at the top of the Screen into another available container, or otherwise known as the "Destination" container.

\section{Input}

CIN: Select the "Search" button to designate the "Destination" container. A list of available containers displays.

- When the user selects the "Copy" button, The Copy-Repack-Combine procedure is executed, and performs all of the following updates.

All further updates to the Destination Container need to occur in the Container Basics screen.

- The container information is already present on the "Container Basics" screen for the container being copied. This option of the copy function inserts the same information as the container being copied (except POD ID).

- Search for the CIN number of the container to copy into (needs to be an existing "Available" container). 
- Select the check box beside "Packaging Component Records" to copy the same packaging items that are in the container being copied to the new container.

- Select the check box beside "Physical Component Records" to copy the same physical component items that are in the container being copied in the new container.

- Select the check box beside "Hazardous Constituent Records" to copy the same chemical constituent items that are in the container being copied in the new container.

- Select the check box beside "Isotope Records" to copy the same isotopes that are in the container being copied in the new container.

- The Screen requests the user to select a PIN for the new container. Select the desired prefix.

- Strike the "Copy" button once the desired information has been selected.

- The Screen redirects the user to the Container Basics Screen of the new PIN number of the container that has been created.

\section{Screen 5-5. Container Copy Function}

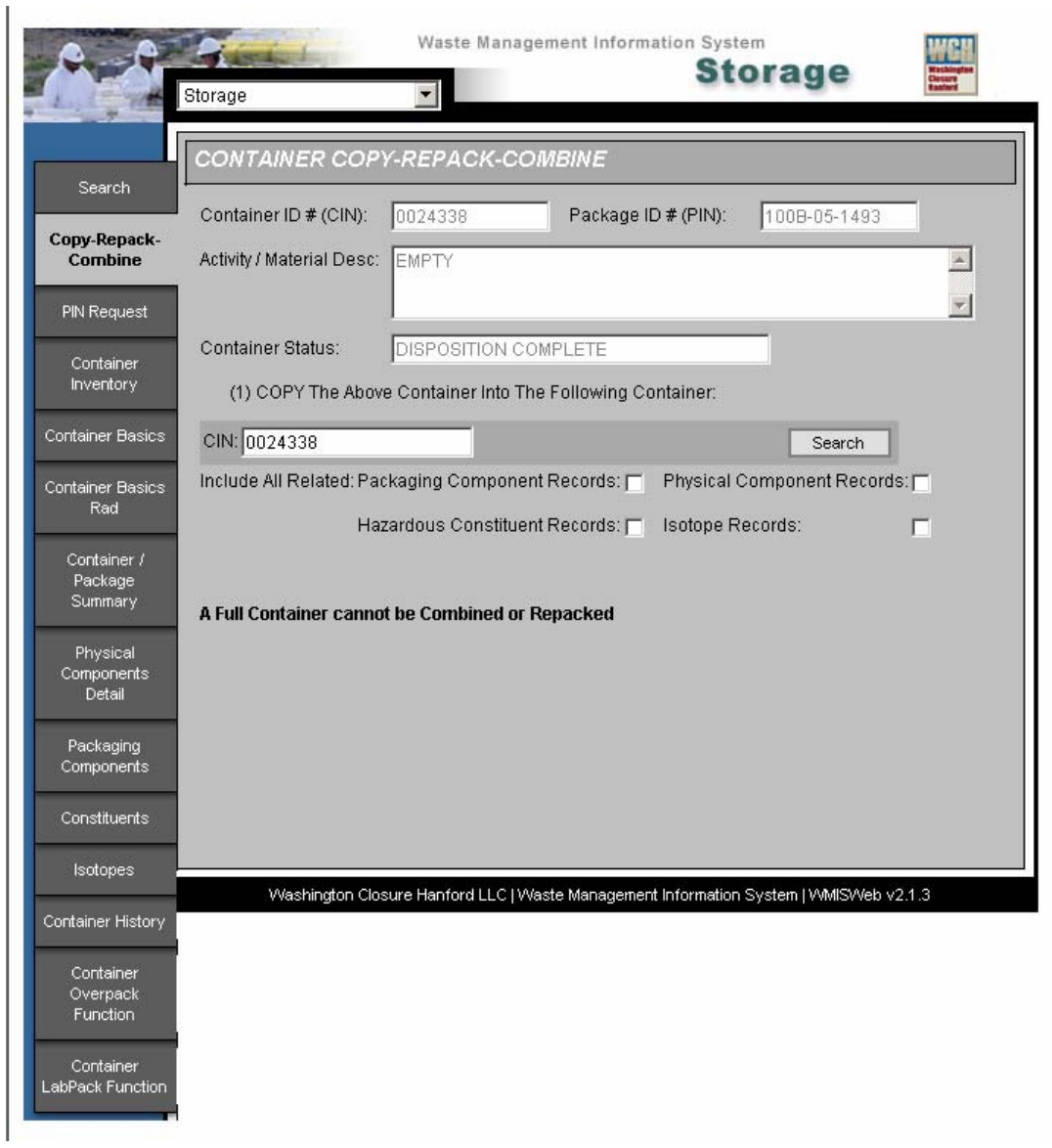




\section{Container Repackage Function}

The existing container's contents may be emptied out and placed into another container. This means that the original Items and all the Components for those Items need to be transferred to another container within the database. The top portion of the Screen shows the container selected to repackage, or the "Source" container.

\section{Input}

CIN: The "Destination" container is selected by pressing on the Search button, and a list of available containers from the Container_Inventory table is displayed.

When the user strikes the "Repack" button, the Copy-Repack-Combine procedure is executed, and cycles through the following updates.

All further updates to the Destination Container need to be done in the Container Basics screen.

The container repackaging is used to transfer the contents, full or partial, from one container to another. This function provides the ability to change the container's CIN and PIN data.

\section{Screen 5-6. Container Repackage Function}

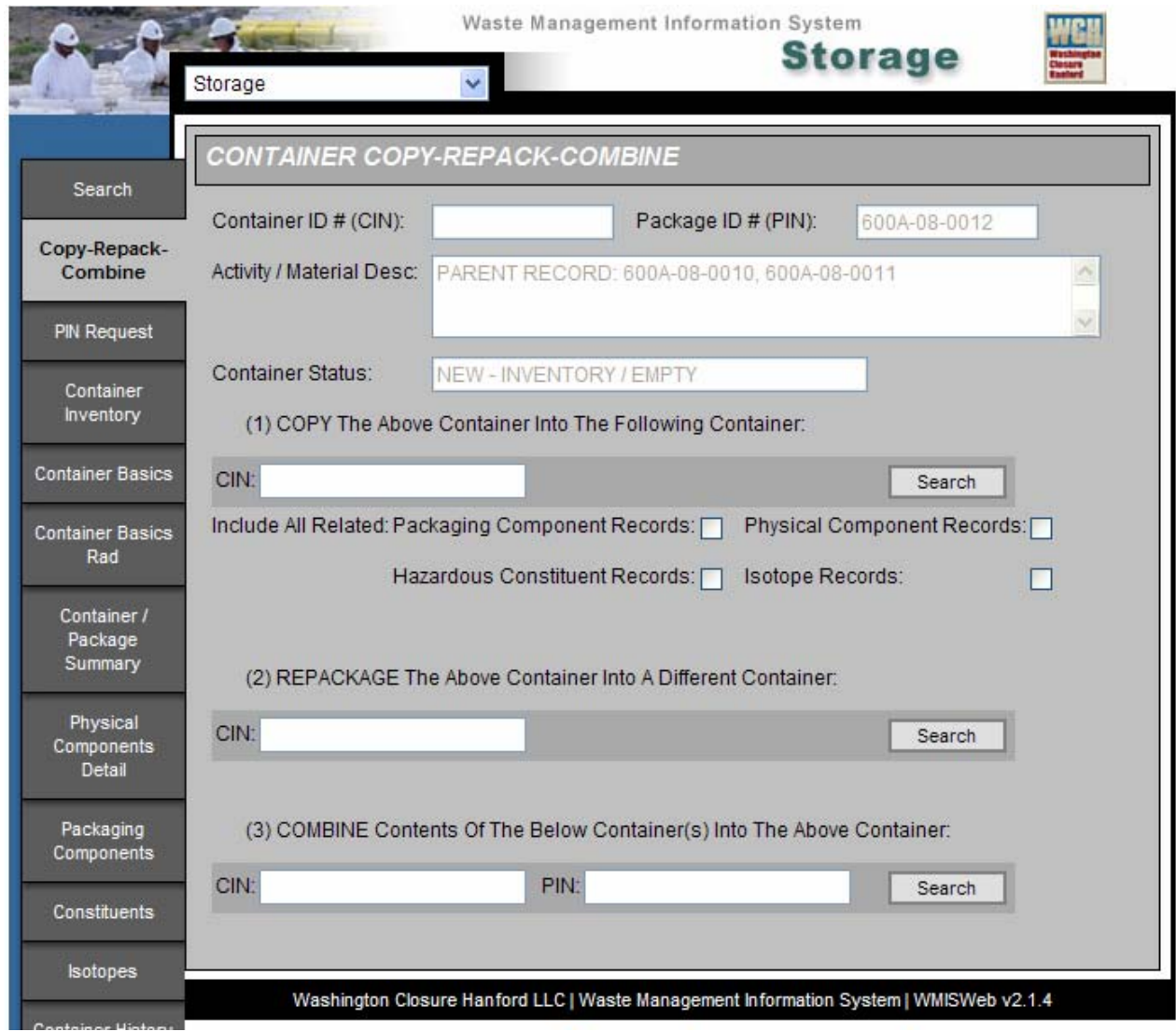




\section{$\underline{\text { Re-Package Container }}$}

After inputting the basic information of the source container and the CIN of the new container, strike on the "Re-Package" button to complete the re-packaging.

\section{Reset Container}

Strike on the "Reset" button to clear all fields.

\section{Combine Container}

A container combining operation involves emptying the entire contents of one or more containers into a different container. The emptied containers remain available for re-use. The "Destination" container, which most likely contains waste of its own, may receive waste from one or more "Source" containers.

\section{Screen 5-7. Container Combine Function}

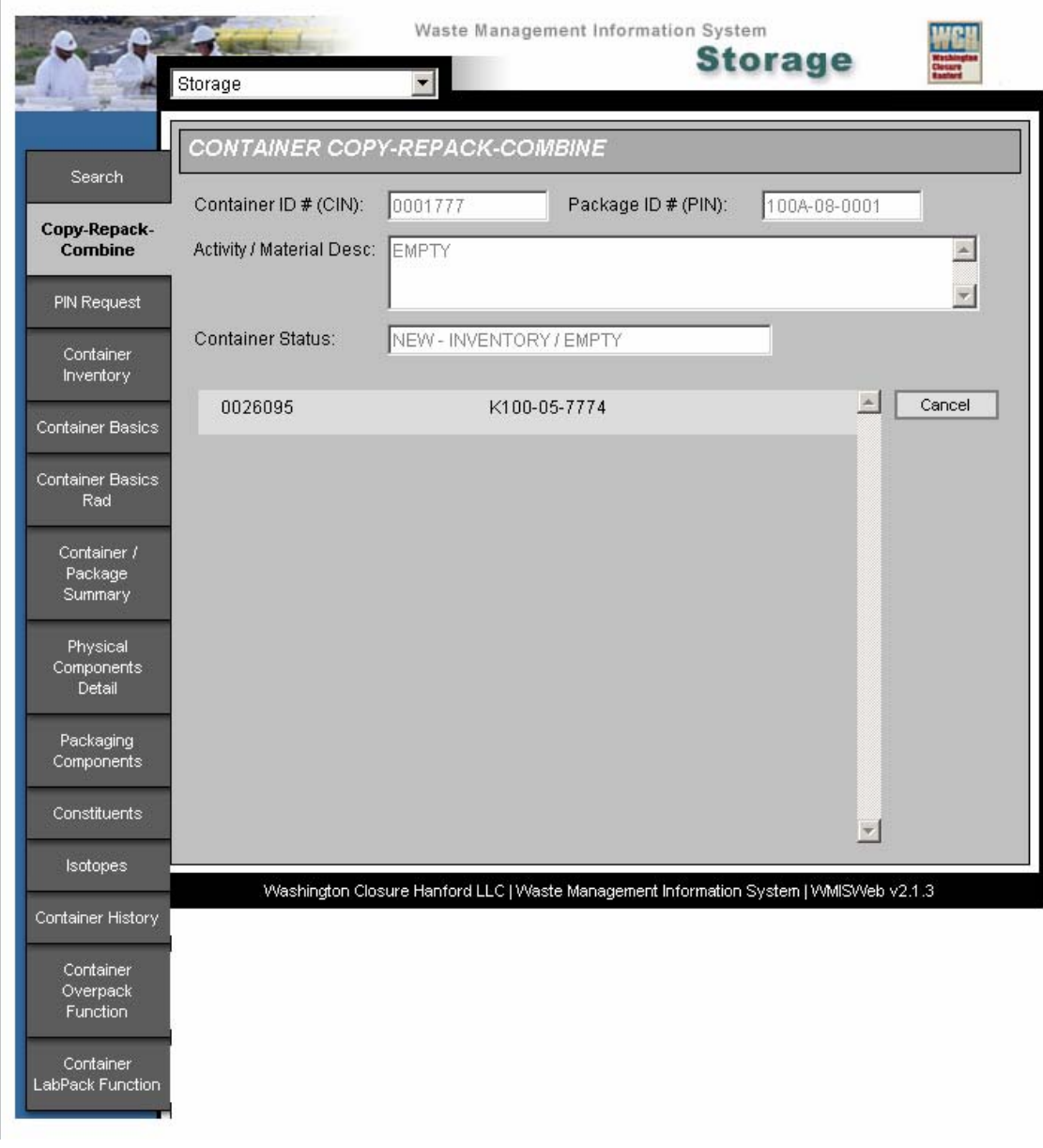




\section{Search for "Destination" Container}

- Enter at least a portion of the CIN or the PIN number for the container to be emptied into the container shown at the top of the screen. The container at the top of the screen is the "Destination" container.

- $\quad$ Strike on the "Search" button, and then strike on the specific container intended to combine. This is the "Source" container.

- $\quad$ Strike on the "Combine" tab located on the right side of the screen.

- The "Destination" container information appears in the Container Basics screen, showing the record now with the additional components from the "Source" container.

- The emptied containers show a history record indicating the combine action. "Combined Into..." message appears in the General Comments field.

- The destination container has a "Combined From..." message in its General Comments field, and has more fields such as row items and packaging components than were present before performing the combine function.

\section{Combine Containers}

The Container at the top of the Screen is the "Destination" Container. Transfer to this container of the contents of other containers selected with the search function.

\section{Input}

CIN: Strike the "Search" button, select the "Source" container, and display a list of all partially filled containers.

Strike the "Combine" button. The CIN and/or PIN numbers build the query to identify the container's records and data elements to update the Destination container. 


\section{Screen 5-8. Copy Repack Combine Destination Screen}

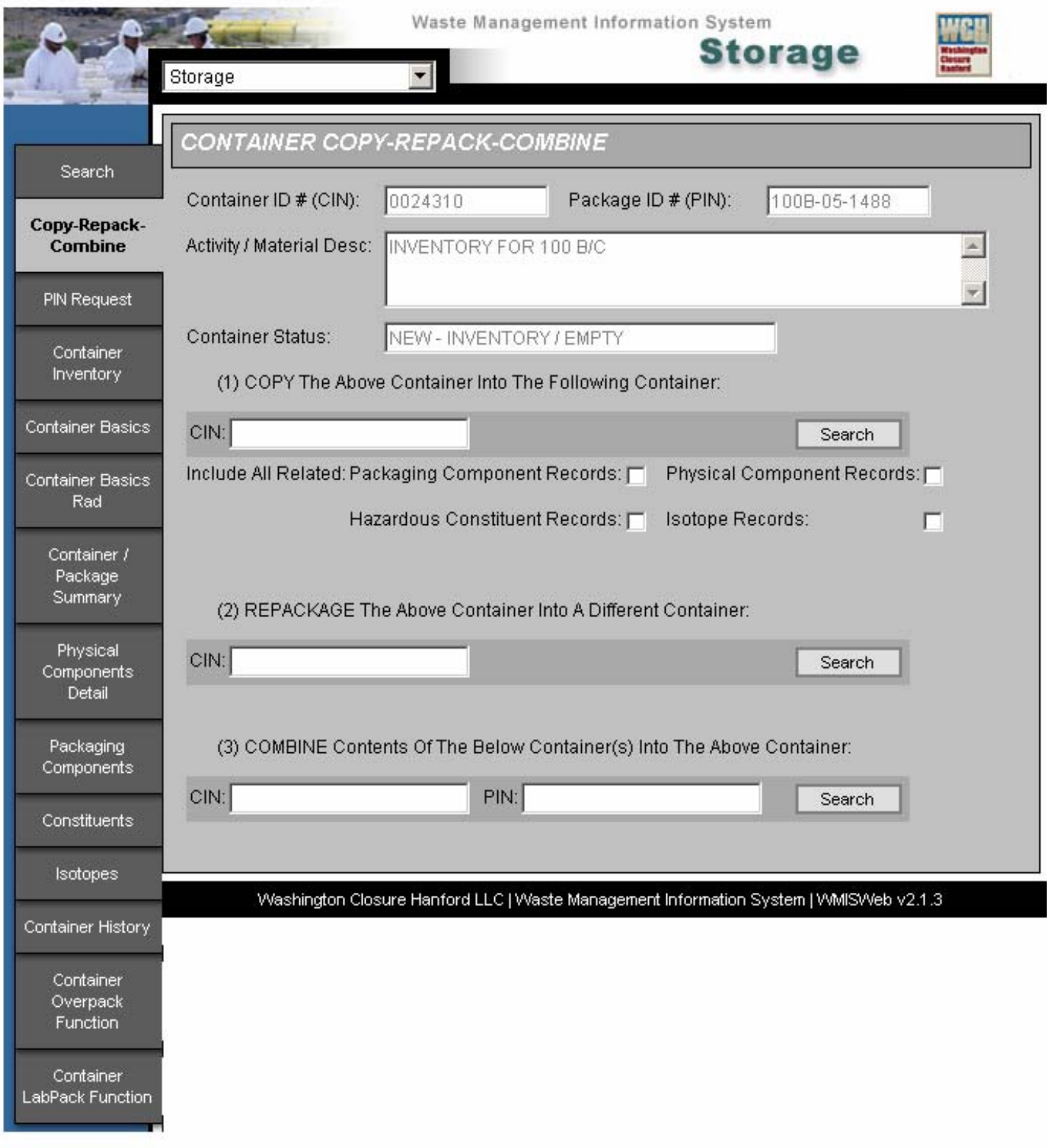




\subsection{WMIS510 PIN REQUEST}

The PIN Request Screen allows the user to assign a number to their waste in the correct format. This routine allows the user to select an "available" container from inventory, assign the correct prefix, and insert a new record into the database containing the requested PIN. The selection Screen displays a drop down to obtain the proper number scheme. The user selects the prefix, selects available containers, and the system returns the requested numbers on the screen. The user also has the capability to enter common data elements for all the PIN numbers requested. If the user enters any of the common data, all the containers contain that same data.

The PIN Request Screen allows the user to assign a Package Identification Number to their waste in the correct format. The PIN assignment typically occurs when the Waste Transportation Specialists are picking the containers that are ready to use. This Screen allows the user to input some common data elements that are applicable to the project. Changes or additions to the common data reflect in all the selected containers getting a new PIN number contains the same data.

The user can search and display the available containers in inventory that are available for issue and use for waste storage/disposal. The user selects the desired available containers by checking the box next to the CIN number. The user then checks the "Assign PINS" button and a PIN is assigned.

The PIN belongs to the waste inside the container, and identifies the waste, not the container. (Cradle to Grave). If the waste transfers into another container, the PIN goes with the waste. The CIN/PIN record shows as "D" (Disposed) in the WMIS database when the destruction or disposal of the container, with the waste inside, occurs. When the container is simply emptied, the database record for that CIN/PIN combination shows disposed, but the container is available for re-use, and appears in the WMIS database as many times as it is re-used, with different PINs for each use.

\section{Search for Available Containers}

The user can select the available containers that can be used by entering Purchase Order, Size desired, or known Storage Location. A list displays the available containers. The user selects those required containers by checking the box next to the listed container. 


\section{Screen 5-9. Storage - PIN Request}

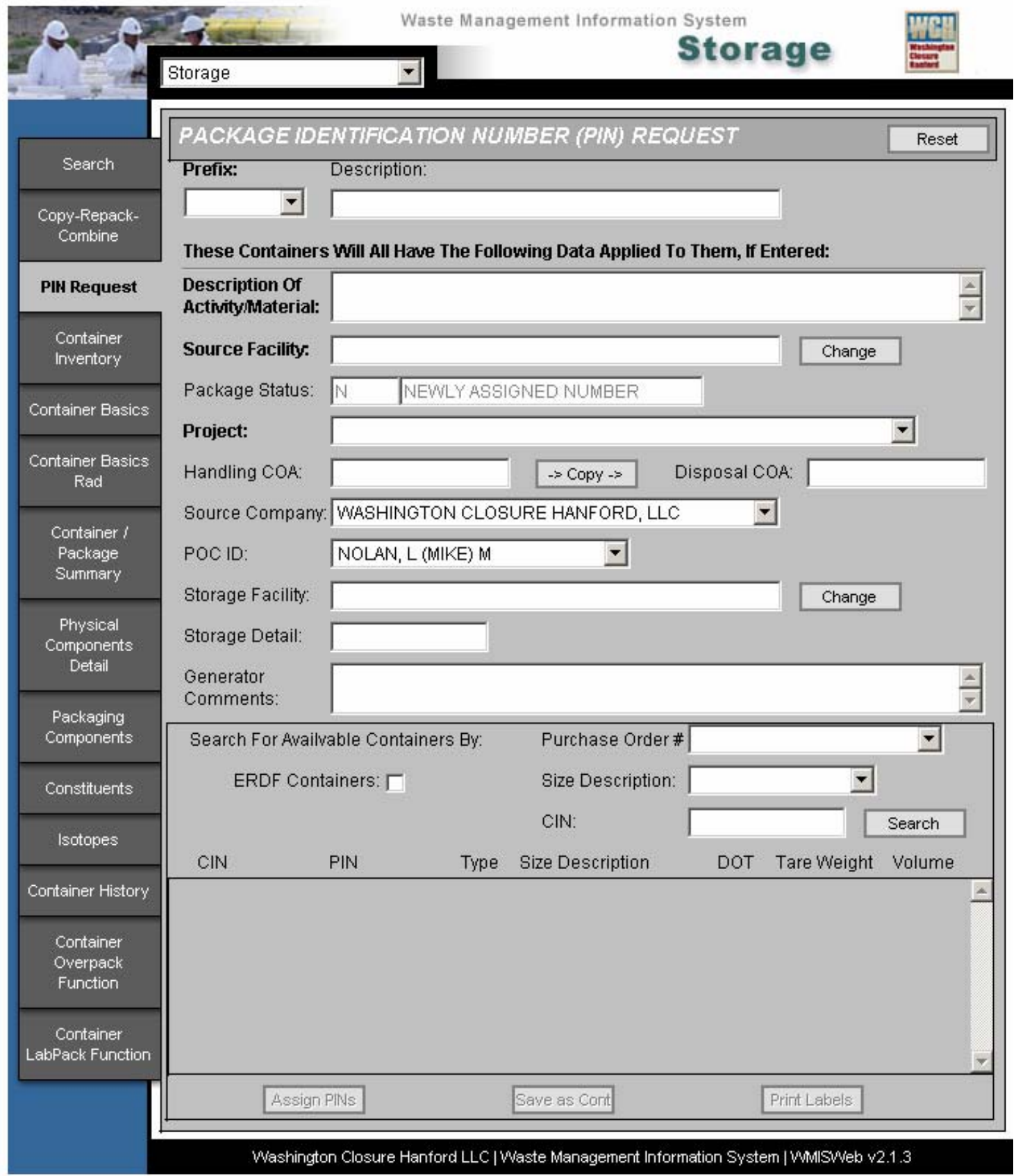

\section{Assign PINs}

- $\quad$ Select the desired containers.

- $\quad$ Strike "Assign PINs." 


\section{Screen 5-10. Example of Search Results}

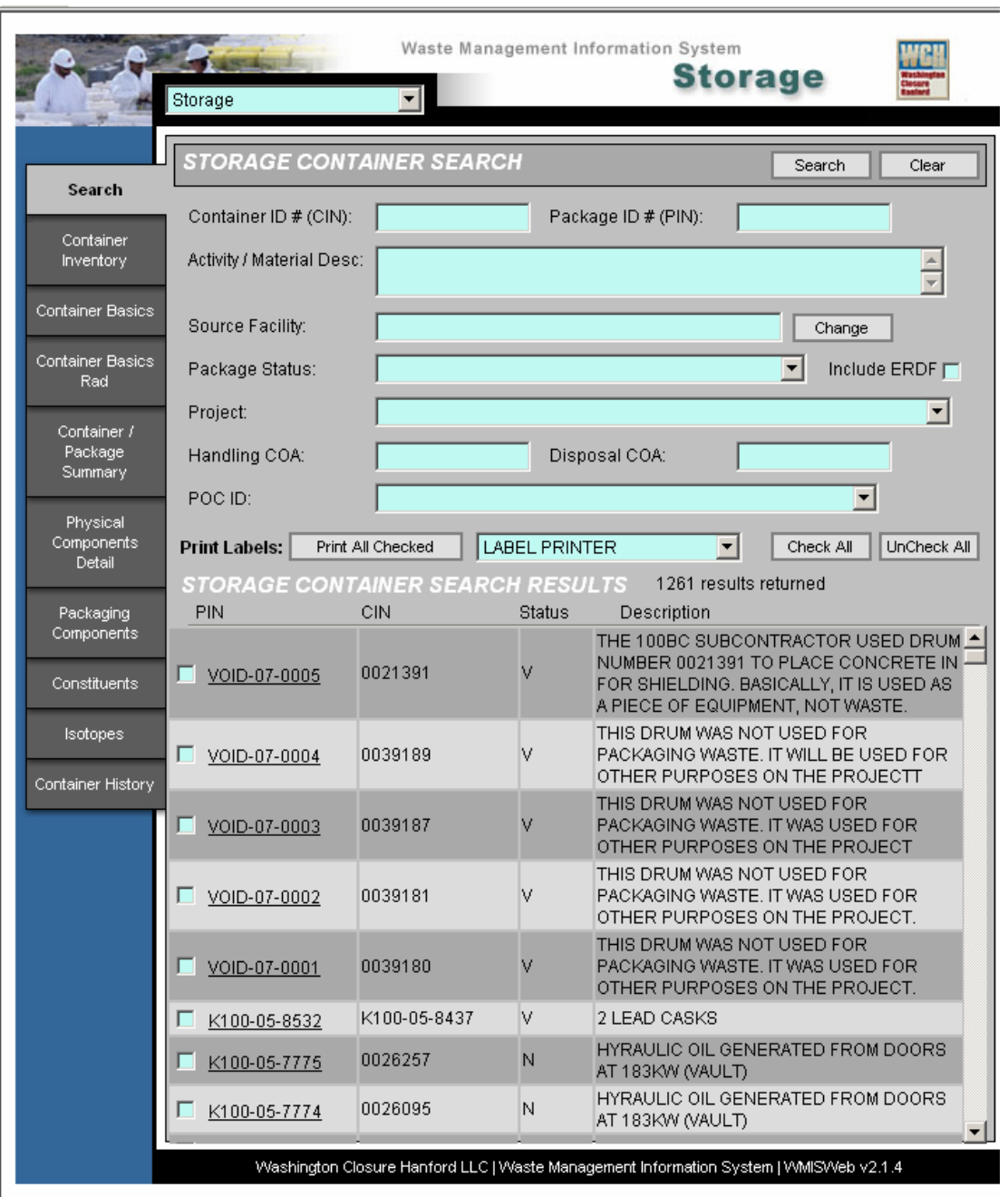

\section{Print PIN Labels}

Reserved for future development.

\section{Request PIN}

- Select a prefix for the PIN numbers.

The user must complete the following sections to complete PIN request: Prefix, Source Facility, Source Company, and POC ID.

NOTE: The user can enter any additional desired information on the container records in the rest of the fields shown on the screen. However, the user should realize the entered information appears on every PIN requested. This can save time if the information is the same for all the requested containers, but can cause problems if the data entered does not apply to all the requested numbers. 
- Enter requested information.

- $\quad$ Strike the "Search" button beside the Storage Detail field in the Search for Available Containers By box, and the available containers in inventory appear.

- $\quad$ Place check marks beside the desired containers.

- Strike "Assign PINS" button.

- The screen displays the containers with the new PINs.

Save As Containers

Strike the "Save As Cont" button.

Print Container Labels

Reserved for future development.

\section{View Container Data}

Select by double-clicking any of the assigned PIN/CIN numbers, and the Container Basics Screen appears for that PIN/CIN record. 


\subsection{WMIS515 CONTAINER INVENTORY}

This screen allows the user to enter search criteria and display containers available for issue and use for waste storage/disposal. Search criteria allows for the "\%" functionality.

\section{Screen 5-11. Storage - Container Inventory}

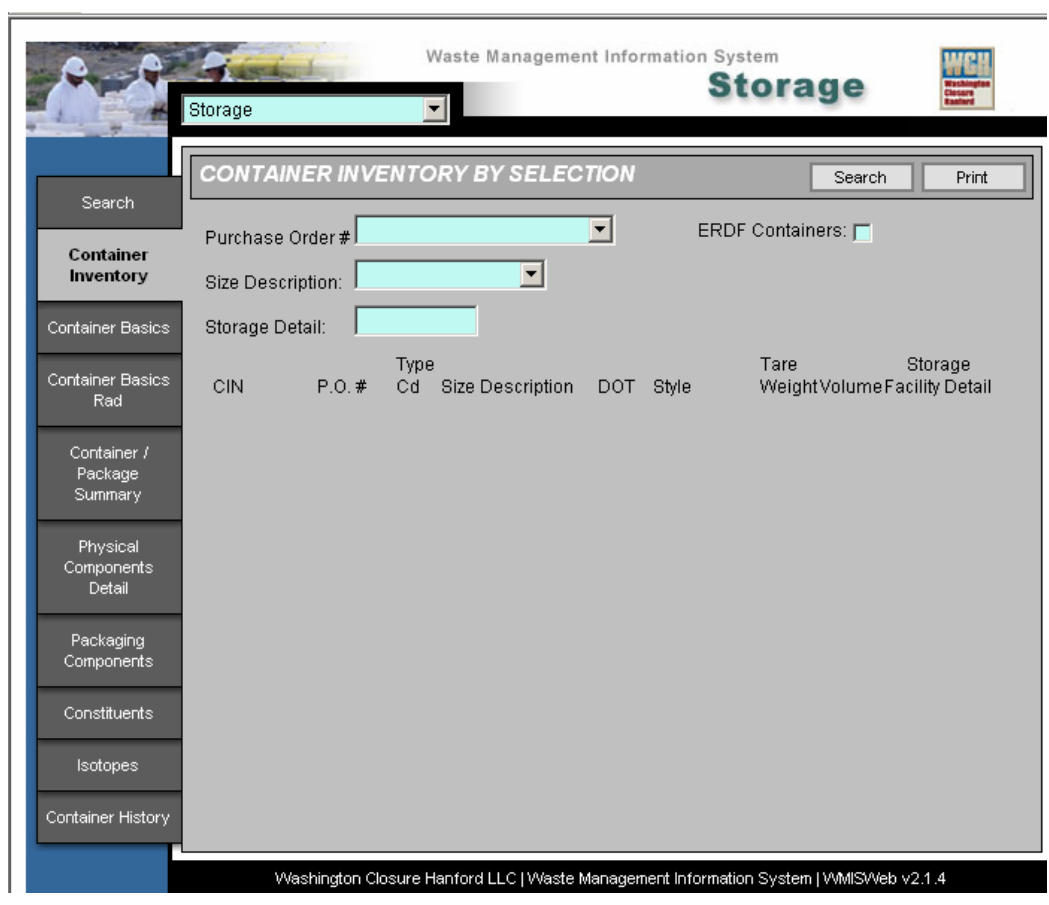

Screen 5-12. Example of Search Results

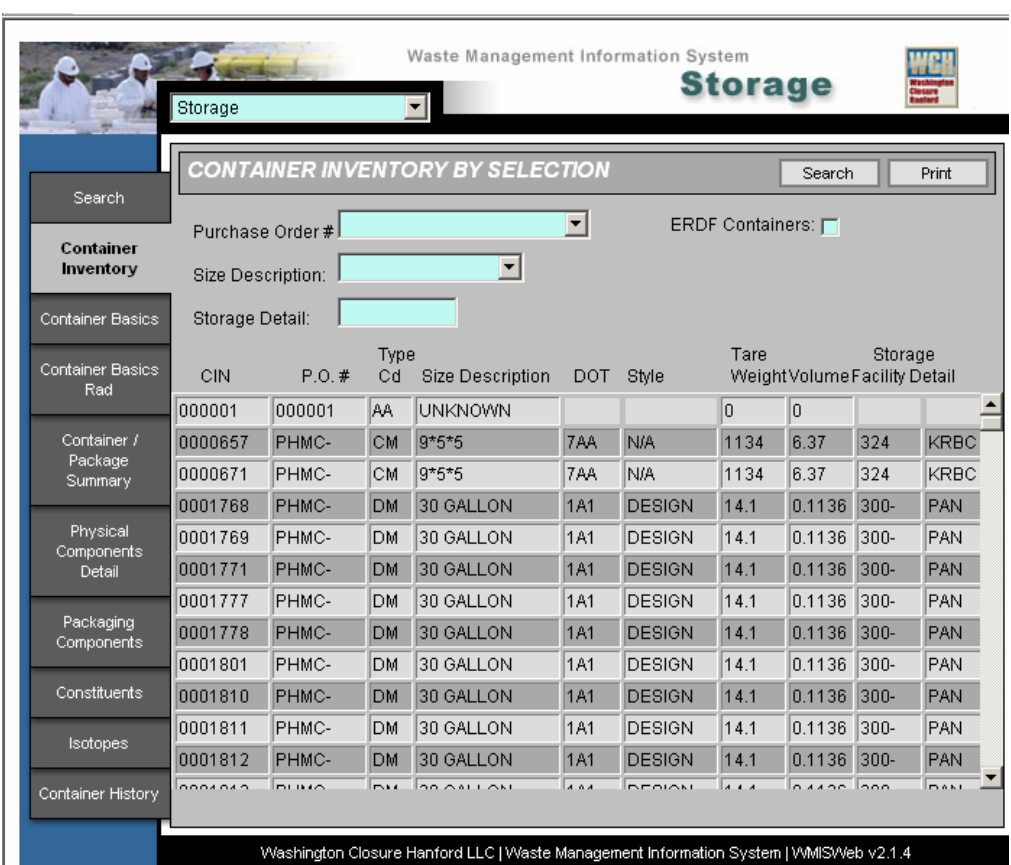




\subsection{WMIS520 CONTAINER BASICS}

The Waste Management Certification Form (WCF) and the Waste Inventory Sheet (WIS) identify the waste, shipper, facility waste originated from, type of waste, and other information describing the waste. The $\mathrm{CIN}$ is the identifier for the container being packaged. In addition, a PIN is assigned and used as the waste tracking number.

\section{Container Basics}

This screen provides the user with information needed to make data input decisions.

\section{Screen 5-13. Storage - Container Basics}

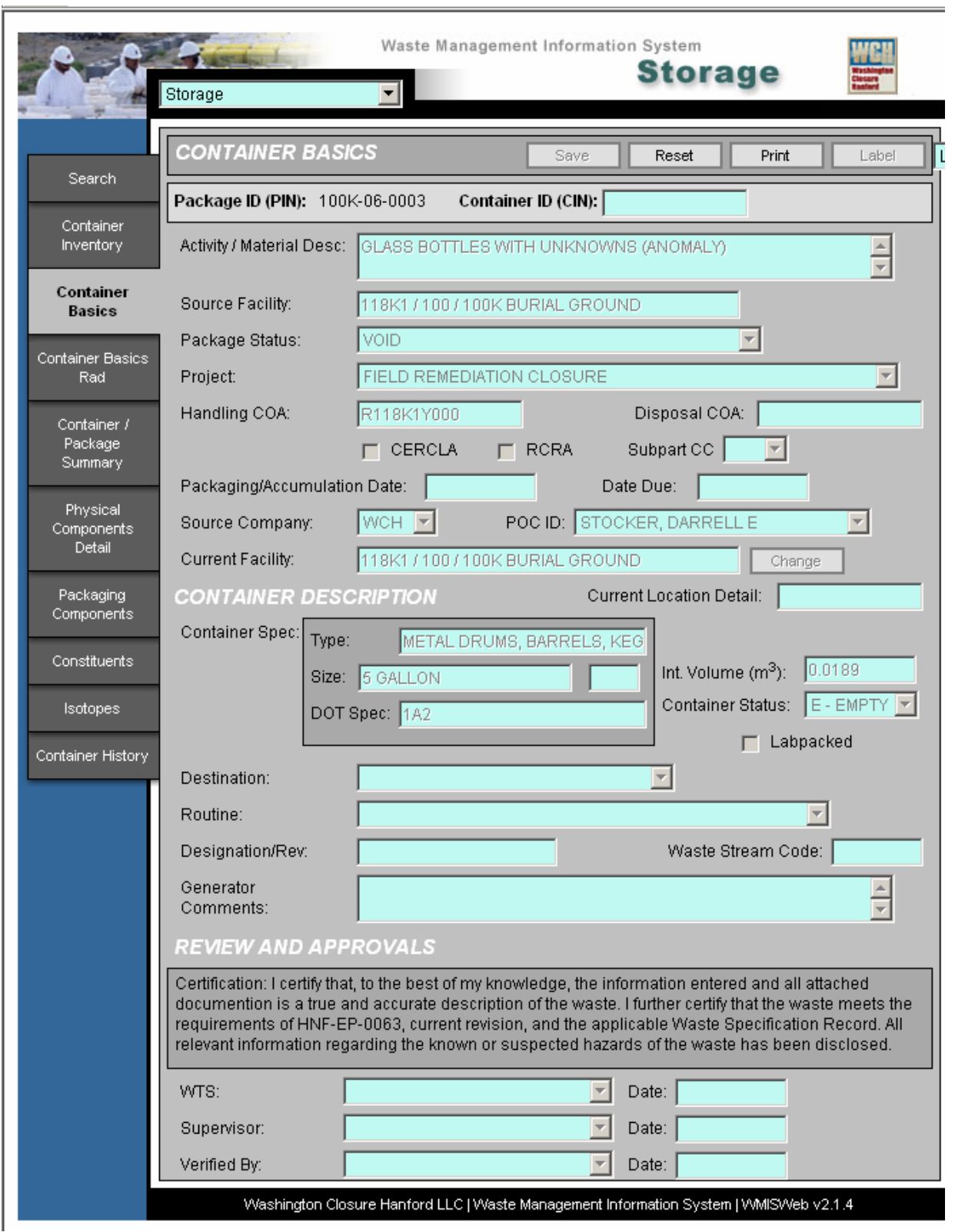




\subsection{WMIS525 CONTAINER BASICS RAD DATA}

\section{Screen 5-14. Storage - Container Basics Rad}

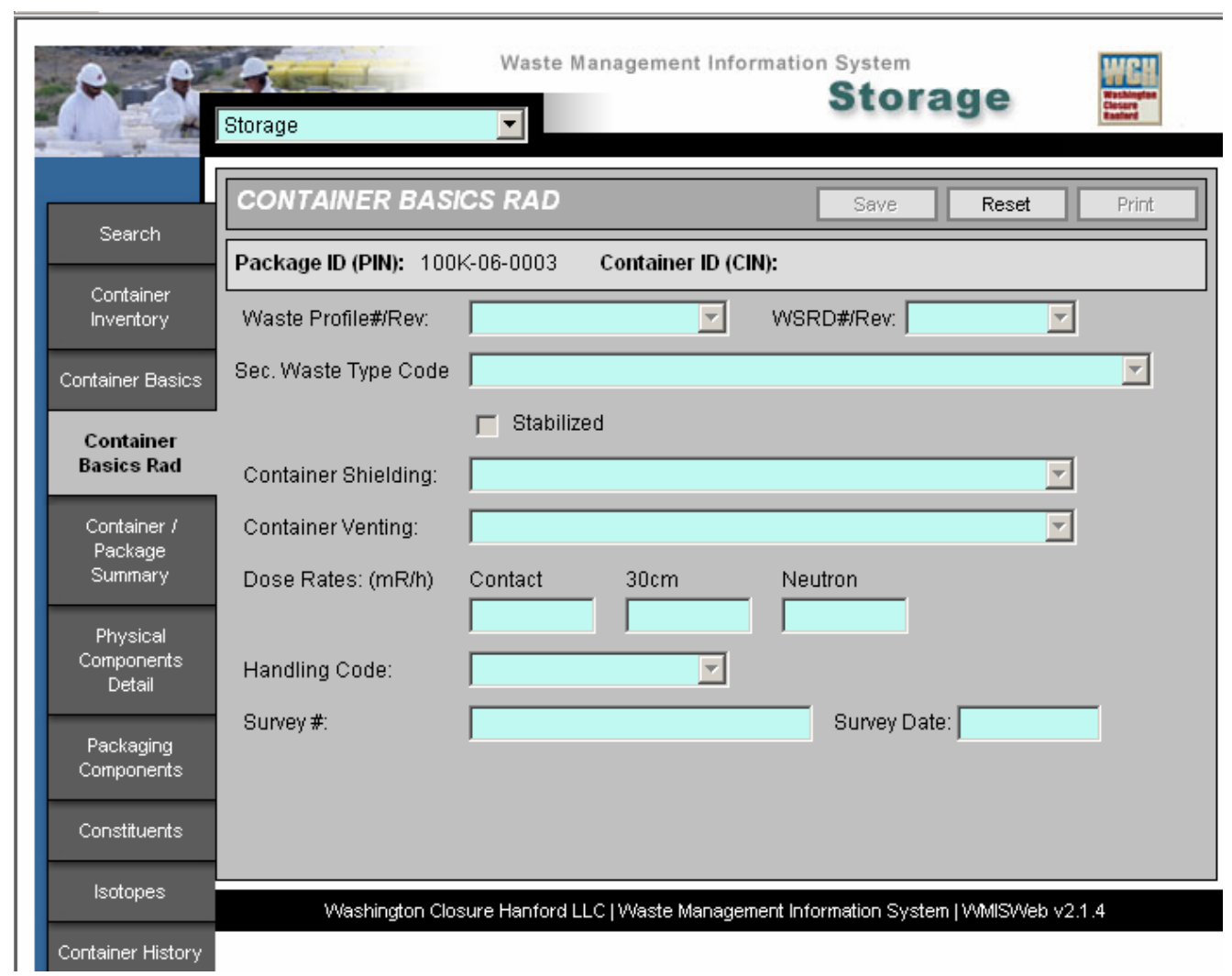

\section{Enter Container Basics Rad Data}

- All fields shown on the Screen are updateable by most users up to the point where the container obtains a "Closed" status.

- $\quad$ Some fields have drop down boxes to define valid values for the field. There are pop-up calendars for all the date fields for ease of entry.

\section{Print Container Listing Report}

- Strike "Print" at the top right corner of the screen to print a Container Listing Report.

- The report displays on the screen.

- $\quad$ Strike the printer icon to print.

- Strike the Container Basics tab to return to the Container Basics screen. 


\section{Print Container Label}

Reserved for future development.

\section{Enter WTS Signature}

- Entry of WTS name changes Package Status to "Closed", indicating no more items are to be included in the container (no more items to be added to Physical Components Detail tab). The WTS is certifying that the contents of the container match what is indicated on the Container Basics Screen and all other screens showing weights, physical components, packaging components, etc.

- Enter date package closed.

- Pressing Save, without entering a date, automatically populates with system date.

\section{Enter Supervisor Signature}

- $\quad$ The supervisor enters a status of "Ready for WCH Review."

NOTE: The entering of a supervisor name indicates the supervisor is certifying that the contents of the container match what shows on the Container Basics screen and all other screens and the supervisor concurs with the WTS as to the contents of the container.

Enter date of entry.

Pressing Save, without entering a date, automatically populates with system date.

\section{Enter Designation Number}

- $\quad$ The WDS (or WITS as necessary) assigns the designation to be associated with this container, usually after the container closure and supervisor approval.

- Strike the "Change" button next to the designation number field.

- $\quad$ The Designation Search screen appears, with the status set to "Approved" already filled in. Only approved designations are with containers.

- $\quad$ Strike the "Search" button for a list of all approved designations.

- $\quad$ Select the desired designation and double-click on the bold number/rev.

- The Container Basics Screen re-appears with the assigned designation number.

- $\quad$ Strike "Save."

- Strike the Constituents tab and the Isotopes tab to confirm that all the components of the designation are correct. 


\section{Enter Verification Signature}

The WTS reviews all the information for the container, and enters their name in the Verified By input box at the bottom of the screen. Entry of name in "Verified By" field changes "Package Status" to

\subsection{WMIS530 CONTAINER PACKAGE SUMMARY}

The Container/Package Summary Screen allows the user to view a summary of the individual contents of a waste package. Related Chemical or Isotope records are not available until the Designation Number and Revision have been associated with this Container.

\section{Screen 5-15. Storage - Container Package/Summary}

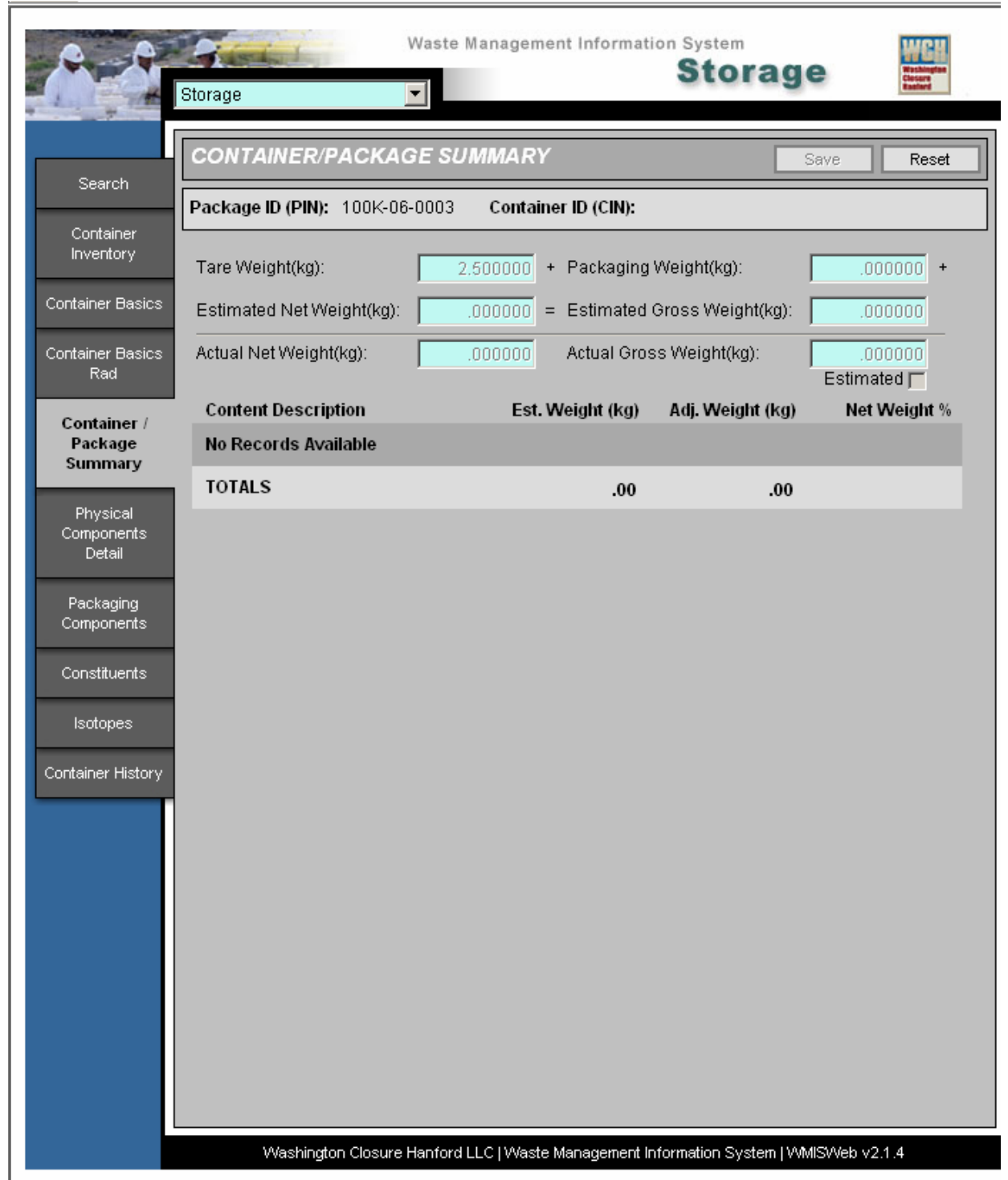


Input or modify container's actual weight on this screen as the Actual Gross Weight $(\mathrm{kg})$. This is the final, weighed weight of the container. Entry of the Actual Gross Weight triggers calculation of the Actual Waste Weight, and the individual chemical constituent's weights.

The Container/Package Summary screen allows the user to view a summary roll-up of the individual component items that are in the container. Adjustment of the weight fields occurs here to reflect the final scaled weight of the container.

\section{Enter Container Tare Weight}

- In the box opposite the Tare Weight label, enter the empty (tare) weight of the container and strike "save." The Estimated Gross Weight increases by any amount entered in the Tare Weight.

- Tare Weight field is populated from Purchase Order module. Each purchase order line item identifies the tare (and volume) for each CIN linked to that line item. Tare weight is not updateable by the user.

\section{Enter Container Actual Gross Weight}

- In the box opposite the Actual Gross Weight label, enter the final, weighed weight of the container.

- Strike the "Save" button.

NOTE: Adjustments occur after pressing the "Save" button.

- The adjusted weights for the components vary up and down, depending on the value entered in the Actual Gross Weight.

- If the actual weight is more than the estimated weight, the adjustments increase the component weight.

- If it is less, the adjustments decrease the component weight.

- If the project has access to equipment to weigh the final package, enter the actual gross weight and strike "Save." If the project does not have means to weigh the final package, strike the Estimated check box below Actual Gross Weight value. The Estimated Gross Weight value will be entered for Actual Gross Weight. Strike "Save."

- For those packages having the actual gross weight, note some adjustments to component weight values after pressing "save." The adjusted weights for the components vary up and down, depending on the value entered in the Actual Gross Weight. If the actual weight is more than the estimated weight, the adjustments increase the component weight. If it is less, the adjustments decrease the component weight. 


\subsection{WMIS540 PHYSICAL COMPONENTS DETAIL}

The Physical Components Detail screen allows the user to view or input the individual physical component row items that make up the contents of the waste package. This is the automated version of the hard-copy WIS.

\section{Screen 5-16. Storage - Physical Components Detail}

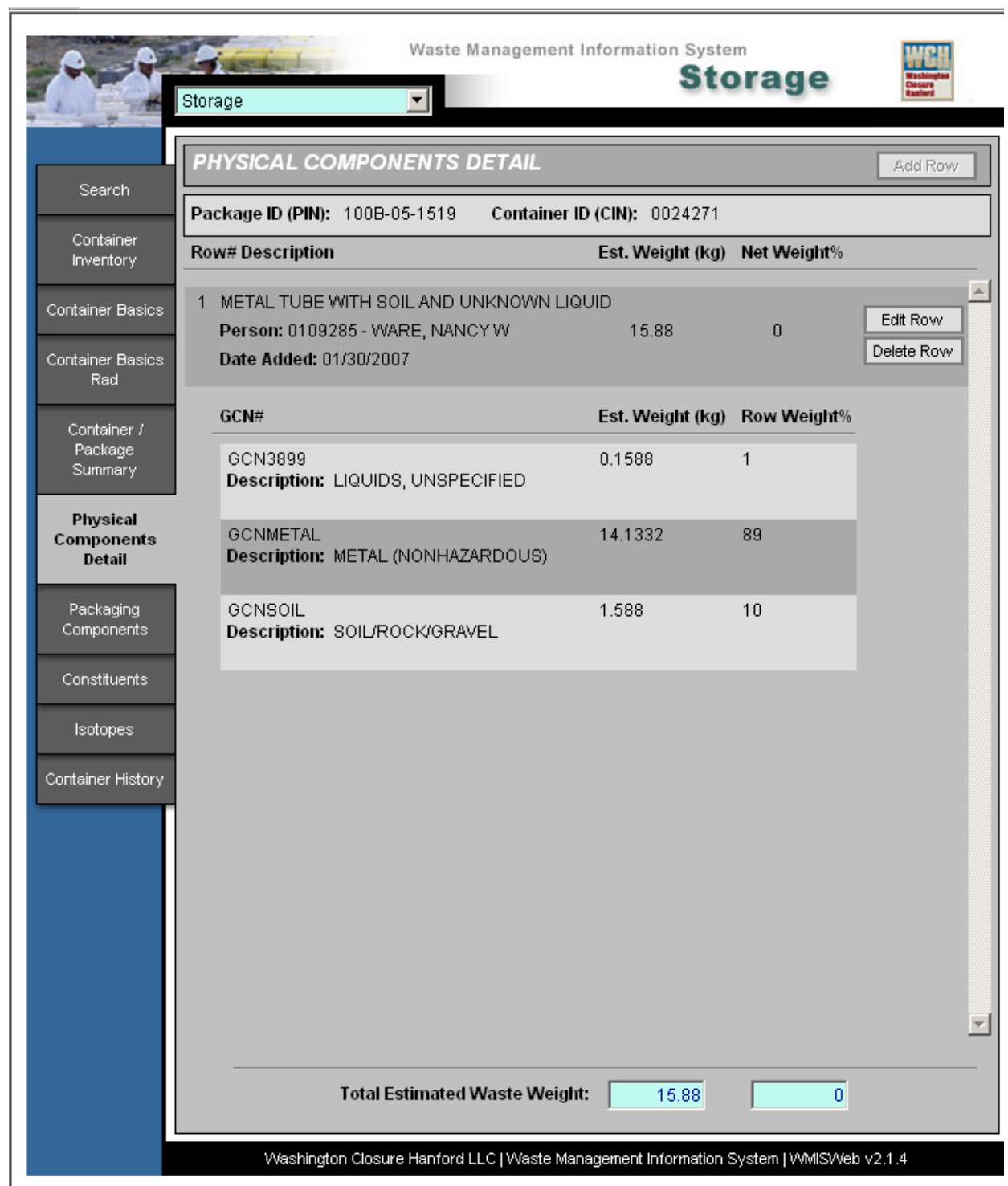

\section{Add Row Item}

- $\quad$ Strike the "Add Row" button at the top of the screen. The "Physical Components Detail Add Row" Screen appears. 
- The user name appears in the "person" text box, and the current date displays in the "Date Added" text box. Both fields are updateable.

- Enter a description of the item and the estimated weight for the row item.

- Strike the "Add" button at the top of the screen. The "Add Physical Components" Screen appears.

\section{Add Physical Components within a Row Item}

- In the "Search Filter" text box, enter text to search on and strike on the "Search" button to the right of the text box.

- The search results display under "Available Components."

- Under "Available Components", strike the applicable check box(es). Search and check multiple components as necessary.

- Verify all Components have been selected.

- Strike on the "Add" button at the top of the screen.

- The "Physical Components Detail - Edit" Screen re-displays with the row item component(s) selected listed below the row item description.

- Enter either the "Est. Weight" or the "Row Weight \%" for each of the row item components.

- The total "Est. Weight" for all row items components must be equal to the "Row Est. Weight" in the row above it. In addition, the total "Row Weight \%" for each row must equal $100 \%$.

- Should either of the above conditions fail, the totals will highlight in pink.

- Repeat the previous Input step, correcting the component values until the totals equal $100 \%$ and are no longer highlighted.

- Strike on the "Save" button at the top of the screen.

- Strike on the "Physical Components Detail" button at the tab at the left side of the screen.

- The list of selected components is below the row description. The "Total Estimated Waste Weight" at the bottom of the screen provides the sum for all rows.

\section{Delete a Physical Component within a Row Item}

- Strike on the "Physical Component Detail" tab and strike on the "Edit Row" button on the right side of the screen to select a row.

- The "Physical Components Detail - Edit" screen displays. 
- Select the row component and Strike on the "Delete" button.

- A comment box appears for an explanation of the disposition of the item (i.e., Material placed in wrong container, removed from PIN\#1, placed in PIN\#2 on 05.01.05).

- Enter an explanation and strike "OK."

- The screen no longer displays the deleted row component.

- At the top of the screen, the pink highlighted row totals are now incorrect. These totals are now incorrect.

- Edit either the Row Item Est. Weight or the Row Item Weight \% so that the totals add up to $100 \%$ at the top of the screen are correct.

- Strike "Save."

- The "Physical Components Detail Edit" screen displays. Verify the row component is gone and totals are correct.

\section{Delete an Entire Row Item, Including All Components}

- At the "Physical Component Detail" screen, strike on the "Delete Row" button on the right side of the screen associated with the row to be deleted.

- A comment box appears for an explanation of the disposition of the item (i.e., Material placed in wrong container, removed from PIN\#1, placed in PIN\#2 on 05.01.05).

- Enter an explanation and strike "OK."

- The screen no longer displays the deleted row. 


\subsection{WMIS550 PACKAGING COMPONENTS}

For updates to the container's packaging components, select the "Packaging Components" tab to display the packaging records that are present for this container.

\section{Screen 5-17. Storage - Packaging Components}

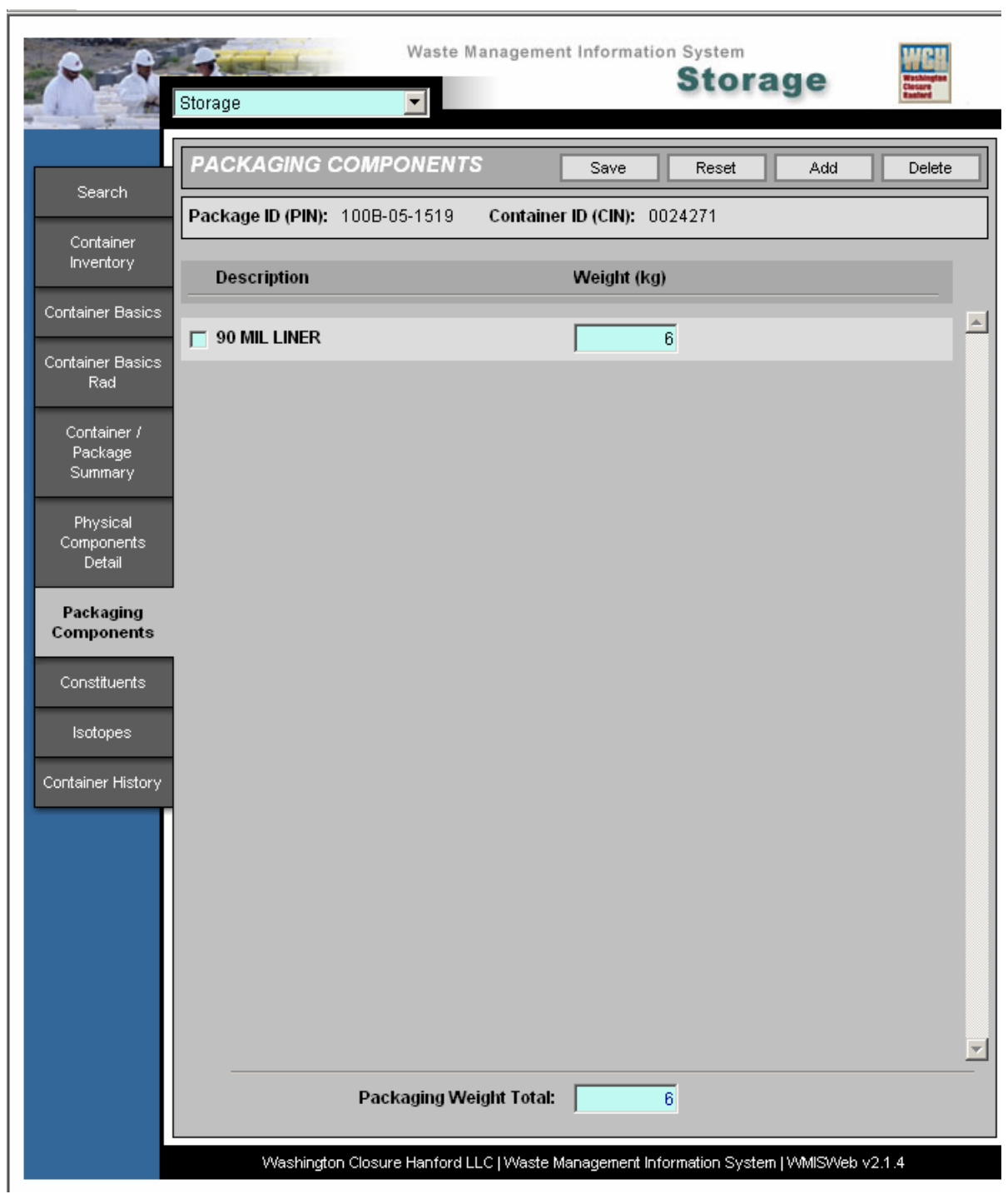

\section{Add Packaging Component}

- $\quad$ Pressing the "Add" button redirects the user to a search Screen. Selection of packaging components occurs here. After checking the box(s) next to the packaging component(s), strike the "Add" button to insert the component(s). After adding a component, enter the weight.

- $\quad$ Strike the "Save" button. 


\section{Delete Packaging Component}

- Checking the box next to the component and then pressing on the "delete" button deletes the component.

- A comment box appears for an explanation of why this component is being deleted.

- $\quad$ Strike the "Save" button.

\subsection{WMIS560 CONSTITUENTS}

The Container Constituents screen allows the user to view the individual constituents for the chemical constituent's items within the container. Related constituent records are unavailable until the designation number and revision have been associated with this container.

The Delete capability is available for ERDF Destination Disposal Only.

\section{Screen 5-18. Storage - Constituents}

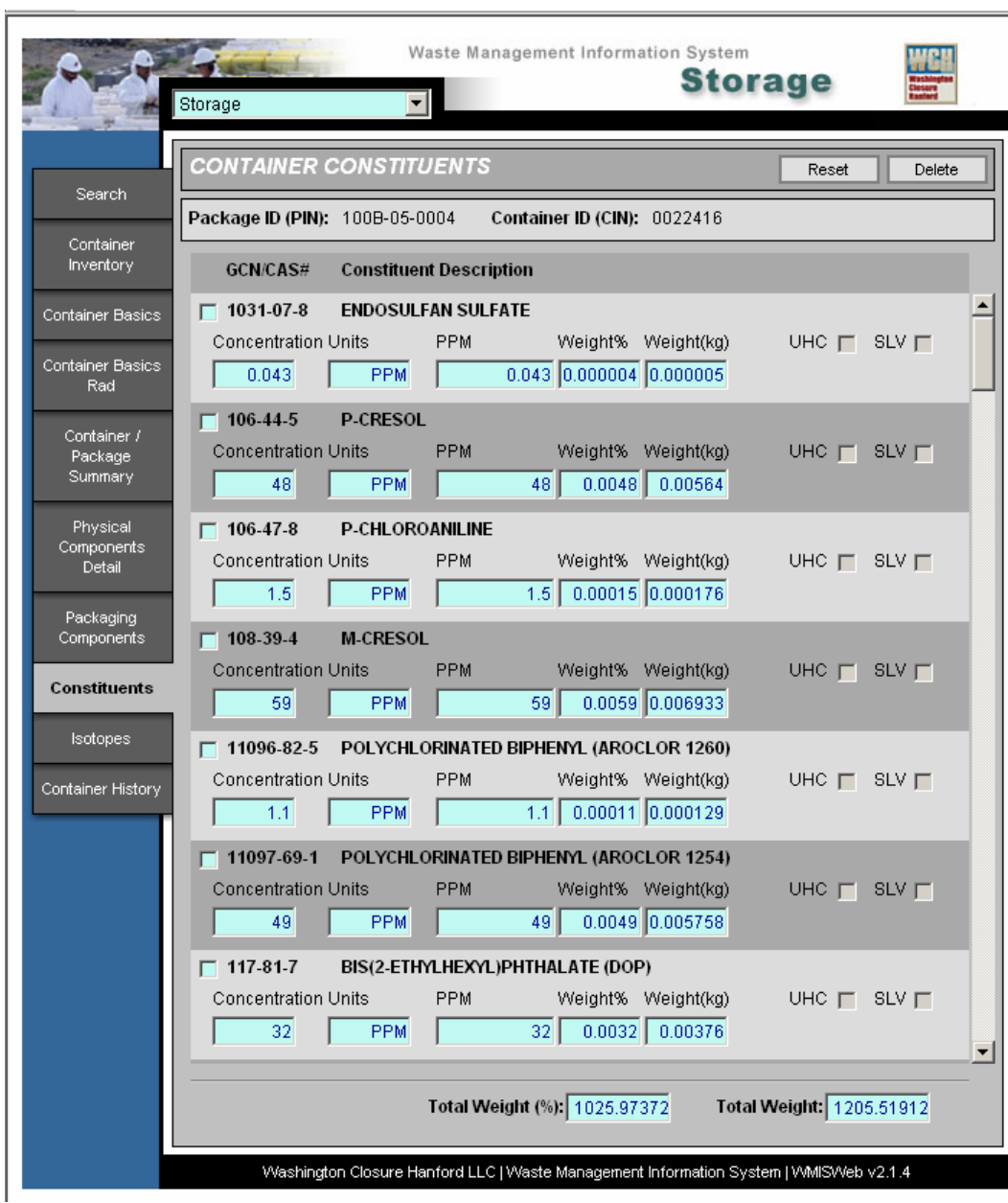




\section{Enter Constituents}

The user cannot enter any new constituents from the container constituents' screen. Additions and modifications of constituents occur in the Designation module.

\section{Delete Constituents}

- Checking the box next to the constituent and then pressing on the "delete" button deletes the constituent.

- $\quad$ The delete capability is only available for ERDF destined packages. 


\subsection{WMIS570 ISOTOPES}

Isotope records associated with the designation number and revision entered on the Container Basics Screen display on this screen. Calculations occur based on the designation activity value entered on the associated Designation module's Isotopes screen.

\section{Screen 5-19. Storage - Isotopes}

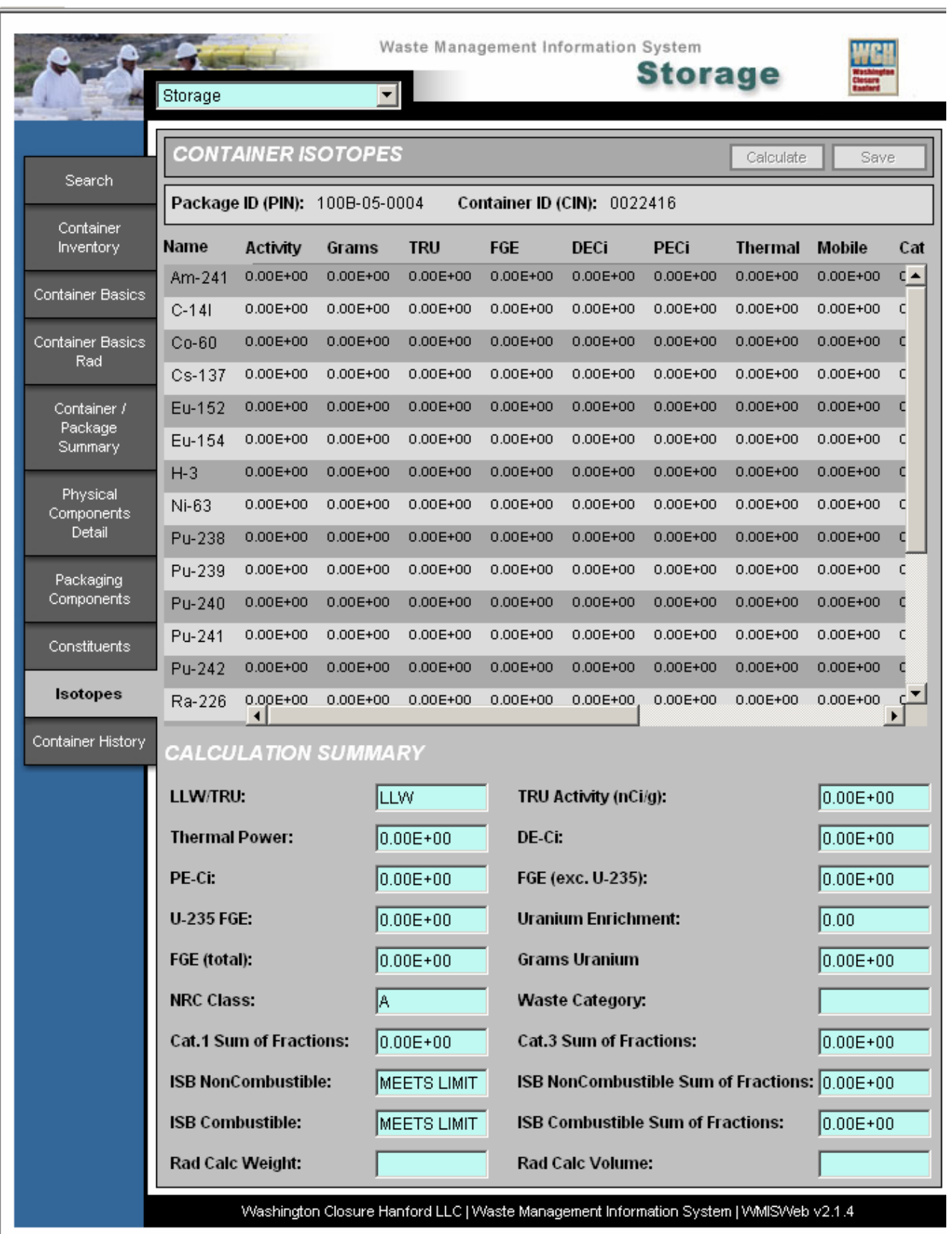




\section{Calculate Button Functionality}

Pressing the "Calculate" button gets the totals for all isotopes and updates the Calculation Summary table.

\section{Enter Rad Calc Volume Field}

If the value in the Rad Calc Volume field changes strike the "Calculate" button to recalculate and save the modified value.

\section{Delete Functionality}

Pressing on the "Delete" button next to an isotope deletes that particular isotope. This functionality is only available for ERDF destination disposal. 


\subsection{WMIS575 CONTAINER HISTORY}

The Container History screen allows the user to view the history of the container, which includes the location history, repackaging, and status changes. The history records for the container displays in a descending order by date.

\section{Screen 5-20. Storage - Container History}

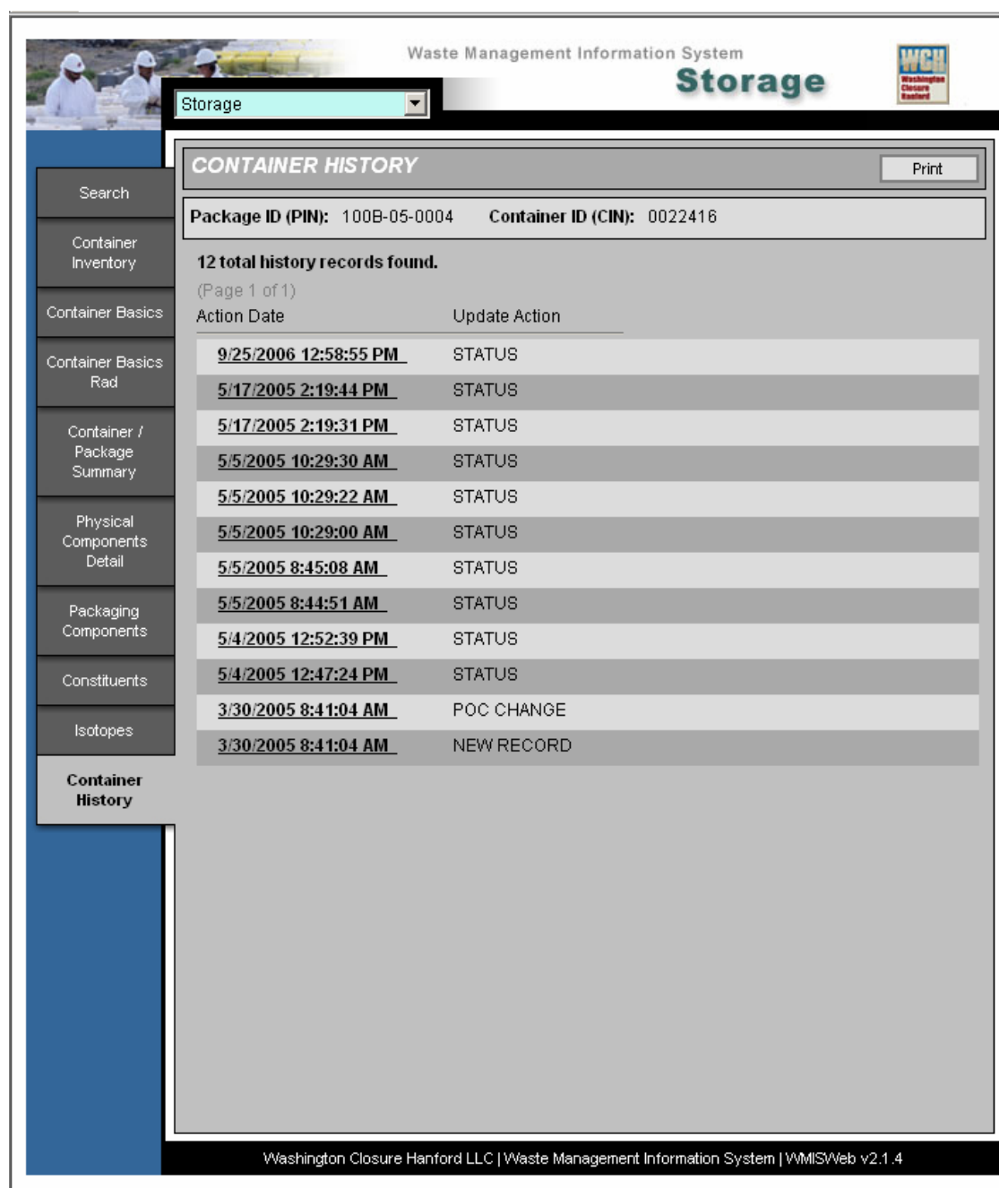

\section{Action Date}

Pressing the date and time of a particular line item displays some basic information about the container and reason for a change in status.

\section{Print Function}

Strike the print button at the top of the screen to print the summary screen. 


\subsection{WMIS 600 - PDA OPERATIONS MODULE}

The PDA Operations Module utilizes Windows CE based Personal Digital Assistants (PDAs) which allows the field personnel to collect or view a subset of the WMIS information.

This module addresses three areas of data collection.

1. The input and recording of physical items, in each container, this includes physical components and packaging materials.

2. The second is the tracking of the physical inventory of containers and their current location, and the associated location history.

3. Recording ERDF waste disposal activities.

With future availability of wireless networking, the PDA may communicate directly with the web server. WMIS allows barcode input for containers.

\subsection{WMIS600 DOWNLOAD DATA}

\section{Download Data Search}

- The screen displays fields available to build query parameters of container records. The more fields entered, the fewer results are displayed, allowing the user to narrow the number of records to be viewed.

- $\quad$ The records will display on the screen.

- Strike the download button. This downloads the container records to the Dolphin.

\subsection{WMIS610 CONTAINER SEARCH}

\section{Container Search}

- The screen displays fields available to build query parameters of container records. The more fields entered, the fewer results are displayed, allowing the user to narrow the number of records to be viewed.

- Strike on a record to view that container's information.

\subsection{WMIS615 - COPYIREPACK/COMBINE}

\section{Copy/Repack/Combine}

- First, use the container search function to identify the source container. 
- $\quad$ Strike WMIS at the top of the screen.

- Strike Copy-Repack-Combine.

- Choose copy, repack, of combine from the drop down menu.

- Strike "Search" and pick the destination container.

- Lastly, strike the appropriate copy/repack/combine button at the top of the screen to complete the process.

\subsection{WMIS620 CONTAINER BASICS}

\section{Container Basics Screen}

- Enter the appropriate information.

- $\quad$ Strike the "Save" button.

\subsection{WMIS625 RAD DATA}

\section{$\underline{\text { Rad Data Screen }}$}

- Enter the appropriate radiological information.

- $\quad$ Strike the "Save" button.

\subsection{WMIS630 CONTAINER/PACKAGE SUMMARY}

\section{Summary Screen}

The Summary screen allows the user to enter the tare weight and the actual gross weight. The Summary screen also displays the net and packaging weights, and the physical components.

\subsection{WMIS640 PHYSICAL COMPONENTS}

\section{Adding Physical Components}

- $\quad$ Strike the "Add" button.

- Input the row description and estimated weight.

- $\quad$ Strike the "Save" button. 


\section{Adding/Editing Components within a Row}

- Select row to edit.

- Strike the "Edit" button.

- Strike "Add" button.

- From the next screen, the user can search for the physical component(s) to be added.

- Strike the "Save" button.

- Enter either the weights or percentages of the items.

NOTE: Total percentage must equal $100 \%$.

- Strike the "Save" button.

\section{Deleting Physical Components}

- To delete an entire row, highlight the row and then strike "Delete."

- To delete a component within a row, highlight the row, and then strike "Edit." Strike the "x" to delete the item(s).

NOTE: User must adjust weight or percent so that the total percent equals $100 \%$.

\subsection{WMIS650 PACKAGING COMPONENTS}

\section{Adding Packaging Components}

- $\quad$ Strike the "Add"

- button.

- From the next screen, the user can search for the packaging component(s) to be added.

- Strike the "Save" button.

- After adding the packaging, enter the weight of each packaging component in kilograms.

- Strike the "Save" button.

\section{Deleting Packaging Components}

- Strike the checkbox next to the component.

- Strike the "Delete" button. 


\subsection{WMIS675 CONTAINER HISTORY}

\section{Container History Screen}

- The History screen displays any changes and dates of change to the container record.

- Strike an individual record for detail changes.

\subsection{WMIS680 INVENTORY}

\subsection{WMIS685 ERDF DISPOSAL}

The ERDF Disposal screen allows the user to scan the container and Onsite Waste Tracking Form (OWTF) barcodes, and then input the ERDF coordinates upon waste disposal.

\section{ERDF Disposal}
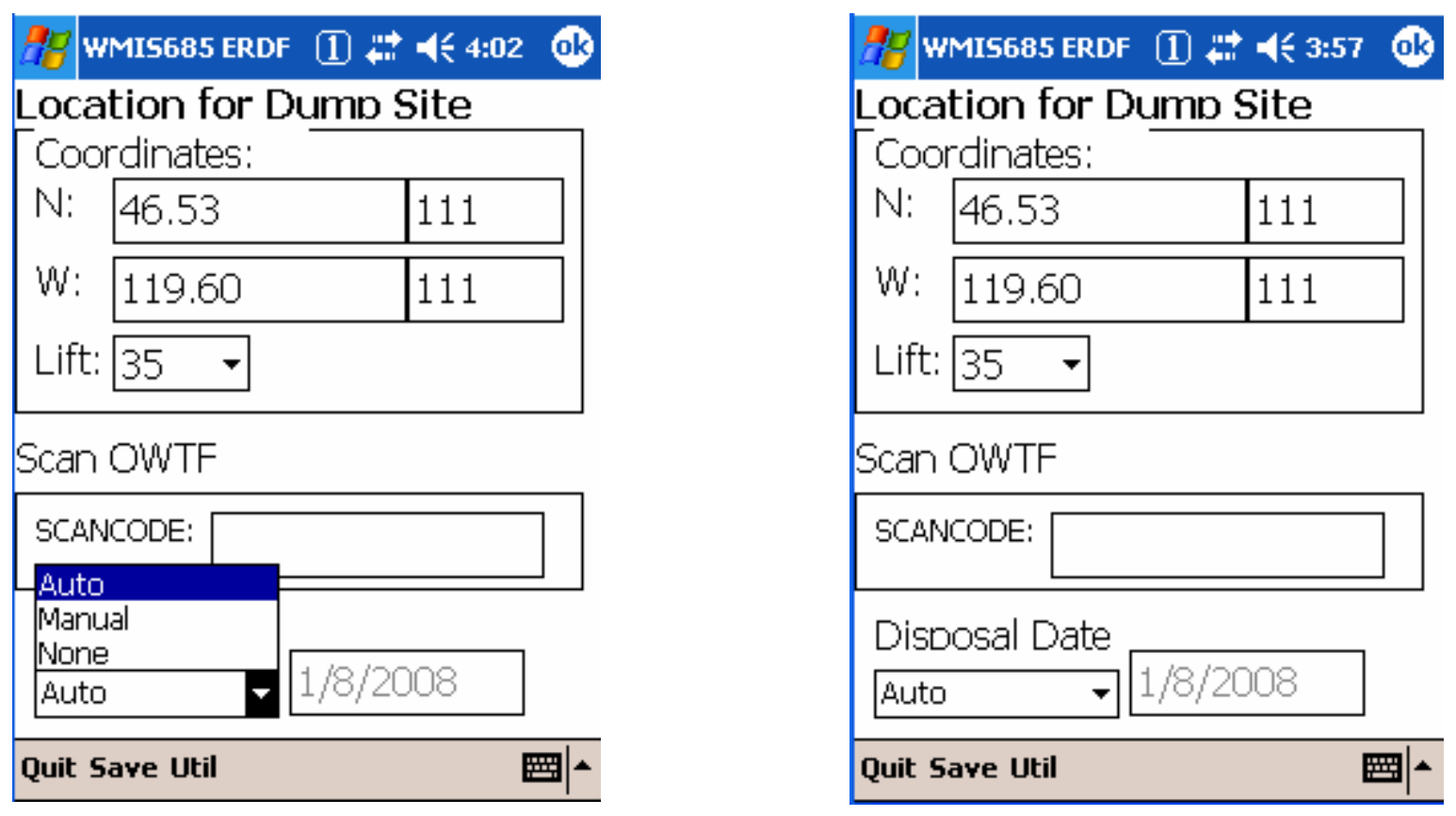

- Scan the container and OWTF barcodes.

- Input the ERDF coordinates upon waste disposal.

- Strike the "Save" button.

- The screen to the right would normally be selected for dump ramp operations, automatically selecting the disposal date. 
- If waste at ERDF is placed in its final disposal location awaiting treatment, disposal coordinates are recorded; however, "NONE" is selected as the disposal date. When treatment is completed, the OWTF is scanned and disposal date recorded.

- If the waste is not placed in its final disposal location (e.g., stockpiled awaiting treatment), neither disposal coordinates, nor disposal date are recorded.

\subsection{WMIS686 ERDF SCALE}

The ERDF Scale screen allows the user to scan the container and truck barcodes, then input the weight (in kilograms) when a truck crosses the scale.

\section{ERDF Scale}

- Scan the container and truck barcodes.

- Input the weight (in kilograms) when a truck crosses the scale.

- $\quad$ Strike the "Save" button.

\subsection{WMIS690 UPLOAD DATA}

Additions, changes or deletions of data on the Dolphin need to be transferred to the WMIS database.

\section{Upload Data}

- $\quad$ Dock the unit.

- $\quad$ Strike the "Start Upload." 


\subsection{WMIS700 - TRANSPORTATION MODULE}

\subsection{OBJECTIVES}

The Transportation Module incorporates the data from other WMIS modules to reduce cycle time and occurrence of errors, eliminate duplication, and improve efficiency throughout the transportation functions. The targeted users of the this module are the specialized staff on the Hanford Site, such as WTS, WDS, and field/project engineers working in conjunction with the ERDF.

\subsection{SCOPE}

The scope of this document is to define the requirements that constitute the Transportation module, focusing primarily on the ERDF. These requirements address the following processes and improvements:

- Acquisition, archiving, management, and storage of shipment data for all ERDF shipments

- $\quad$ Automated process of generating the Onsite Waste Tracking Forms (WCH-EE-286) for the movement of waste from a generator (i.e., dig site or facility) to the ERDF

- An extensible template-based storage system in which to handle both large volumes of shipped containers per day, as well as highly complex mixtures per load

- Improved data flow from the Designation module of all isotope and chemical constituent data to their appropriate waste profiles and waste designations

- Reduce errors and potential problems (i.e., illegible writing and duplication errors) during the excavation and hauling of waste

- Better tracking of the waste from "cradle to grave"

- An up-to-date and stable system that accurately tracks ERDF containers

- Reduce data entry errors, weighing errors, and to streamline the process so as to remove any foreseeable bottlenecks

- Allow simultaneous access to any number of authorized users to the new system

- Integrate RFID tags on all containers and trucks to track the waste shipments from the time loaded until the point of disposal

- Replace the aging and non-supported Ingress database system, which currently holds all of the ERDF shipping records, bringing it under the $\mathrm{WCH}$ umbrella of standardized systems 


\subsubsection{Shipment Management Form}

An actual shipment provides the basis for generation of a management form. This form provides the key criteria of the shipment manifest number, weight of the shipment, the date of the shipment, the container type, and the CIN. By relationship with the data, the RFID of the container links to the WCH CIN. The user has the ability to print a shipping document and manifest summary from this screen.

\subsection{PROVIDE TRANSPORTATION REPORTS}

\subsubsection{Onsite Waste Tracking Form}

Form WCH-EE-286, Attachment A, Onsite Waste Tracking Form, contains a variety of information that must be attached to every shipment processed. The form is placed in the document pouch and attached to the ERDF container. When the transporter loads the container for shipment, the document pouch is placed in the cab of the transport vehicle.

\subsubsection{Uniform Hazardous Waste Manifest}

Form EPA 8700-22, Uniform Hazardous Waste Manifest: Create this form when necessary for shipment finalization.

\subsubsection{Uniform Hazardous Waste Manifest Summary Attachment Document}

Form EPA 8700-22A, Attachment Summary, contains a line item summary of the contents of a particular shipment in accordance with U.S. Environmental Protection Agency guidelines. Key fields include item line number, package identification, DOT (U.S. Department of Transportation) specification, size, date, storage category and PCB (polychlorinated biphenyl) removal date. 


\subsection{WMIS790-0 SHIPMENT SEARCH}

From the main WMIS page, pick "Transportation/ERDF" from the drop-down menu. Templates are used to create OWTFs.

\section{Screen 7-1. Transportation/ERDF - Shipment Search}

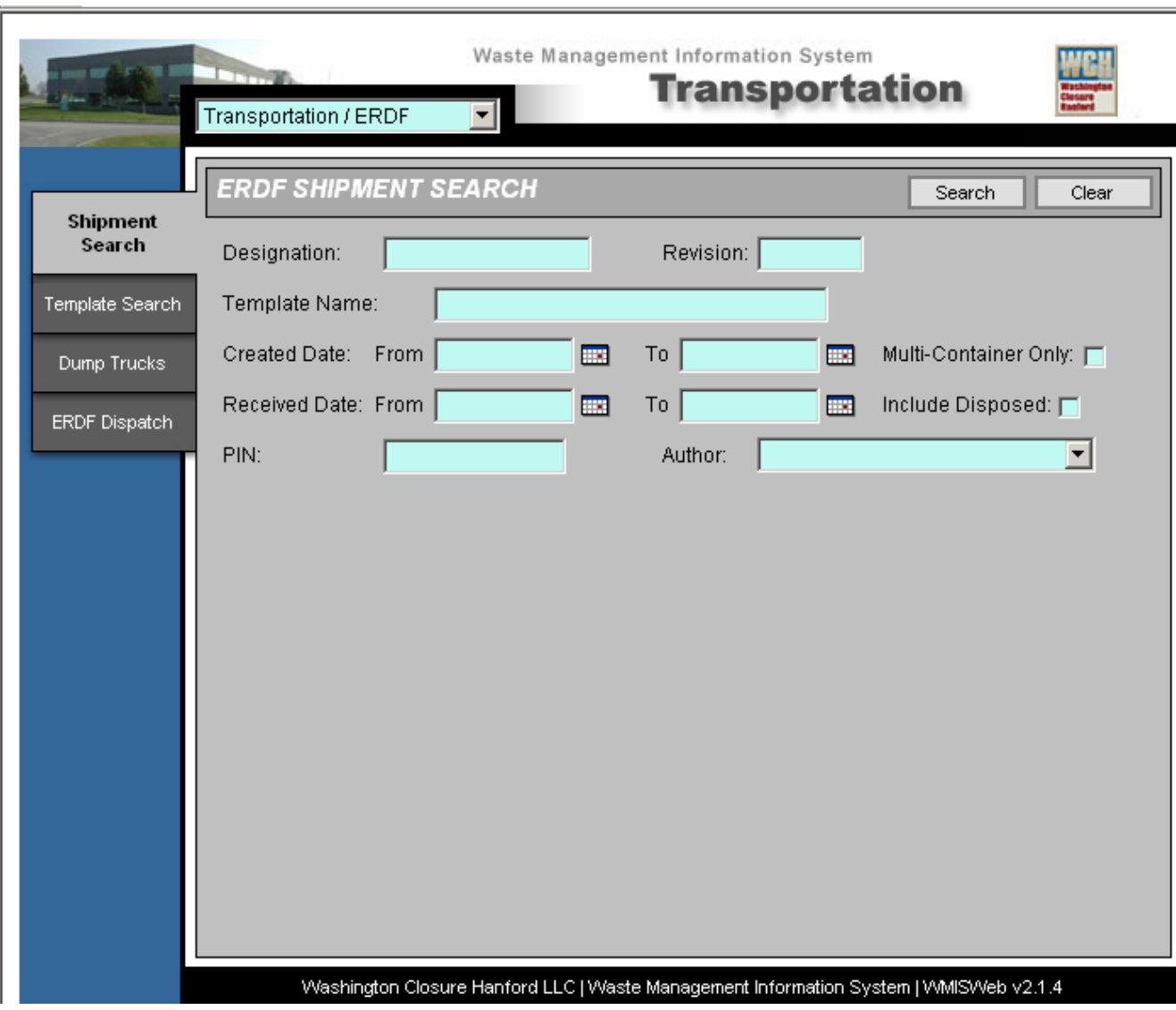

\section{Search Function}

- The fields available on the screen can be used to search for ERDF shipment records. The more fields entered, the fewer results are displayed, allowing the user to narrow the number of records to be viewed.

- Enter date range must be entered.

- $\quad$ Strike the "Search" button.

- A results table displays.

- From here, the user can highlight any record to view the shipment record and print an OWTF. The user also has the ability to check any, or all, of the shipment records to print OWTFS. 


\subsection{WMIS 790-2 ERDF SHIPMENT}

\section{Screen 7-2. Transportation/ERDF - ERDF Shipment}

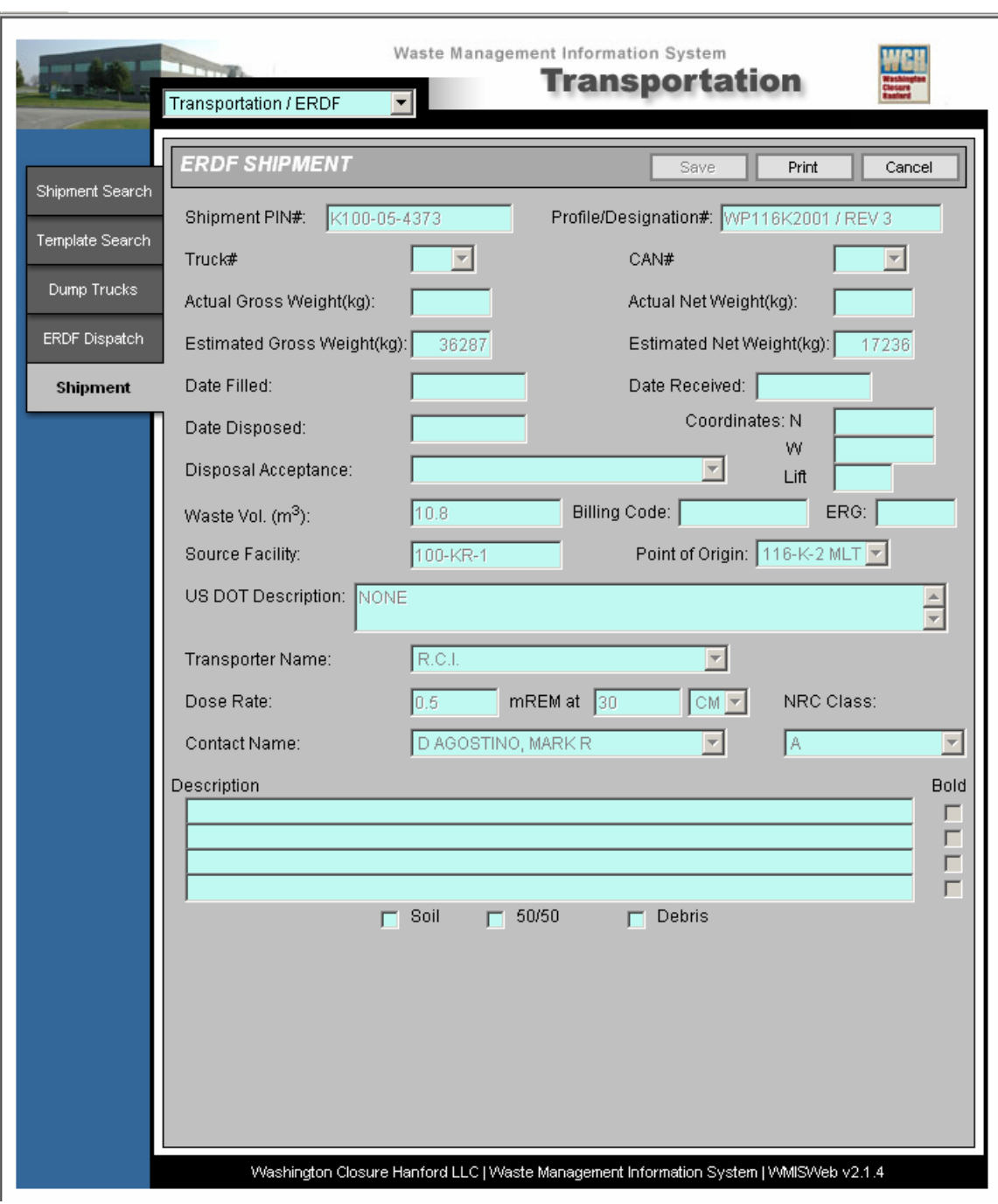

\section{Shipment Form}

The shipment form screen is used to display and/or input the pertinent details required to create an OWTF from an ERDF Template. After entering the appropriate information, strike the "Save" button.

\section{Print Function}

- Strike the "Print" button. Screen displays the OWTF.

- Review OWTF, if correct.

- $\quad$ Strike the "Print" button to print. 


\subsection{ERDF TEMPLATE SEARCH}

The Template Search screen is used to search for previously created ERDF shipment templates.

\section{Screen 7-3. Transportation/ERDF - ERDF Template Search}

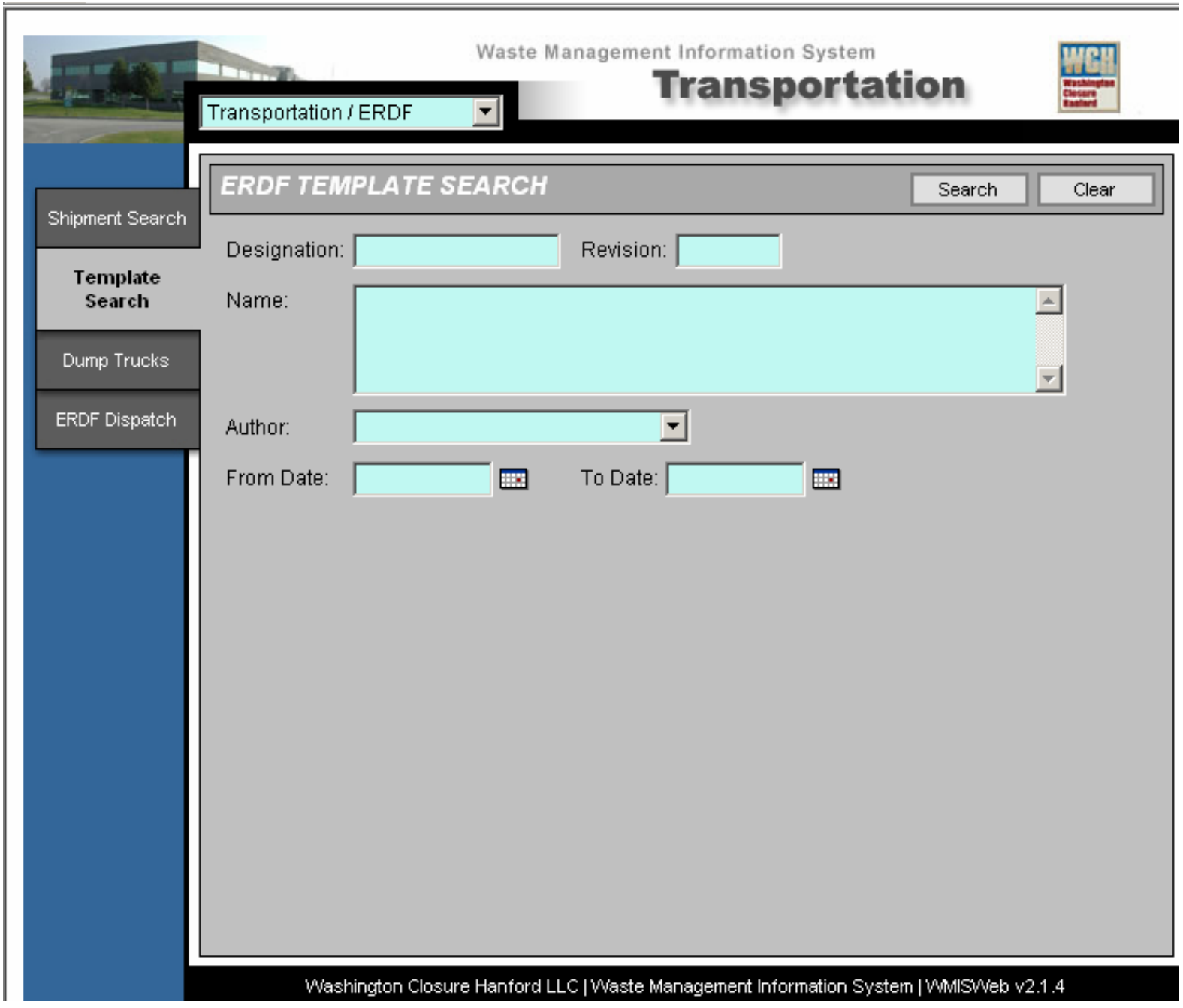

\section{Search Function}

- The fields available on the Screen can be used to search for ERDF templates. The more fields entered, the fewer results are displayed, allowing the user to narrow the number of records to be viewed.

- After pressing the search button, a results table displays. From here, the user can highlight any record to view the ERDF template. 


\subsection{CREATE ERDF TEMPLATE}

The Create ERDF Template Screen is used for the creation of new ERDF shipment templates.

\section{Screen 7-4. Transportation/ERDF - Create ERDF Template}

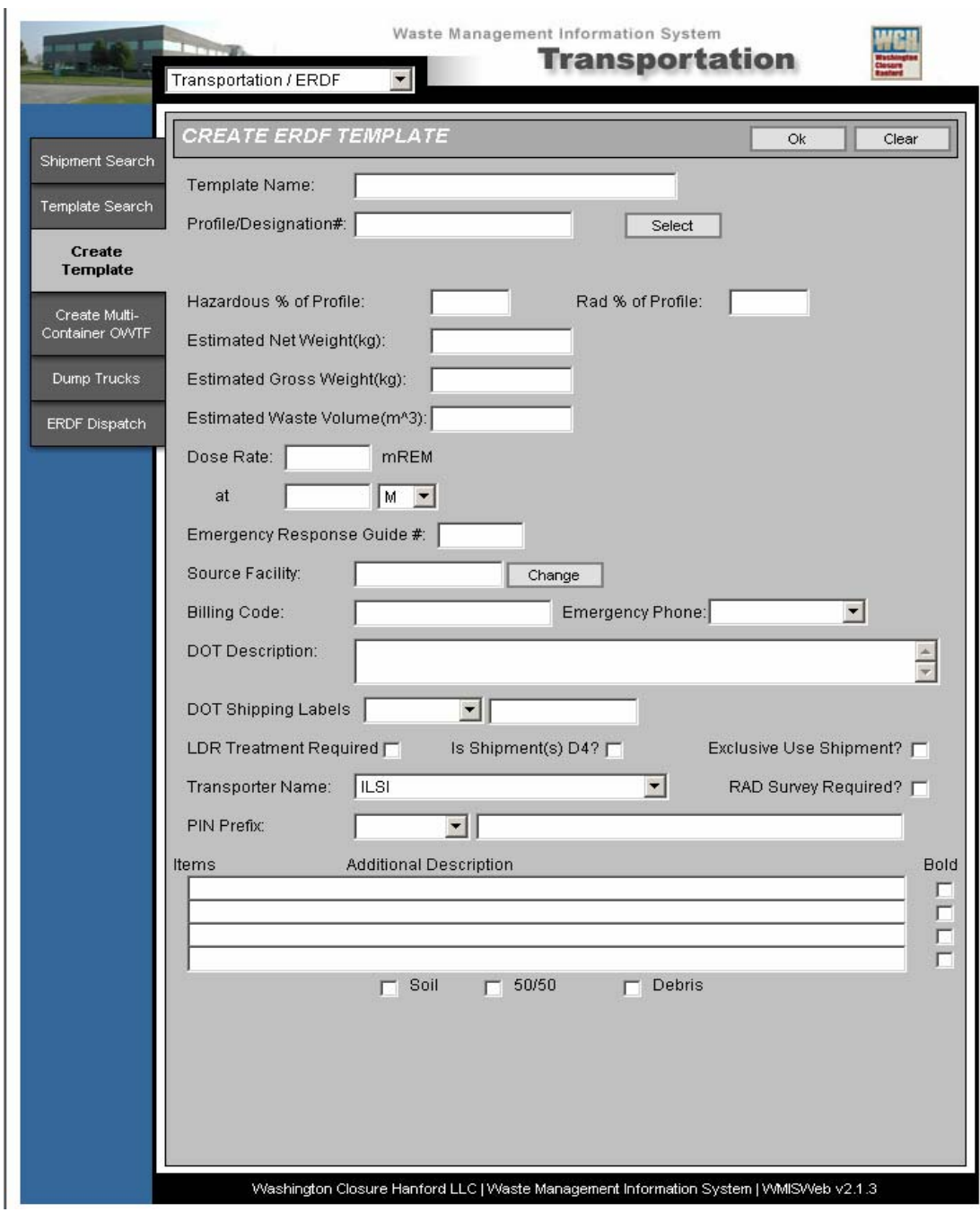

\section{Create ERDF Template Form}

- The fields Template Name, Profile/Designation \#, Hazardous \% of Profile, and Rad \% of Profile must all be entered before pressing "OK" to create a new template.

- If you are inputting specific values for individual constituents or isotopes then strike OK and proceed to the respective EDIT TAB as discussed below and input values. 


\subsection{ERDF TEMPLATE}

The template form is used to display and modify ERDF based templates. The user is presented with an input that allows for changing the overall "percent of profile" for the template. There are buttons that allow the user to adjust the template by the entered percent; as well as save the template. There are also four active tabs, "Edit Constituents," "Edit Isotopes," "Edit Items," and "Copy Template," that take the user to screens where individual (static or percentage) values may be entered for each chemical constituent, radiological isotope, or item descriptions. If any static values have been entered for constituents or isotopes, then the "adjust" button on the main ERDF template screen is disabled.

\section{Screen 7-5. Transportation/ERDF - Template Create Shipments}

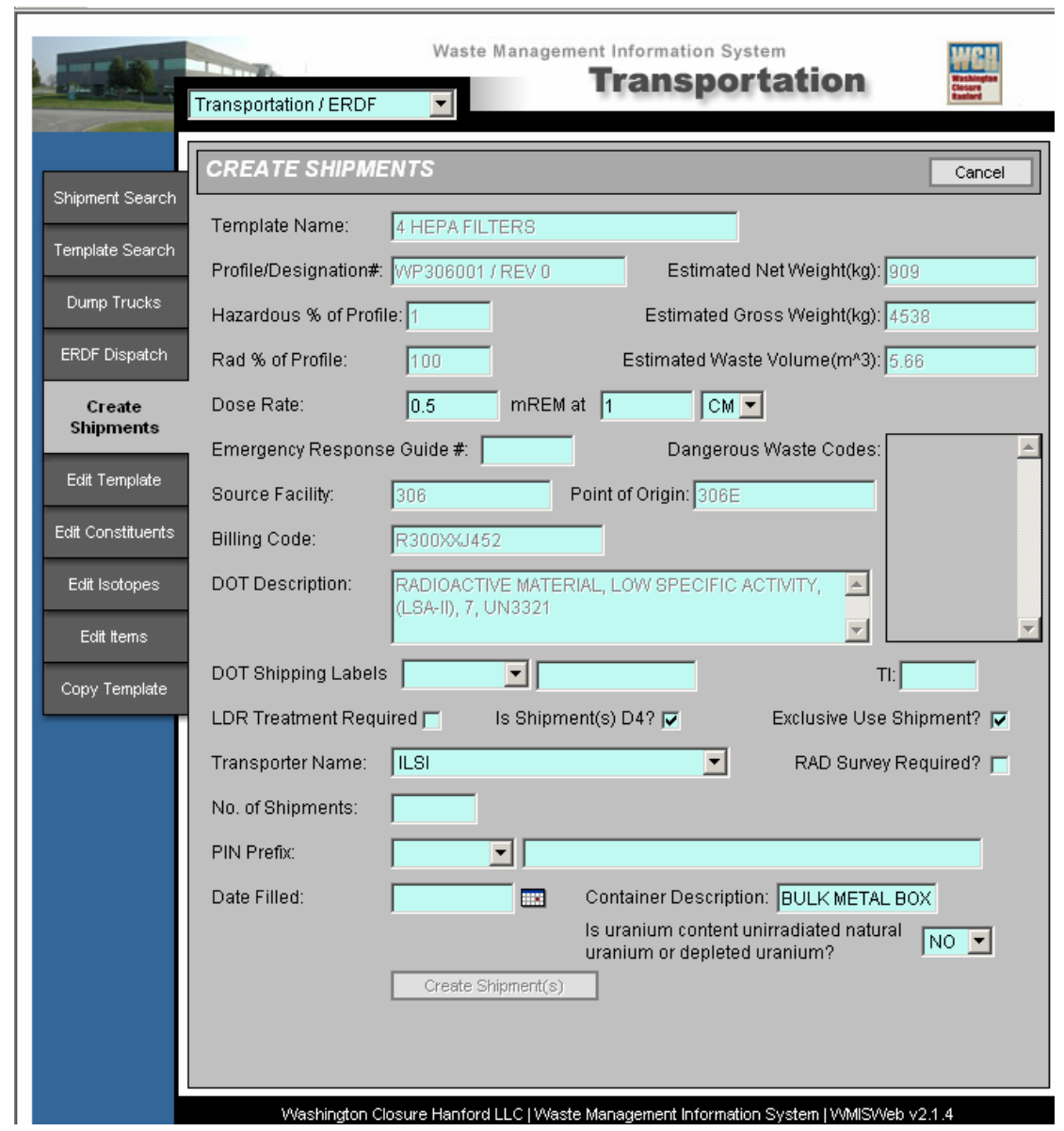

\section{$\underline{\text { Template Form }}$}

- After entering the appropriate information, in all active tabs, strike the "Create Shipment" button. This creates a shipment paper based on the current template. 


\section{Edit Constituents}

\section{Screen 7-6. Transportation/ERDF - Edit Template Constituents}

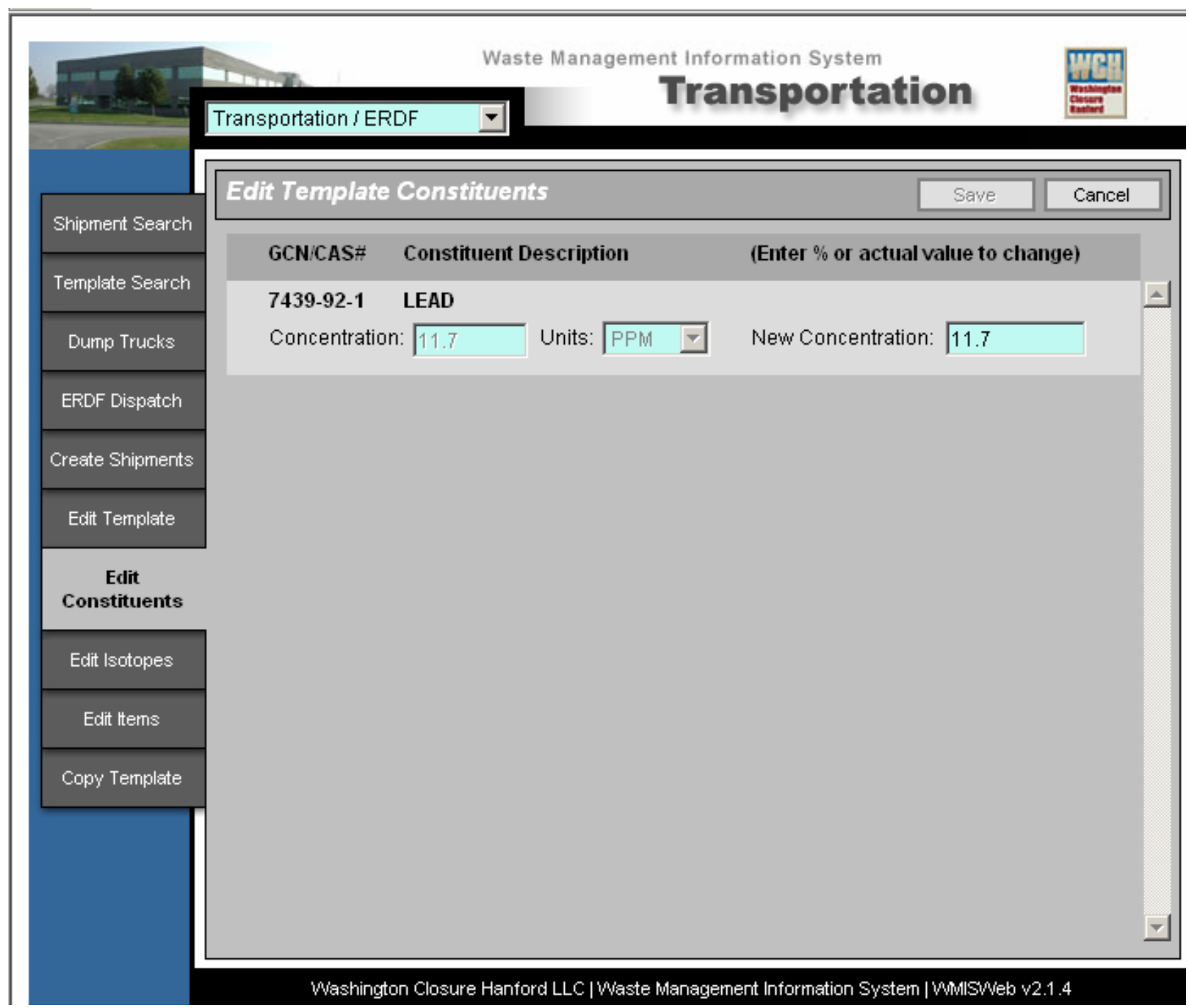

- $\quad$ The "Edit Constituents" screen shows the original concentrations and units of measurement. The user can then enter a new concentration value or the percent of the concentration. Strike the "Save" button when done.

- $\quad$ The "Save" Function will save the inputted values to the Template for future use. 


\section{Edit Isotopes}

- The "Edit Isotopes" screen shows the original activity concentrations. The user can then enter a new activity concentration value or the percent of the concentration. Strike the "Save" button when done.

- $\quad$ The "Save" Function will save the inputted values to the Template for future use.

\section{Screen 7-7. Transportation/ERDF - Edit Template Isotopes}

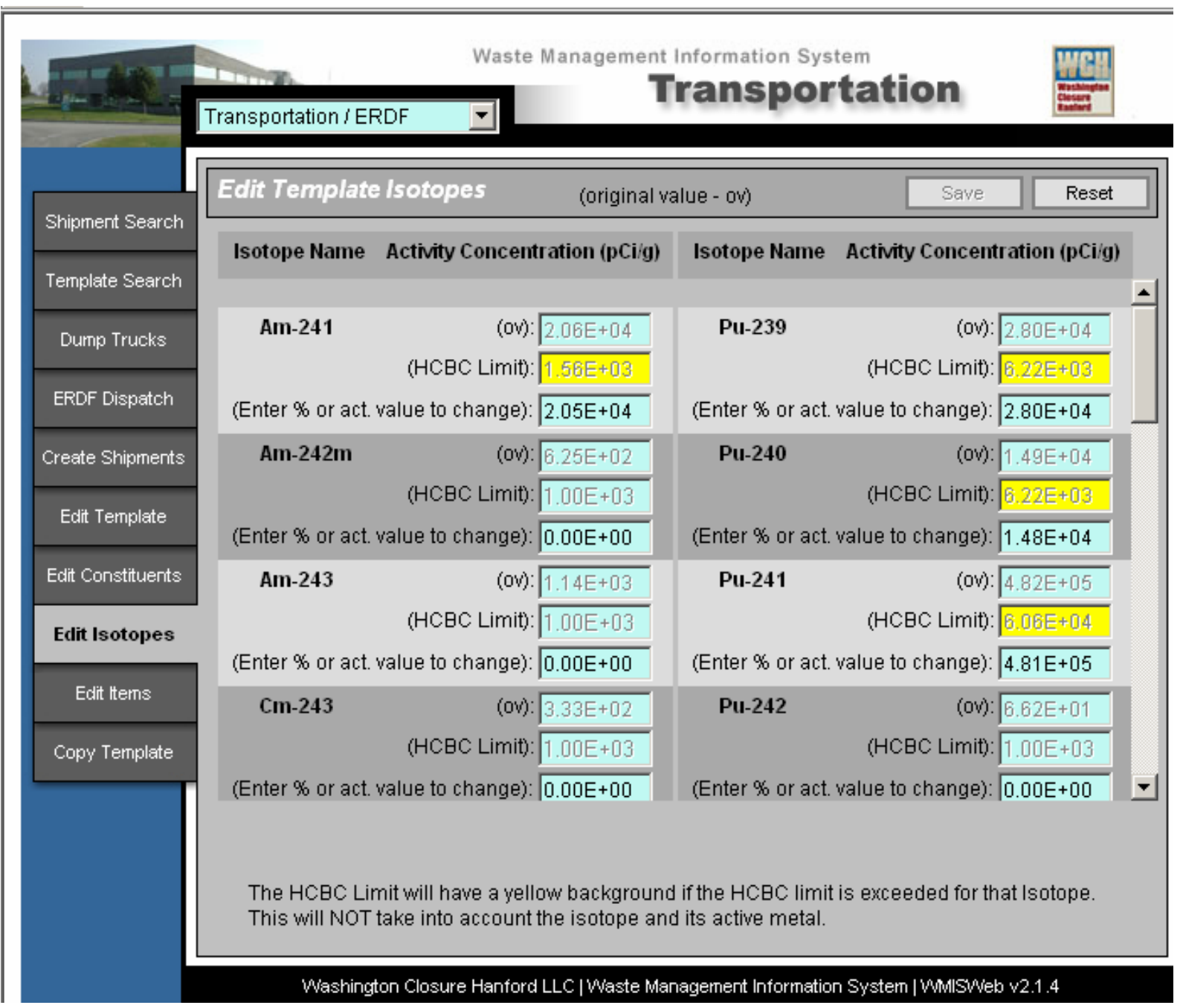




\section{Edit Items}

\section{Screen 7-8. Transportation/ERDF - Edit Template Items}

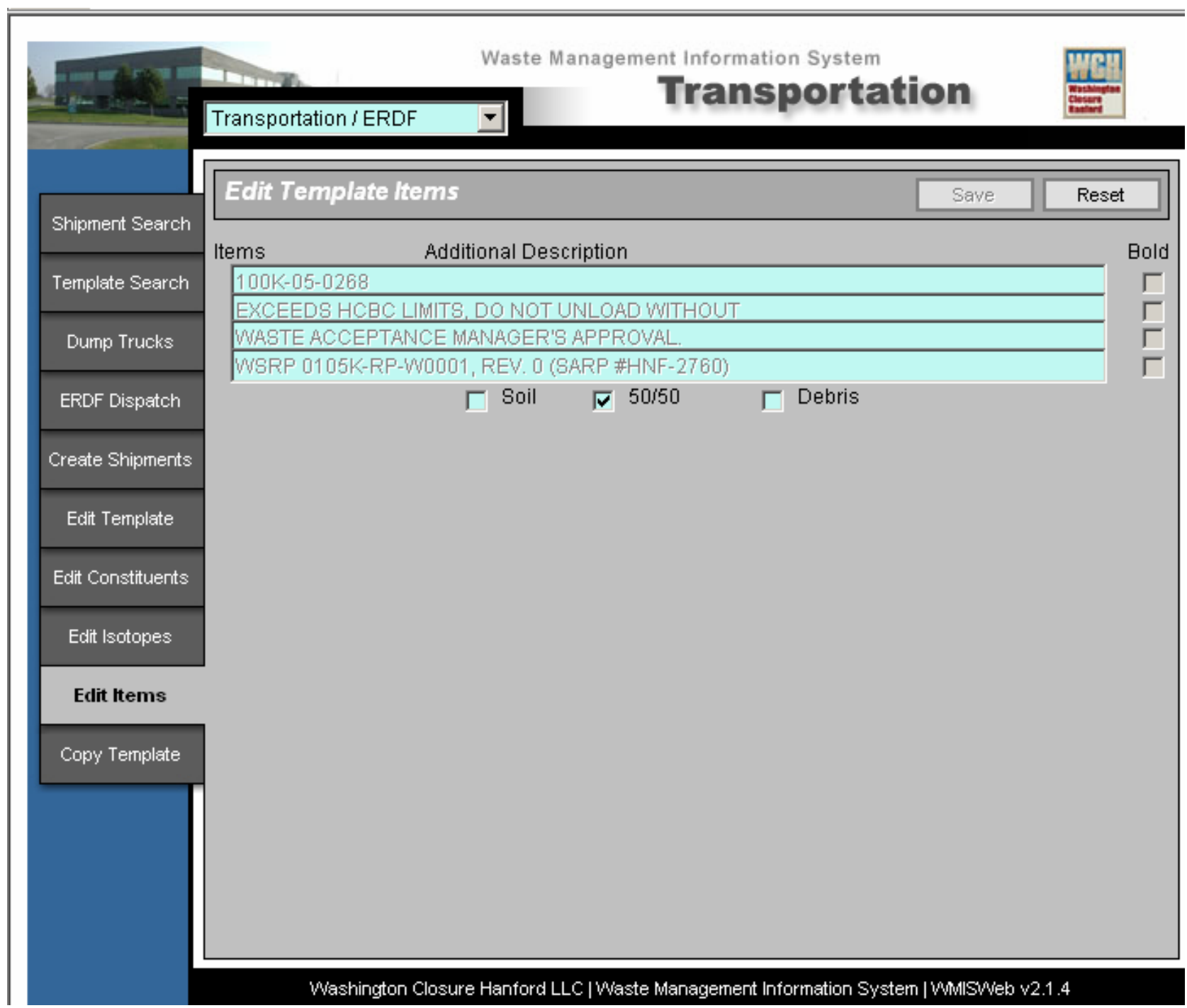

- The "Edit Items" screen shows the items and additional descriptions. The user can check on the items check box(es) and add the additional description(s). The user can also check the "Bold" checkbox to highlight that description on the OWTF. There is also estimated volume percentages checkboxes, for an even further description. Strike the "Save" button when done.

- $\quad$ The "Save" Function will save the inputted values to the Template for future use.

NOTE: Once an OWTF is generated the user may edit the items section of the OWTF by clicking the individual PIN \# as described in Section 5.16. This action will not alter the original template. 


\section{Copy Template}

\section{Screen 7-9. Transportation/ERDF - Copy Template}

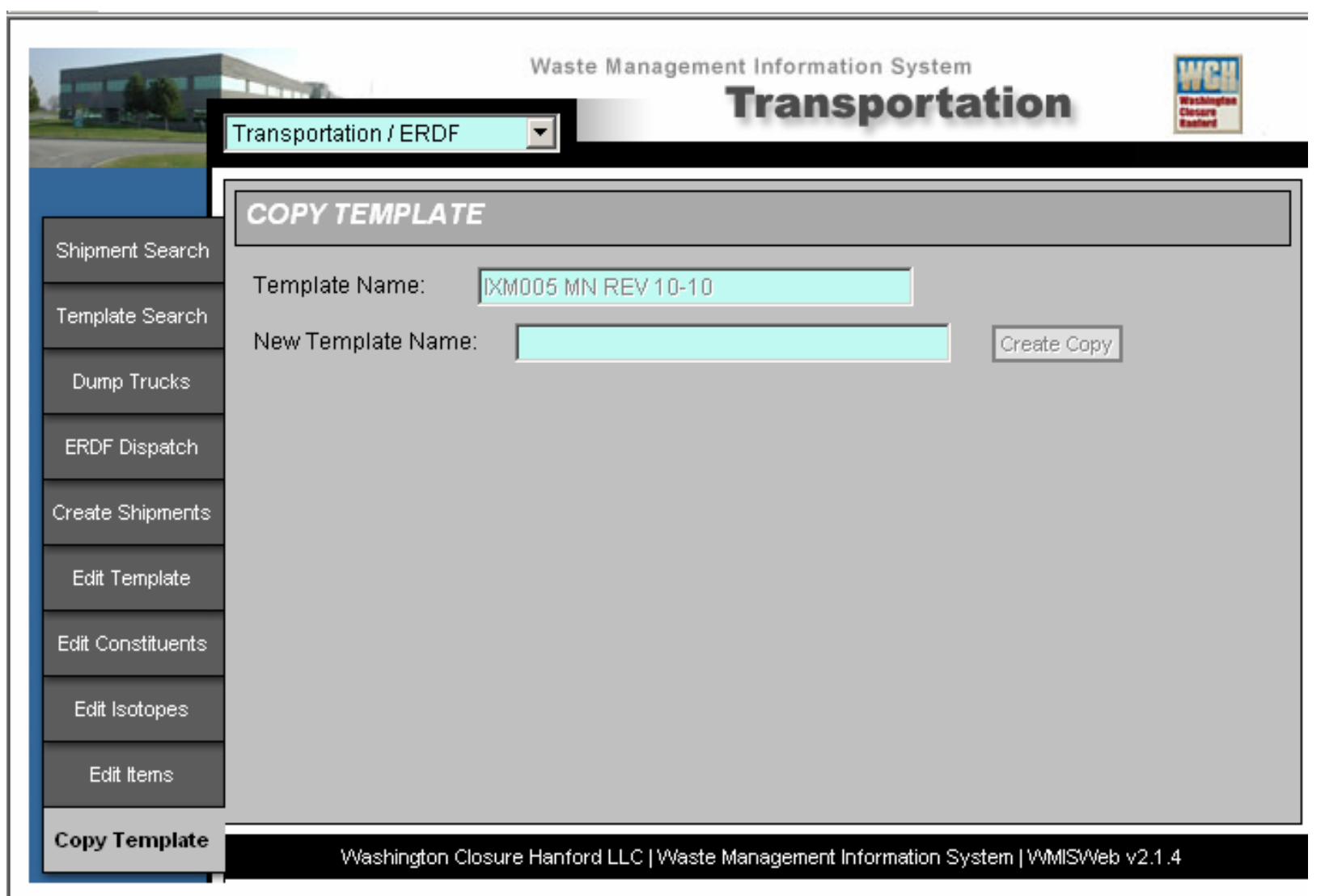

The Copy Template Screen allows the user to copy the active template. The active template name is already shown, all the user has to do is create a new template name and strike "Create Copy." 
WMIS800 - Purchase Order MODULE

\subsection{OVERVIEW}

The RCC contractor obtains containers used for waste operations in several ways. Purchase from the Prime Hanford Management Contractor, fabricated onsite, or purchased through the RCC contractor's own purchasing program.

The CIN is a permanent identifier, which does not change for the life of the container. Existing CIN numbers are only on the containers purchased through the other Hanford contractors. For all others, CIN assignment is done through WMIS and bar code labels can be printed which show the readable CIN number as well as a bar code. The labels allow the PDA/Dolphin portable devices to quickly identify the container markings in the field.

The PIN belongs to the waste that is placed inside the container and identifies the waste from cradle-to-grave. If the waste is moved into another container, the PIN goes with the waste, which now has a different CIN for the new container. The PIN is not assigned until the waste is being prepared for disposal.

When the container, with the waste inside, is destroyed or disposed of the CIN/PIN record is shown as disposed. When the container is simply emptied, the database record for that CIN/PIN combination indicates disposed. However, the container is available for re-use and appears in the WMIS database as many times as it is re-used, with different PINs for each use. This Purchase Order Module consists of the processes necessary to track all containers obtained by the RCC. 


\subsection{WMIS800 PURCHASE ORDER SEARCH}

The Purchase Order Search Screen allows the user to view the container purchase orders. The user can bring up the purchase orders and view information such as the status and location of the containers ordered.

Screen 7-10. Purchase Order - Search

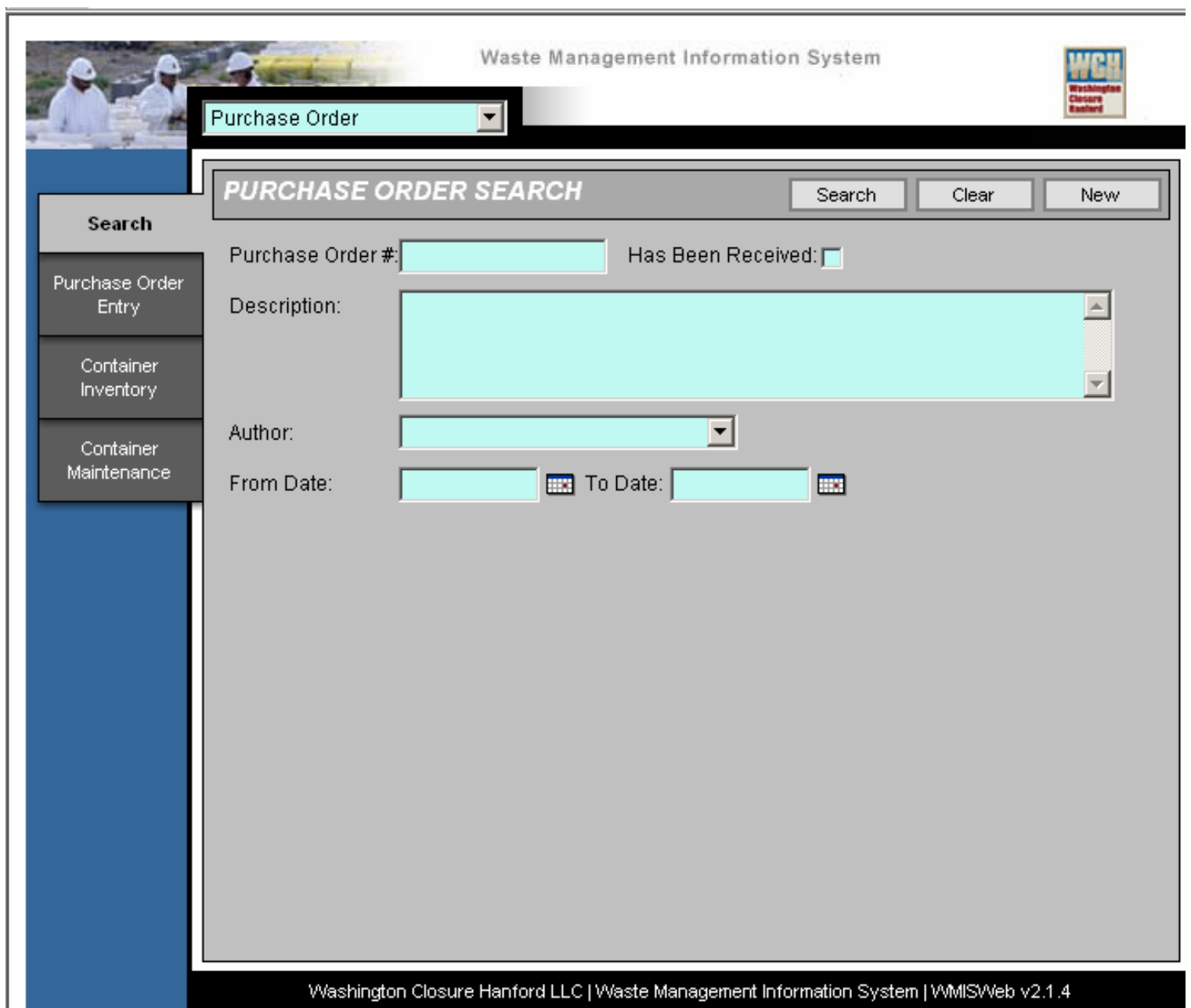

\section{Search for Existing Purchase Orders}

Existing purchase orders may be viewed by entering some criteria and pressing "Search." 


\section{Insert New Purchase Orders}

\section{Screen 7-11. Purchase Order Entry (Add)}

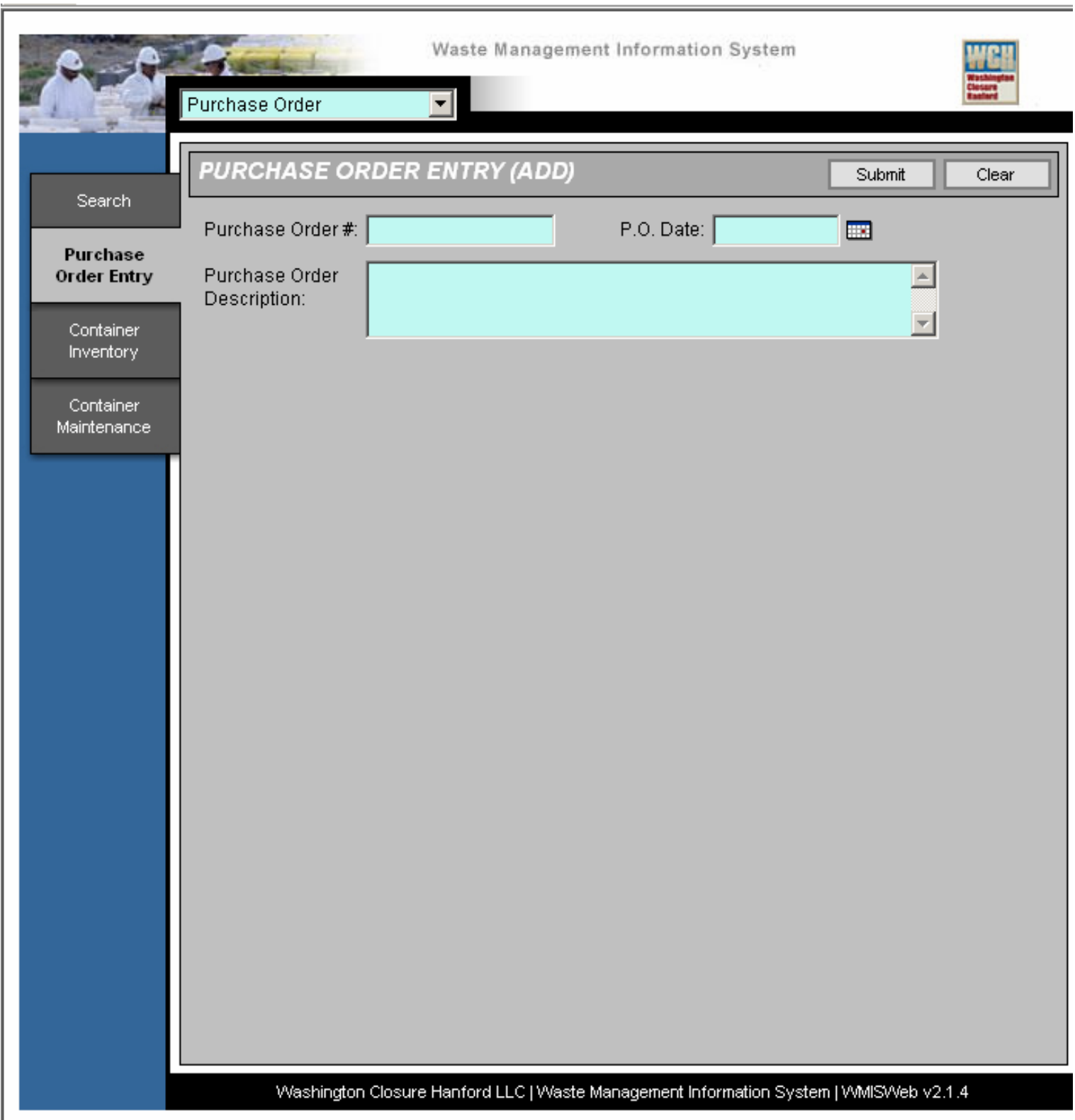

To enter a new purchase order, strike the "New" button in the upper right portion of the screen. 


\subsection{WMIS810 PURCHASE ORDER INPUT}

This Screen is used to insert new Purchase Order items.

\section{Screen 7-12. Purchase Order - Information Entry}

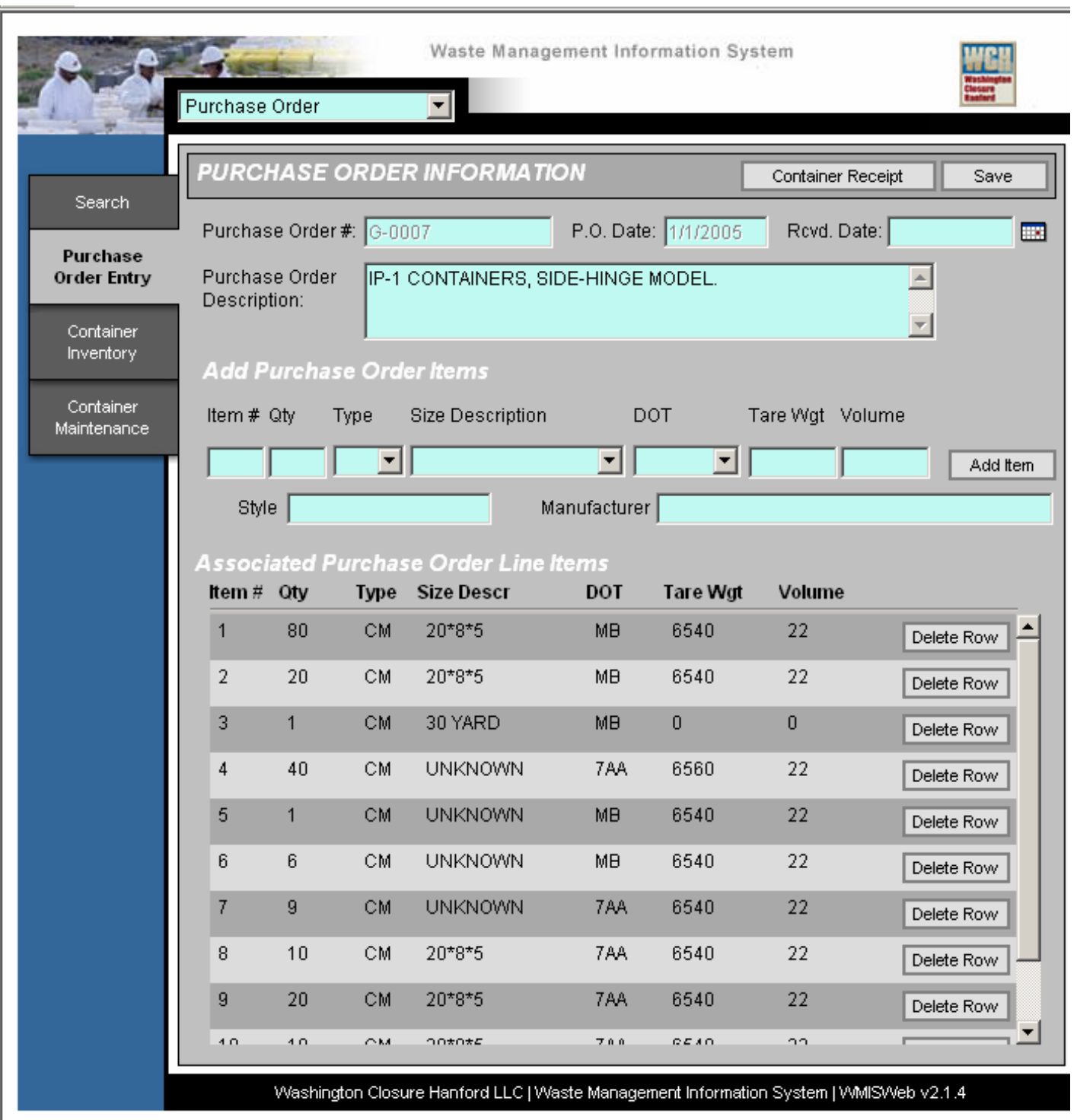




\subsection{WMIS820 CONTAINER RECEIPT}

The receipt of containers, ordered on $\mathrm{WCH}$ purchase orders, or those containers which have been ordered from the PHMC contractor and are received with pre-assigned CINs, are entered on this screen. CINs can be assigned to all the $\mathrm{WCH}$ containers received, and labels printed.

\section{Screen 7-13. Purchase Order - Container Inventory}

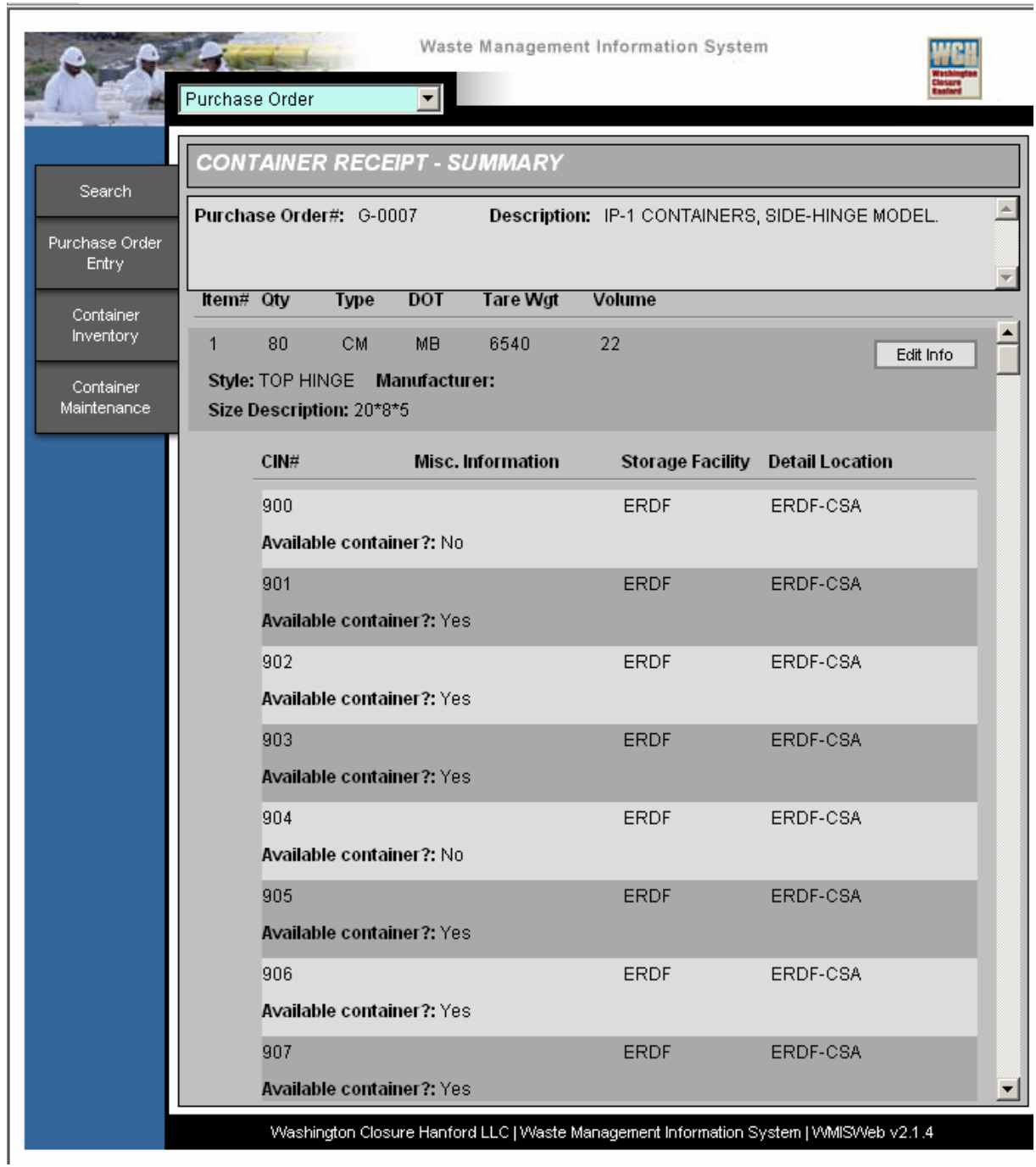

\section{Container Receipt Summary}

This screen shows a detailed summary of the purchase order. This summary shows all the containers within each row item. Displaying CIN numbers, storage facility, detailed location, misc. information, and if the container is available. To change this information, strike the "Edit Info" button. 


\subsection{WMIS820 CONTAINER RECEIPT DETAIL}

The Container Receipt Detail Screen allows the user to view and update the individual items on a particular purchase order.

\section{Assign CINs}

- For those containers that have been purchased by WCH from off-site sources, or those fabricated on site, CINs can be assigned by pressing the "Assign CIN" button.

- If containers have come with pre-assigned numbers, manually enter those numbers in the $\mathrm{CIN}$ field for the container, and bypass using this option.

- Storage locations can be entered for all containers by entering the values and pressing the "Copy to All Records" button.

\section{Print CINs}

Reserved for future development.

\section{Save As Inventory}

Once CIN numbers have been assigned, strike this button, and the containers are inserted into the database. The storage location entered is assigned to all the containers, while the Miscellaneous Information is assigned only to those containers where entered.

\subsection{CONTAINER INVENTORY}

\section{Inventory Search}

The user can search by purchase order number, size description, storage detail, and/or ERDF containers. Strike the "Search" button to execute the search.

\section{Print Function}

Strike the "Print" button to print an inventory report. 


\subsection{WMIS900 - REPORTING MODULE}

The Reporting Module contains all pre-defined reports. Pre-defined reports consist of several formatted layouts of information, with a search screen that lets the user select and narrow the search grid.

\subsection{WMIS900 - REPORT PARAMETER VALUES}

This page provides data elements the user is requesting to any of the reports able to be executed in the system. In the reporting section the user-inputted data elements create a query, which is then passed to the different reports selected. The parameter input is formatted to be similar to the Container Input screen, although not as many fields are available for selection purposes. Users have the option to save queries that are generated on this Screen and also to load previously saved queries.

Screen 8-1. Report - Report Values

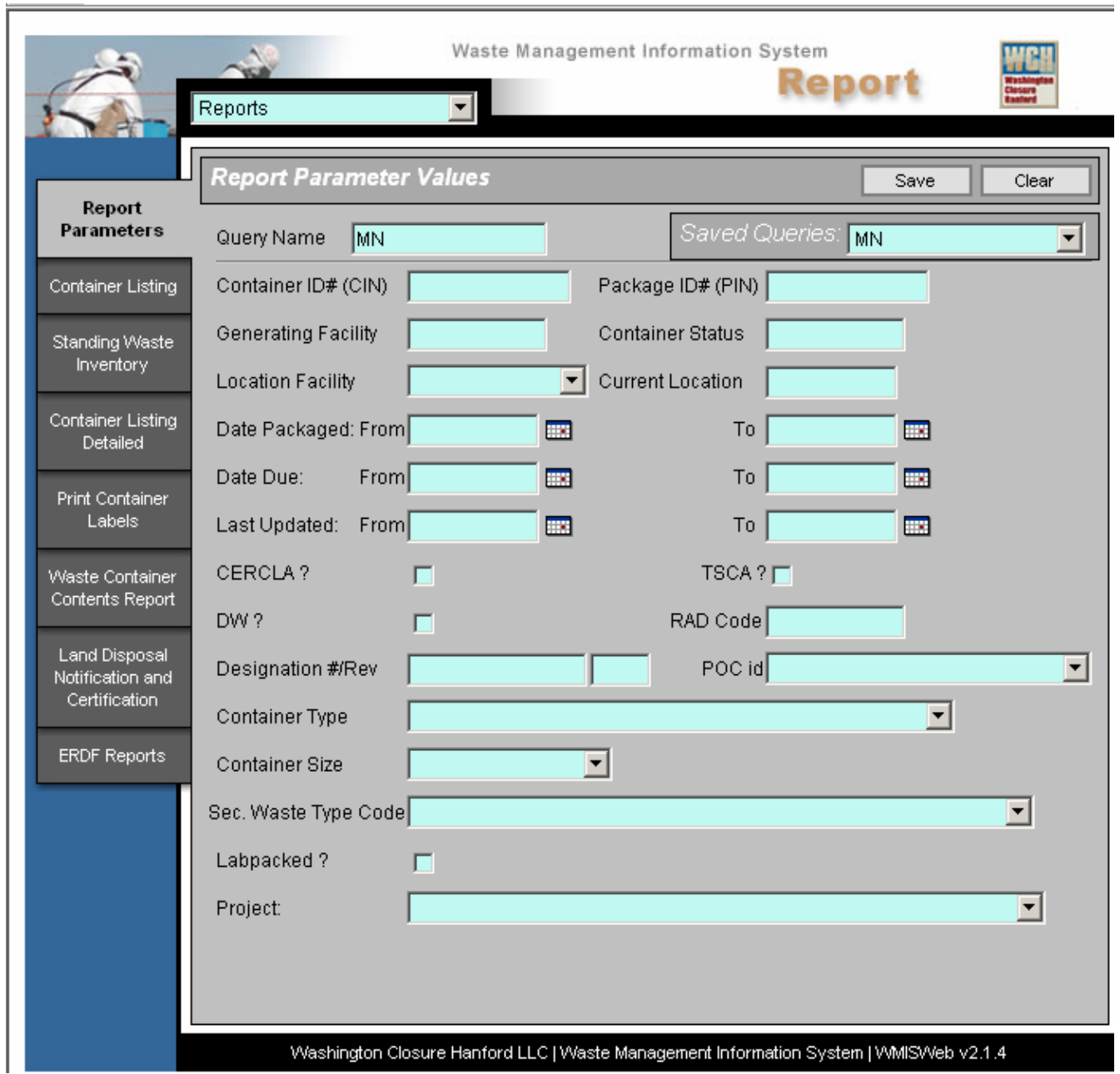


To generate pre-defined reports identify desired parameters on Report Parameter Values screen. Enter Query Name; enter parameters; and select "Save". Then select report tab to generate desired pre-defined report.

\subsection{WMIS910 - CONTAINER LISTING}

The WCH Container Listing Report is a report of a container's content, displaying all information related to a container. It needs to be able to be ran and printed by the users on demand. The user has the ability to enter certain parameters from their workstation and select only the data needed for their report - for example, by facility, area, waste pad, date, etc.

\subsection{WMIS920 - STANDING WASTE INVENTORY}

The WCH Standing Waste Inventory/Aging report needs to be able to be ran and printed by the users on demand. The user has the ability to enter certain parameters from their workstation and select only the data needed for their report - for example, by facility, area, waste pad, date, etc.

\subsection{WMIS930 -CONTAINER LISTING DETAILED}

\subsection{WMIS930 -PRINT CONTAINER LABELS}

Screen 8-2. Reports - Print Container Labels

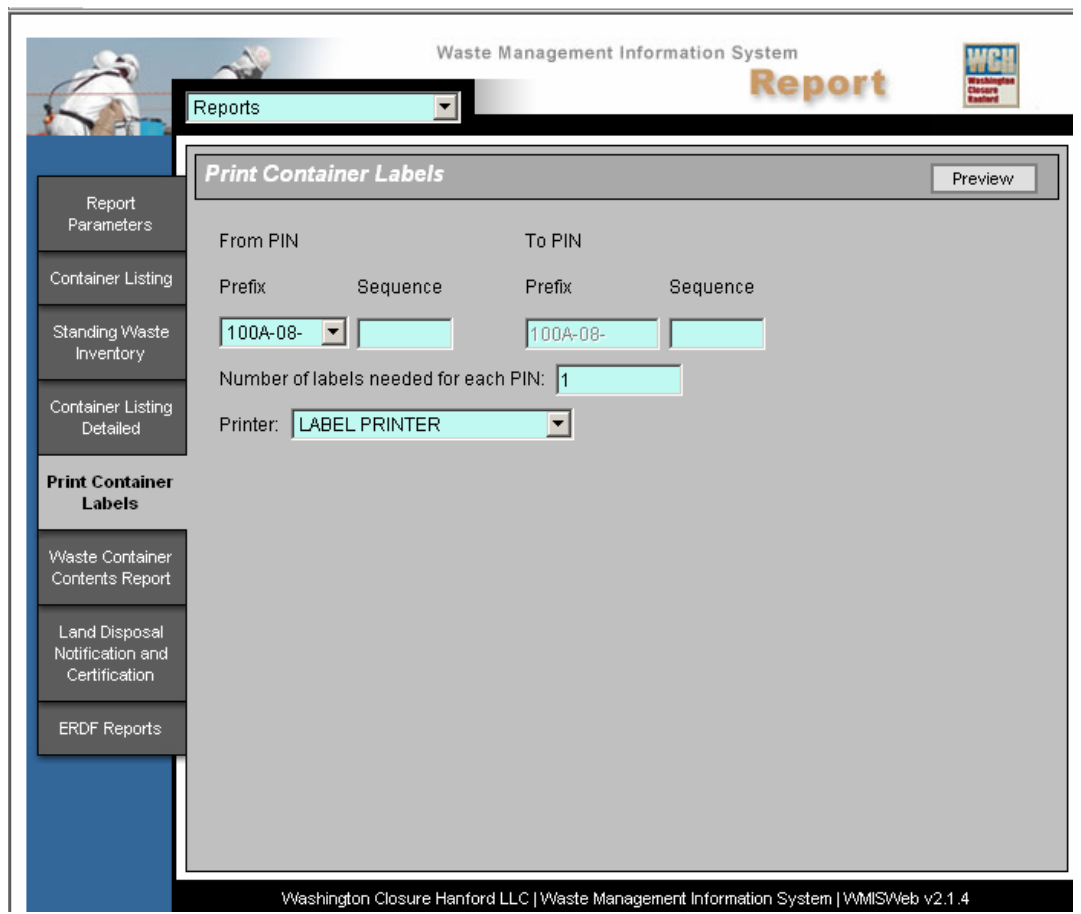




\subsection{WMIS930 -WASTE CONTAINER CONTENTS REPORT}

\subsection{WMIS930 -LAND DISPOSAL NOTIFICATION AND CERTIFICATION}

\section{$8.8 \quad$ WMIS930 -ERDF REPORTS}

\section{Screen 8-3. Reports - ERDF Reports}

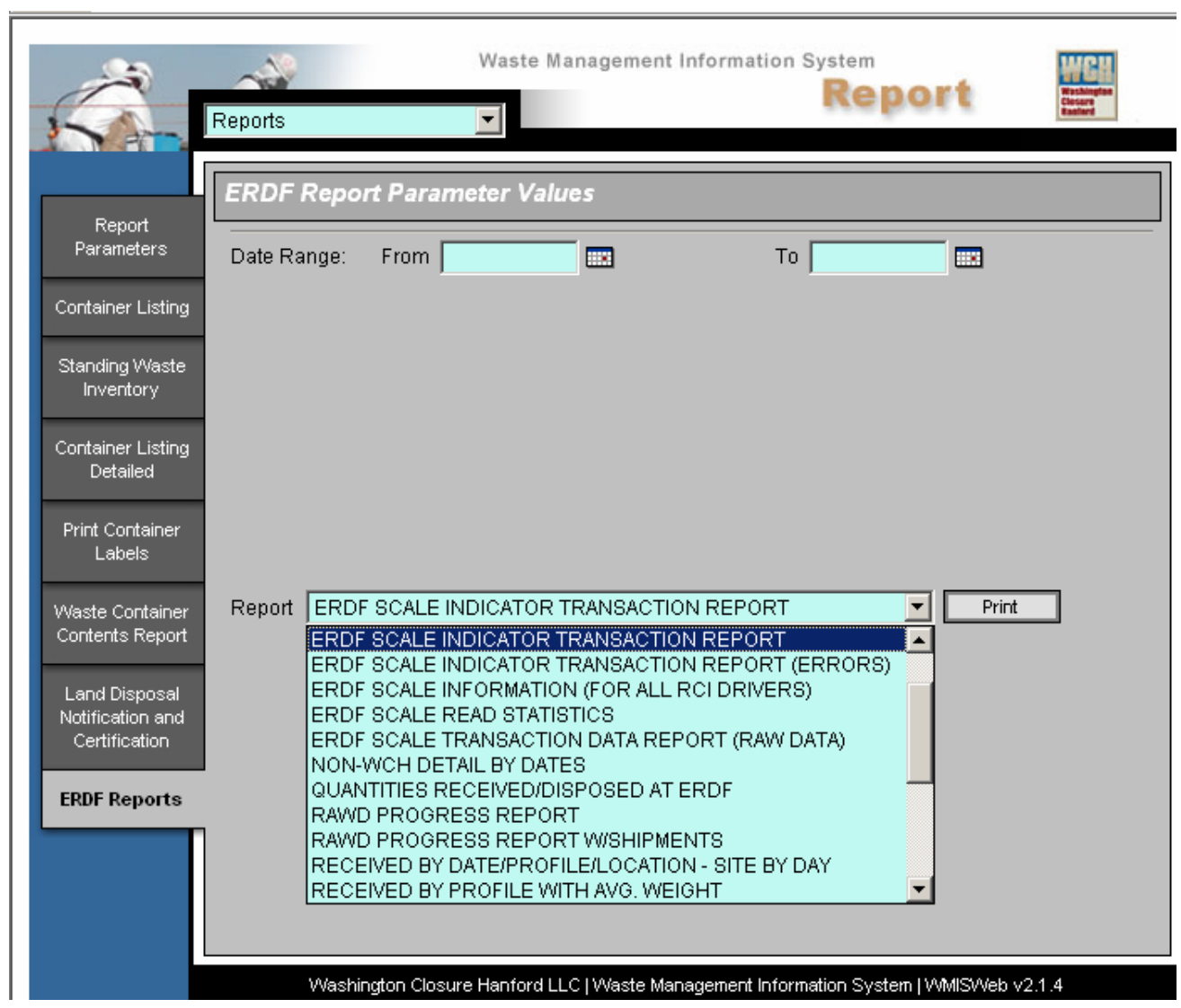

Table 8-1. Available WMIS Reports.

\begin{tabular}{|l|l|}
\hline Report Title & Description \\
\hline Container Listing & $\begin{array}{l}\text { Provides a report with all the major data fields for a single } \\
\text { container. Report may be run for a single package id or for all } \\
\text { containers on a shipment }\end{array}$ \\
\hline Waste Acceptance Receipt & $\begin{array}{l}\text { Provides information to the receiving TSD prior to shipment. May } \\
\text { be printed by package id or shipment number. } \\
\text { this NOTE: to print } \\
\text { must be completed first** }\end{array}$ \\
\hline Waste Profiles & $\begin{array}{l}\text { Lists information about a profile or group of profiles. This report } \\
\text { may be run by profile number or by company. The profile number } \\
\text { allows wildcards (such as 222S\%). }\end{array}$ \\
\hline
\end{tabular}




\subsection{REFERENCES}

BHI-01722, Waste Management Information System Software Design Description (SDD), Bechtel Hanford, Inc., Richland, Washington.

DOE Order 414.1C (Quality Assurance)

SWTD-0011, 2008, "Waste Management Information System Training," Washington Closure Hanford, Richland, Washington.

WCH-114, 2008, Cyber Security Program Plan, Washington Closure Hanford, Richland, Washington.

WCH-186 [Washington Closure Hanford Information Technology System Configuration Management Plan (SCMP)/July 2007]

WCH-192 (Washington Closure Hanford Software Quality Assurance Program Plan).

WCH-213 [Waste Management Information System (WMIS) Software Project Management Plan $(\mathrm{SPMP})]$. 
WCH-138

References

Rev. 2 


\section{APPENDIX A}

WASTE MANAGEMENT ON-LINE FORMS 
WCH-138

Rev. 2 


\section{APPENDIX A}

\section{WASTE MANAGEMENT ON-LINE FORMS}

WMIS forms are identical to forms in use thereby eliminating the need to duplicate the data in the SWITS interface. Validation and editing routines to confirm entries and eliminate current manual verification activities further enhances the automation of this process.

\section{WCH-EE-243, RCC Waste Management Certification Form}

The Waste Management Certification Form identifies the container, shipper, the originating facility, type of waste, and other information for the container.

\section{WCH-EE-238, RCC Waste Inventory Sheet}

The RCC Waste Inventory Sheet (WIS) provides basic waste inventory information necessary for the generator to properly designate, characterize, and manage waste.

\section{Routing and Electronic Signature Capability}

WMIS provides the capability of routing the form for signatures. 


\section{DISTRIBUTION}

\section{Washington Closure Hanford}

J. F. Armatrout T2-03

R. H. Bidstrup X2-07

D. L. Boecker T2-03

G. J. Borden N3-20

N. E. Brower L6-06

R. E. Broz N3-20

K. R. Christensen N3-20

M. D. Clark N3-20

M. H. Conilogue N3-20

P. A. Drago X9-10

D. A. Duranceau T2-05

J. J. Ehlis X0-18

R. G. Gana L6-06

P. W. Garvie T2-03

T. M. Greager X9-08

E. M. Harding X9-08

R. T. Hynes N3-20

F. O. Lamb T2-05

M. E. Lewis L6-06

R. S. Lipinski X2-07

R. B. McPherson H4-24

C. M. Miller L6-06

B. A. Nielsen N3-20

M. G. Peloquin T2-03

M. A. Sams L1-12

R. J. Vallem L6-06

Document Control H4-11 
WCH-138

Rev. 2 